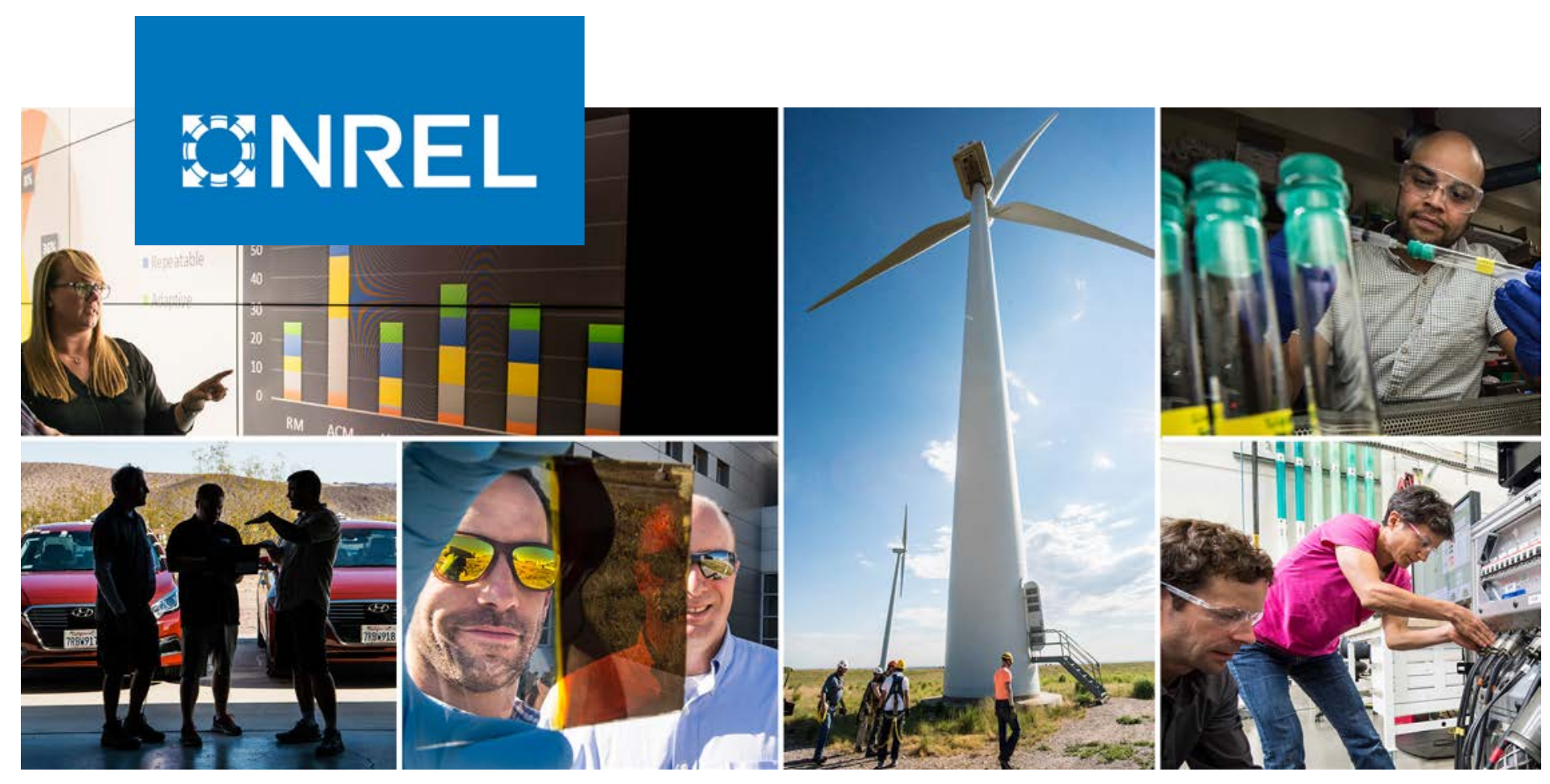

\title{
Surat Municipal Corporation Bus Electrification Assessment
}

Cabell Hodge, ${ }^{1}$ Matthew Jeffers, ${ }^{1}$ Jal Desai, ${ }^{1}$ Eric Miller, ${ }^{1}$ and Varsha Shah ${ }^{2}$

1 National Renewable Energy Laboratory

2 Sardar Vallabhbhai National Institute of Technology

NREL is a national laboratory of the U.S. Department of Energy

Office of Energy Efficiency \& Renewable Energy

Operated by the Alliance for Sustainable Energy, LLC

This report is available at no cost from the National Renewable Energy Laboratory (NREL) at www.nrel.gov/publications.

\section{Technical Report}

NREL/TP-5400-73600

May 2019 


\title{
GNREL
}

\section{Surat Municipal Corporation Bus Electrification Assessment}

Cabell Hodge, ${ }^{1}$ Matthew Jeffers, ${ }^{1}$ Jal Desai, ${ }^{1}$ Eric Miller, ${ }^{1}$ and Varsha Shah ${ }^{2}$

\author{
1 National Renewable Energy Laboratory \\ 2 Sardar Vallabhbhai National Institute of Technology
}

\section{Suggested Citation}

Hodge, Cabell, Matthew Jeffers, Jal Desai, Eric Miller, and Varsha Shah. 2019. Surat Municipal Corporation Bus Electrification Assessment. Golden, CO: National Renewable Energy Laboratory. NREL/TP-5400-73600. https://www.nrel.gov/docs/fy19osti/73600.pdf.

NREL is a national laboratory of the U.S. Department of Energy Office of Energy Efficiency \& Renewable Energy Operated by the Alliance for Sustainable Energy, LLC

This report is available at no cost from the National Renewable Energy Laboratory (NREL) at www.nrel.gov/publications.

Contract No. DE-AC36-08GO28308
Technical Report NREL/TP-5400-73600 May 2019

National Renewable Energy Laboratory 15013 Denver West Parkway Golden, CO 80401

303-275-3000 • www.nrel.gov 


\section{NOTICE}

This work was authored in part by the National Renewable Energy Laboratory, operated by Alliance for Sustainable Energy, LLC, for the U.S. Department of Energy (DOE) under Contract No. DE-AC36-08G028308. Funding provided by U.S. Department of Energy Office of International Affairs. The views expressed herein do not necessarily represent the views of the DOE or the U.S. Government.

This report is available at no cost from the National Renewable Energy Laboratory (NREL) at www.nrel.gov/publications.

U.S. Department of Energy (DOE) reports produced after 1991 and a growing number of pre-1991 documents are available free via www.OSTI.gov.

Cover Photos by Dennis Schroeder: (clockwise, left to right) NREL 51934, NREL 45897, NREL 42160, NREL 45891, NREL 48097, NREL 46526.

NREL prints on paper that contains recycled content. 


\section{Acknowledgments}

The authors would like to thank Dr. D. N. Basak and Mustafa Sonasath of the Surat Municipal Corporation for welcoming them to Surat, providing the information necessary to complete this report, and taking the initiative to consider electrification of their buses. Partha Mishra with the National Renewable Energy Laboratory (NREL) deserves special thanks for his analysis of battery lifecycles. In addition, the authors would like to thank Andrew Kotz, Leslie Eudy, Margo Melendez, and Mollie Putzig at NREL for their contributions and input to the report. They would also like to thank Shimin Sudhakar and Atlul Vijay Deva with the Sardar Vallabhbhai National Institute of Technology for assisting with data collection. The work would not have been possible without the leadership from Russel Conklin and Rudy Kahsar with the U.S. Department of Energy. Finally, the authors would like to thank Anya Breitenbach for her diligence, responsiveness, and attention to detail while editing this report. 


\section{List of Acronyms}

\begin{tabular}{|c|c|}
\hline $\mathrm{AC}$ & alternating current \\
\hline APFC & automatic power factor control \\
\hline BEB & battery electric bus \\
\hline BLAST & Battery Lifetime Analysis and Simulation Tool \\
\hline BRTS & bus rapid transit system \\
\hline BYD & Build Your Dreams \\
\hline $\mathrm{C}$ & Celsius \\
\hline capex & capital expense \\
\hline DCFC & direct current fast chargers \\
\hline dLe & diesel liter equivalent \\
\hline DGVCL & Dakshin Gujarat Vij Company Limited \\
\hline DOE & U.S. Department of Energy \\
\hline DRIVE & Drive-cycle Rapid Investigation, Visualization, and Evaluation \\
\hline ESS & energy storage system \\
\hline EVSE & electric vehicle supply equipment \\
\hline FAME & Faster Adoption and Manufacturing of Hybrid and Electric Vehicles \\
\hline FASTSim & Future Automotive System Technology Simulator \\
\hline GCC & gross cost contract \\
\hline GPS & Global positioning system \\
\hline GVWR & gross vehicle weight rating \\
\hline HT & high-tension \\
\hline $\mathrm{Hz}$ & hertz \\
\hline $\mathrm{kg}$ & kilogram \\
\hline $\mathrm{km}$ & kilometer \\
\hline $\mathrm{kph}$ & kilometers per hour \\
\hline $\mathrm{kW}$ & kilowatt \\
\hline $\mathrm{kWh}$ & kilowatt-hour \\
\hline INR & Indian Rupees \\
\hline $\mathrm{L}$ & liter \\
\hline LFP & lithium iron phosphate \\
\hline LT & low-tension \\
\hline $\mathrm{m}$ & million \\
\hline M & million \\
\hline NCA & lithium nickel cadmium aluminum \\
\hline NMC & lithium nickel manganese cobalt oxide \\
\hline NREL & National Renewable Energy Laboratory \\
\hline OEM & original equipment manufacturer \\
\hline opex & operating expense \\
\hline SMC & Surat Municipal Corporation \\
\hline SOC & state of charge \\
\hline SVNIT & Sardar Vallabhbhai National Institute of Technology \\
\hline U.S. & United States \\
\hline USD & U.S. dollars \\
\hline VCB & vacuum circuit breaker \\
\hline
\end{tabular}




\section{Executive Summary}

This report examines the potential for Surat Municipal Corporation (SMC) to electrify its bus rapid transit system (BRTS) in Surat, India. Researchers from the National Renewable Energy Laboratory (NREL) partnered with the Sardar Vallabhbhai National Institute of Technology (SVNIT) to collect data from SMC, log in-use GPS data of SMC buses, and analyze the results. The ensuing analysis focuses on the operational feasibility and life-cycle costs of battery electric buses (BEBs) compared to diesel buses operated on eight BRTS routes out of four bus depots (Figure ES-1).

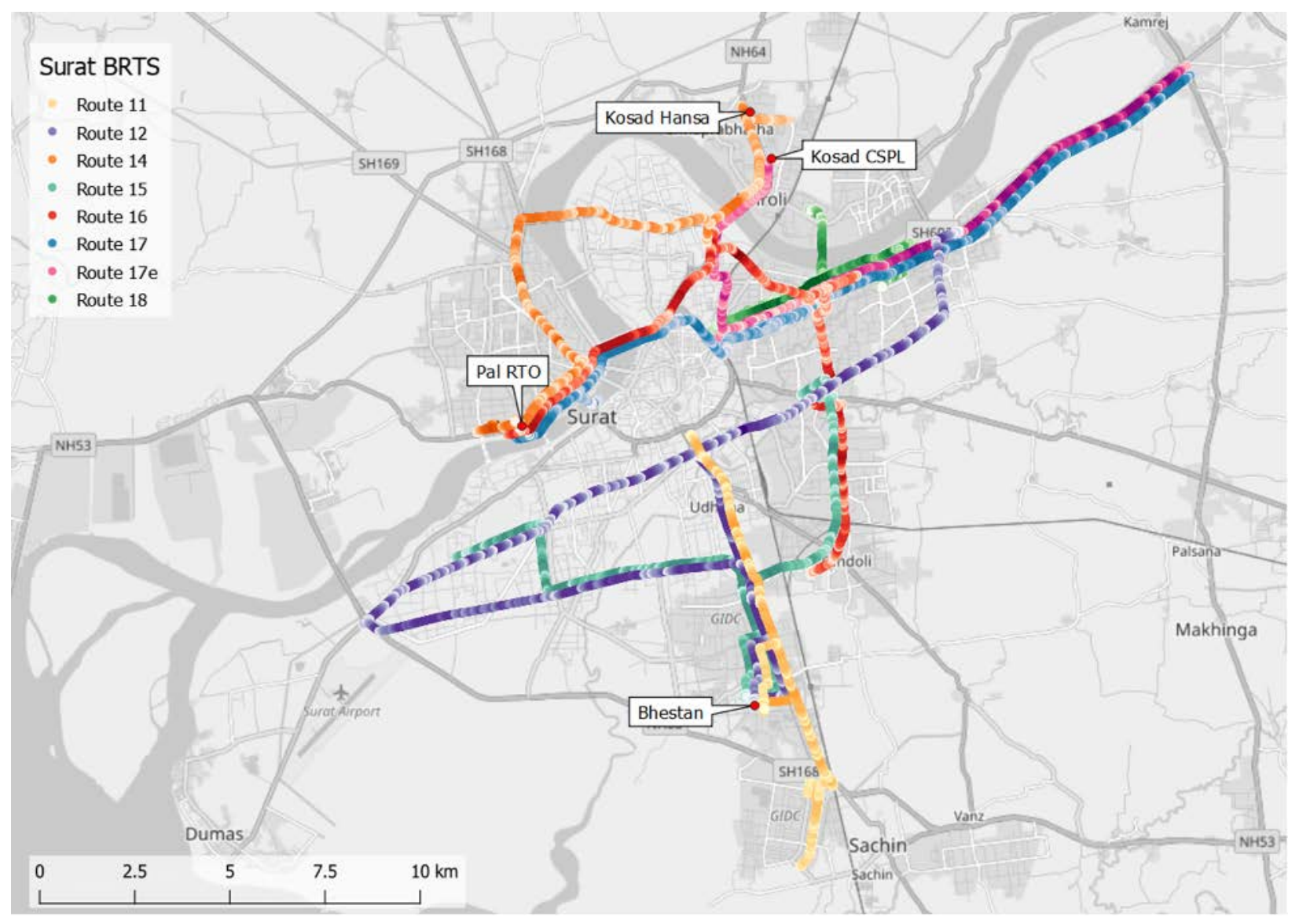

Figure ES-1. Map of logged BRTS routes and depot locations

NREL used a backward-looking model to calculate power requirements for a BEB based on vehicle speed profiles for the BRTS routes. The model uses actual vehicle operation to solve for the power requirements of the BEB, accounting for regenerative braking, as shown in equation ES-1 and more fully described in section 3.3.1. Estimated battery power was used to calculate the required battery size.

\section{Battery $\leftarrow$ Motor $\leftarrow$ Transmission $\leftarrow$ Differential $\leftarrow$ Wheel $\leftarrow$ Chassis $\leftarrow$ Logged Data (ES-1)}

Modeled power requirements for each of these routes varied due to distance, time, route conditions, and driving behavior. In addition, weight of the bus including passenger load and ambient temperature (assuming that each bus used air conditioning) were significant factors 
contributing to the BEB efficiency. Table ES-1 shows the average calculated BEB efficiency for a range of vehicle mass and ambient temperatures, as simulated on the Surat BRTS routes. The ambient temperatures used in the model are representative of the range of operating temperatures experienced in Surat, and the range of modeled vehicle mass (7,000 kg to $18,000 \mathrm{~kg})$ covers the estimated vehicle mass for the BEBs with publicly available gross vehicle weight ratings in India.

Table ES-1. BEB Efficiency by Temperature and Mass (kWh/km)

\begin{tabular}{c||c|c|c|c|c|}
\multirow{2}{*}{ Mass (kg) } & \multicolumn{5}{|c}{ Temperature ( $\left.{ }^{\circ} \mathbf{C}\right)$} \\
\hline & $\mathbf{2 5}$ & $\mathbf{2 8}$ & $\mathbf{3 0}$ & $\mathbf{3 5}$ & $\mathbf{4 0}$ \\
\hline 7,000 & 0.56 & 0.61 & 0.64 & 0.72 & 0.80 \\
\hline 8,000 & 0.60 & 0.65 & 0.68 & 0.76 & 0.84 \\
\hline 9,000 & 0.64 & 0.69 & 0.72 & 0.80 & 0.89 \\
\hline 10,000 & 0.69 & 0.74 & 0.77 & 0.85 & 0.93 \\
\hline 11,000 & 0.74 & 0.79 & 0.82 & 0.90 & 0.98 \\
\hline 12,000 & 0.79 & 0.84 & 0.88 & 0.96 & 1.04 \\
\hline 13,000 & 0.85 & 0.90 & 0.94 & 1.02 & 1.10 \\
\hline 14,000 & 0.92 & 0.97 & 1.00 & 1.08 & 1.17 \\
\hline 15,000 & 0.99 & 1.04 & 1.07 & 1.15 & 1.24 \\
\hline 16,000 & 1.07 & 1.12 & 1.15 & 1.23 & 1.32 \\
\hline 17,000 & 1.15 & 1.20 & 1.23 & 1.31 & 1.40 \\
\hline 18,000 & 1.23 & 1.28 & 1.32 & 1.40 & 1.48 \\
\hline
\end{tabular}

NREL modeled the power requirements for each route using a range of assumptions on vehicle efficiency, and then estimated the minimum energy storage system (ESS) capacity required to meet the daily service requirements of each BRTS route.

Figure ES-2 provides an estimated range of ESS sizes per cumulative fraction of BRTS service met by BEBs. Hashmarks indicate each BRTS route. The bold blue line represents an efficiency of $1.08 \mathrm{~kW} / \mathrm{km}$, which correlates to $14,000 \mathrm{~kg}$ and $35^{\circ} \mathrm{C}$ in Table ES-1. For this modeled average efficiency, conventional BRTS buses could begin to be replaced by depot-charge BEBs with 250-300 kWh battery capacity. 


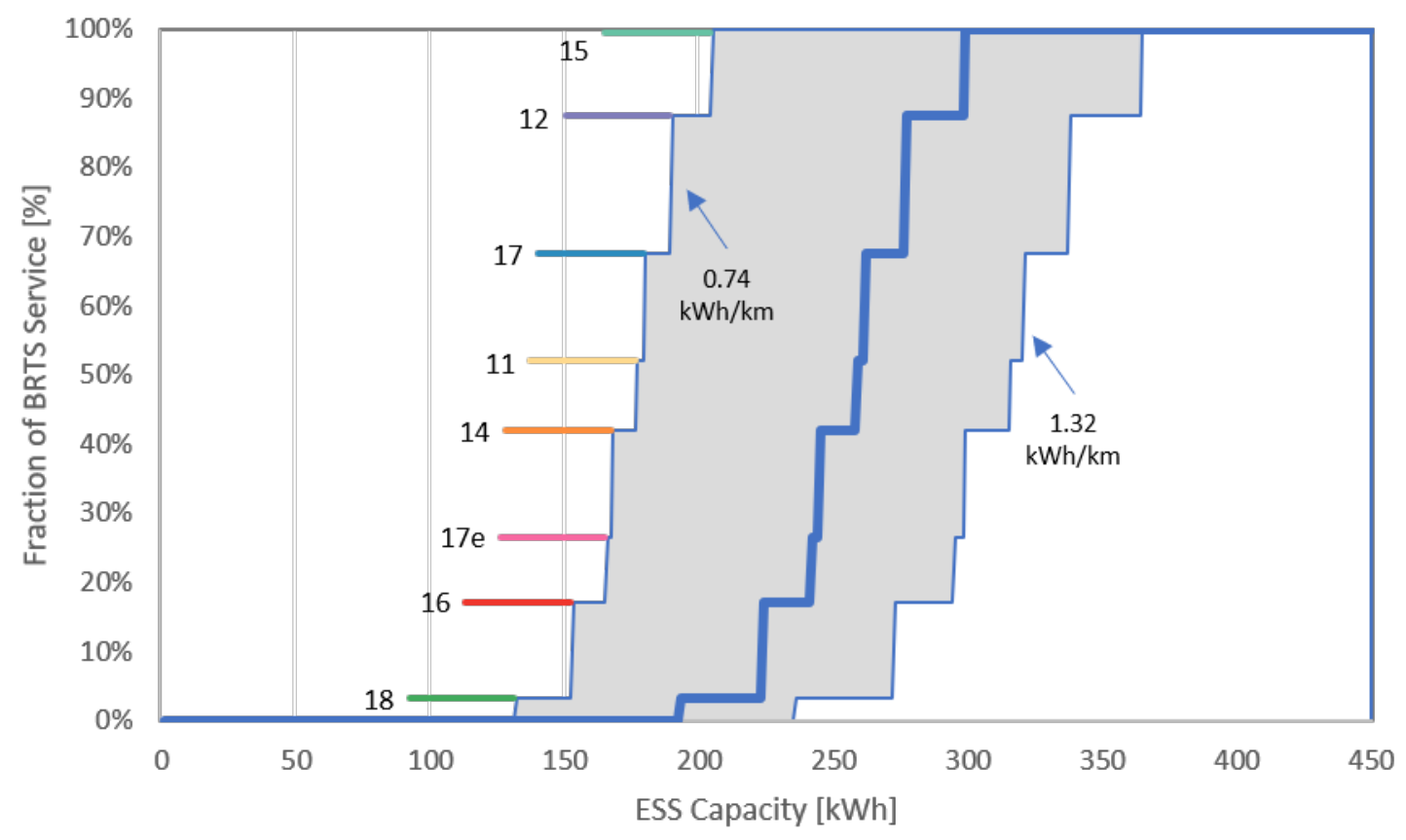

Figure ES-2. Cumulative fraction of BRTS bus fleet vs ESS capacity

When calculating the necessary ESS capacity for BEBs, SMC should consider that traction batteries will degrade over time. Manufacturer warranties often specify $80 \%$ or $85 \%$ of original capacity as the level at which batteries should be replaced, suggesting fleet owners should purchase vehicles with an initial ESS capacity of $17 \%$ to $25 \%$ over the required energy consumption. SMC should also consider that stated ESS capacity is sometimes larger than usable capacity.

NREL modeled battery degradation for three different battery chemistries with the Battery Lifetime Analysis and Simulation Tool (BLAST). Using the power requirement calculations described above, the team simulated a $500-\mathrm{kWh}$ battery that was fully charged to $100 \%$ of actual capacity an hour before the start of daily operation. Leaving a lithium-ion battery at $100 \%$ state of charge (SOC) is not optimal for battery longevity. Some manufacturers limit the maximum and minimum SOC for their batteries in order to improve battery longevity, and operators can extend lifespan by keeping SOC as close to $50 \%$ as possible. NREL recommends securing an acceptable battery warranty as well.

The Government of India Department of Heavy Industries (DHI) has financial incentives available for BEBs and charging infrastructure. The Faster Adoption and Manufacturing of Hybrid and Electric Vehicles (FAME) II program provides a purchase incentive for BEBs of $₹ 20,000 / \mathrm{kWh}^{1}$ of battery capacity or $40 \%$ of the bus value, whichever is lower. In addition, DHI has proposed to cover the entire project cost of electric vehicle supply equipment (EVSE) for one

\footnotetext{
${ }^{1}$ The majority of the monetary values in this report are written in Indian rupees (denoted as ₹ or INR) or derivations as noted (e.g. million INR). NREL used 71.029 INR to 1 U.S. dollar (USD) as the conversion rate in this report based on Indian Rupee, the Economy Forecast Agency (http://dollarrupee.in/), January 17, 2019.
} 
slow charger per bus or one fast charger per every ten buses. This incentive structure is significantly different from FAME I, but the combined impact to BEBs and EVSE costs is similar under both programs.

To complete a life-cycle cost comparison, NREL applied several assumptions, including that BEBs could replace diesel buses at a one-to-one ratio. While this would be accurate in some cases, longer routes or less favorable conditions could require a greater ratio of BEBs to diesel buses. NREL used published purchase cost data for four BEBs and two diesel buses available in India. SMC provided a diesel fuel price of ₹74.3/liter, and NREL calculated the cost of electricity using DGVCL rates assuming overnight charging at the depots to take advantage of time-of-use pricing rebates. Maintenance costs were based on three published reports comparing electric and diesel buses operating within U.S. transit agencies using adjusted labor rates to account for relative differences between the United States and India. The economic analysis did not account for on-route charging or swappable batteries due to insufficient information.

Based on these calculations, three of the four BEBs identified were less expensive than the two reference diesel buses over seven years of ownership (Figure ES-3). However, the BEB with the largest ESS - which will likely be necessary for Surat BRTS routes - may be slightly more expensive in the seven-year period when compared to the most affordable diesel bus. If maintenance costs for Surat BEBs are more similar to the U.S. BEBs under warranty, then even the $324 \mathrm{kWh}$ bus may be less expensive than the most affordable diesel bus considered.

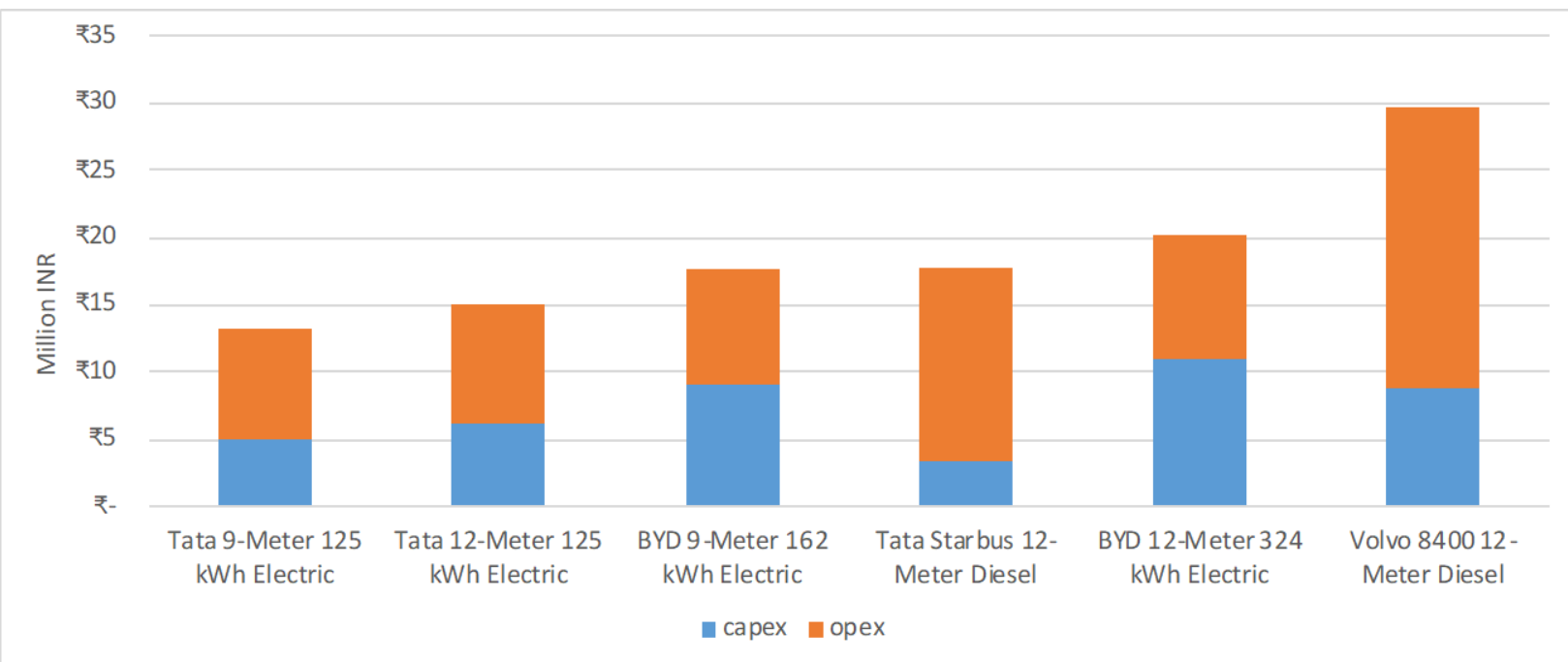

Figure ES-3. Total cost of ownership comparison

NREL recommends subsequent analysis to verify the operational results model with a pilot deployment of BEBs. SMC could validate the power requirements for various routes at various ambient temperatures, precipitation conditions, and passenger loads in order to determine how many routes could be electrified without impacting BRTS service. The economic analysis will take longer to verify — particularly maintenance costs, which can vary significantly from year to year with small-scale vehicle deployments. However, this report indicates that several Surat BRTS routes could be electrified using BEBs currently available in India, and SMC could benefit from significantly reduced operational costs. 


\section{Table of Contents}

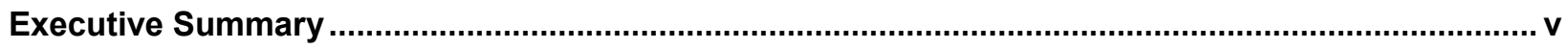

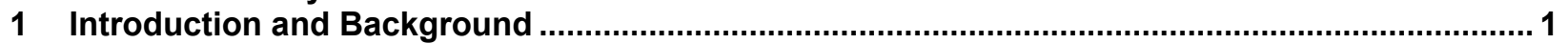

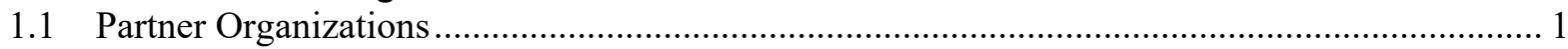

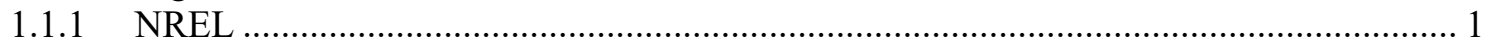

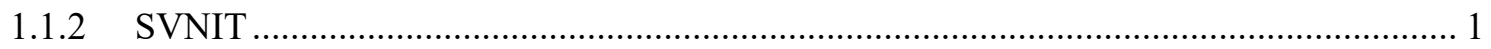

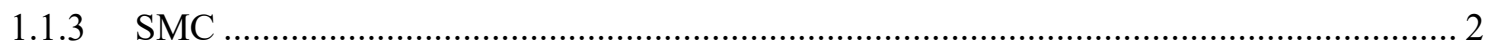

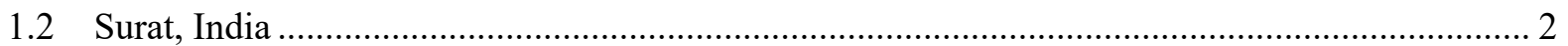

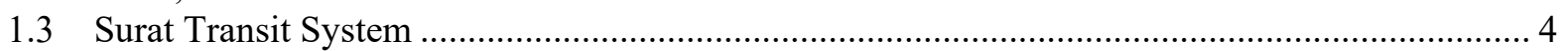

1.3.1 Transit Business Model ........................................................................ 4

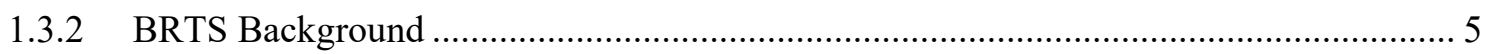

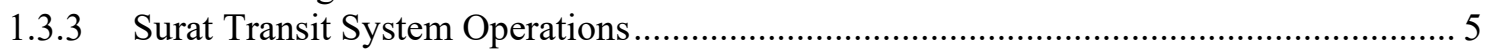

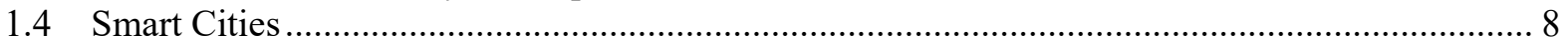

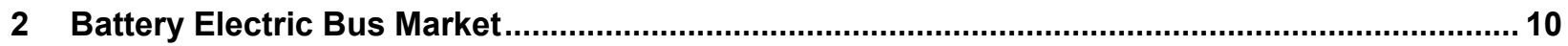

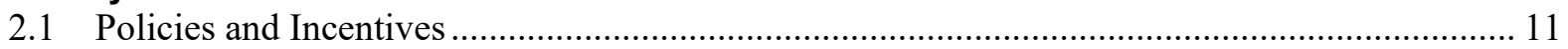

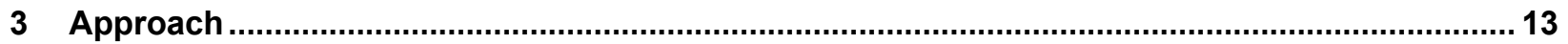

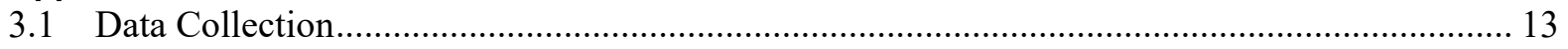

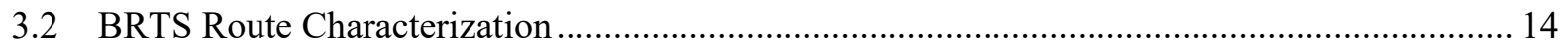

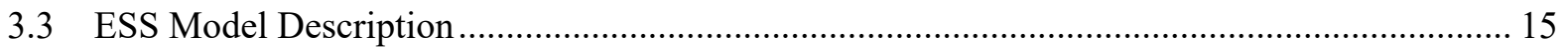

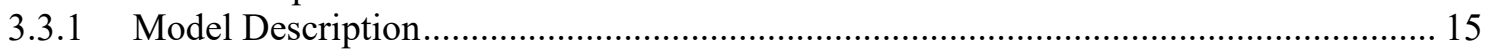

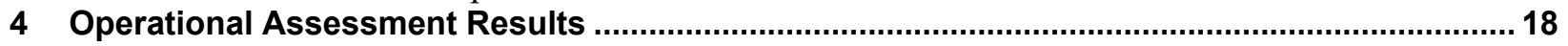

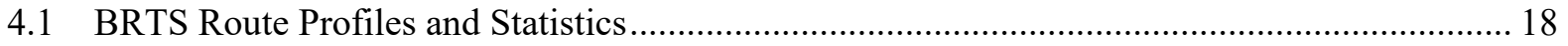

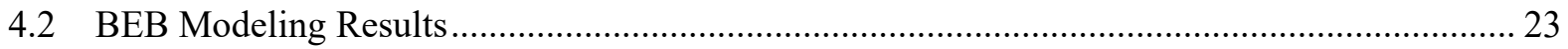

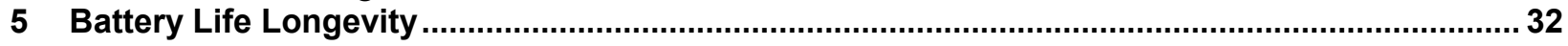

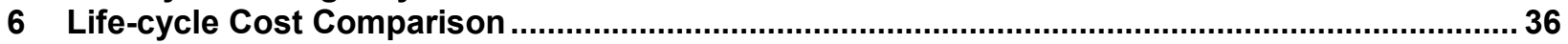

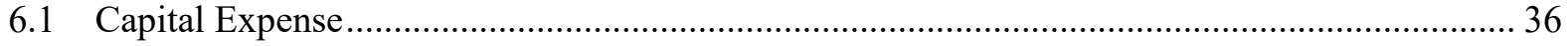

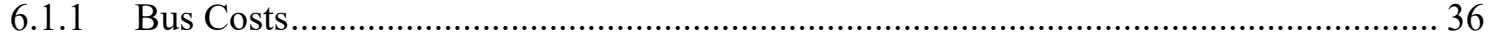

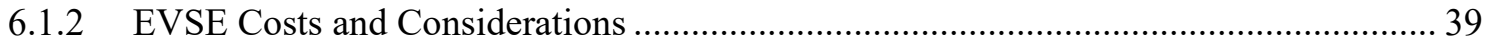

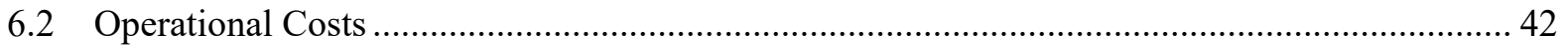

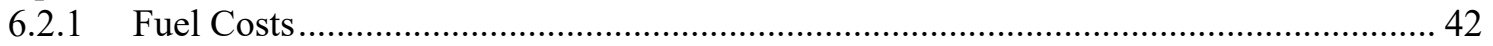

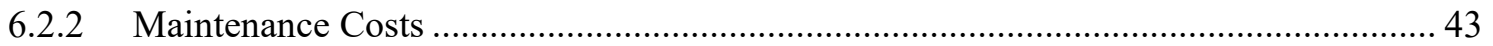

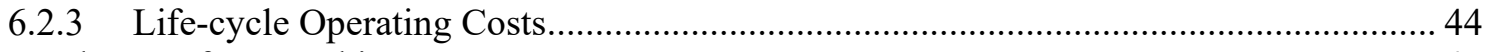

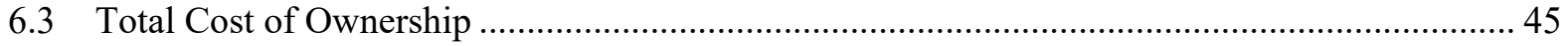

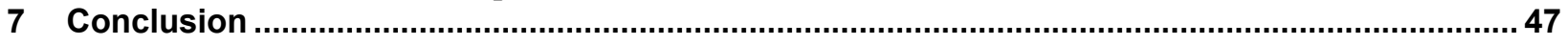




\section{List of Figures}

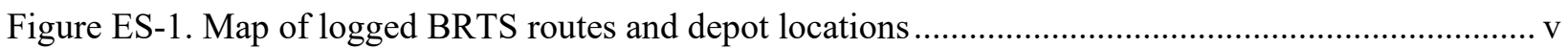

Figure ES-2. Cumulative fraction of BRTS bus fleet vs ESS capacity ................................................... vii

Figure ES-3. Total cost of ownership comparison.................................................................................. viii

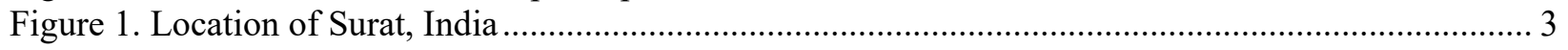

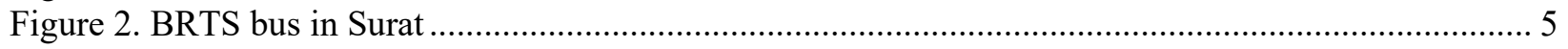

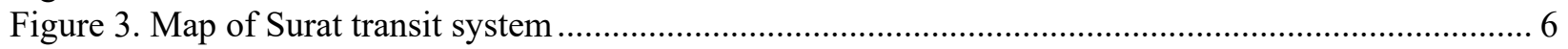

Figure 4. Average diesel fuel economy by daily driving distance for all routes................................... 8

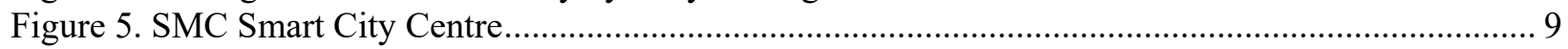

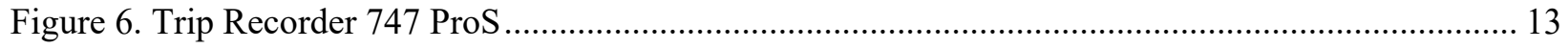

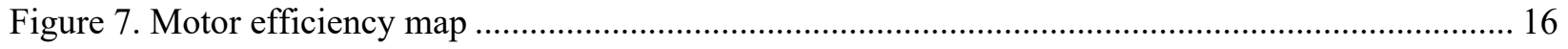

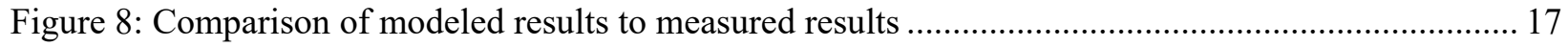

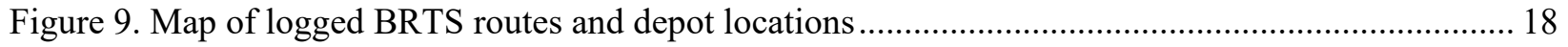

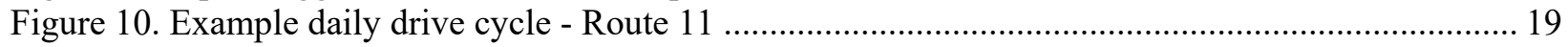

Figure 11. Kinetic intensity vs driving average speed for BRTS routes............................................... 22

Figure 12. Characteristic acceleration vs aerodynamic speed for BRTS routes ..................................... 22

Figure 13. Example speed profile for a measured conventional bus and the modeled electric bus............ 23

Figure 14. Instantaneous power requirement and cumulative energy use .............................................2 24

Figure 15. Sankey diagram displaying the dissipation of battery energy for a BEB on Route 11,

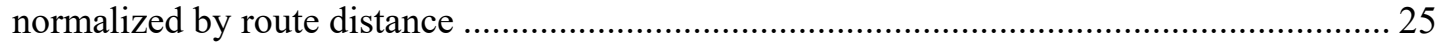

Figure 16. Sankey diagram displaying the dissipation of fuel energy for a conventional bus on Route 11,

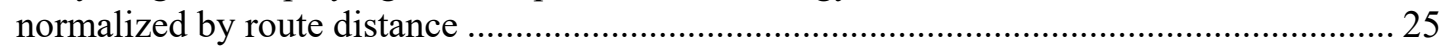

Figure 17. Fuel economy by BRTS route for baseline diesel buses (measured in-use data) and BEBs

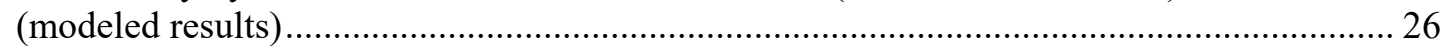

Figure 18. Impact of ambient temperature on BEB energy consumption rate ....................................... 27

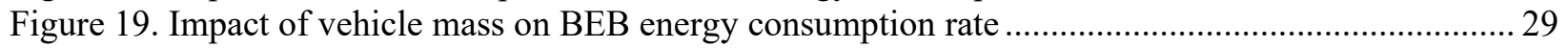

Figure 20. Cumulative fraction of BRTS bus fleet vs ESS capacity ................................................. 31

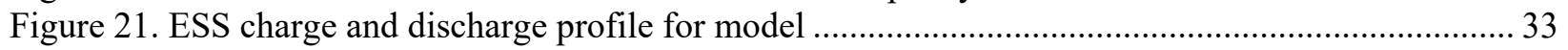

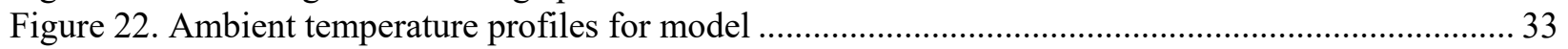

Figure 23. Quoted rates for electric buses - gross cost contract (GCC) ................................................ 37

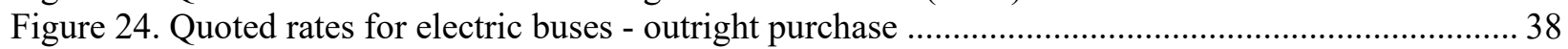

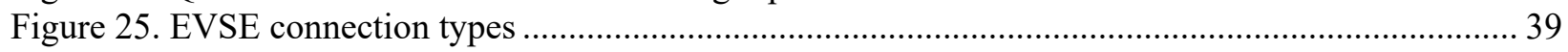

(a) handheld conductive (b) automatic conductive (c) automatic wireless .......................................... 39

Figure 26. Single line diagram of electrical upgrades to support BEBs .............................................. 41

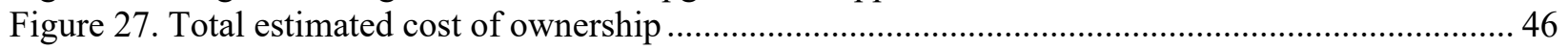




\section{List of Tables}

Table ES-1. BEB Efficiency by Temperature and Mass $(\mathrm{kWh} / \mathrm{km})$..................................................... vi

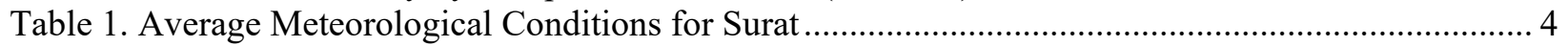

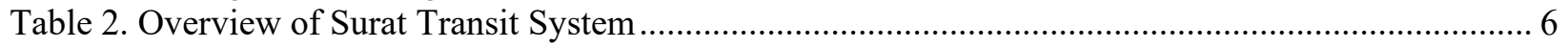

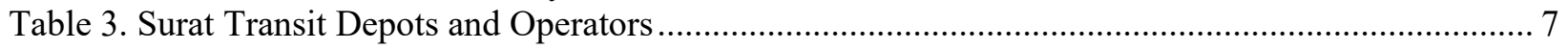

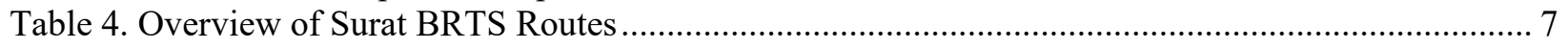

Table 5. Key Specifications for Battery Electric Buses Available in India .......................................... 11

Table 7. BRTS Route Summary Statistics from Logged Data............................................................... 20

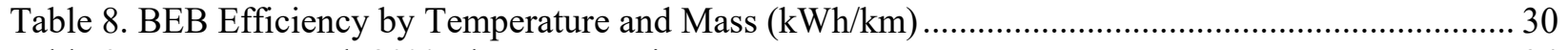

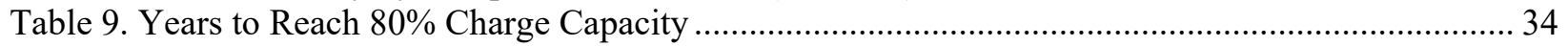

Table 10. Bus Purchase Costs Before and After FAME Incentives.................................................... 38

Table 11. Utility Setup Charges for 600 and 1,000 kVA Transformers .................................................. 41

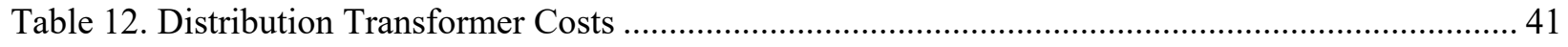

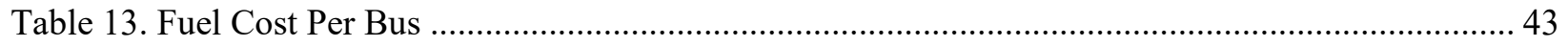

Table 14. Maintenance Costs for Electric and Diesel Buses from NREL Evaluations ............................ 44

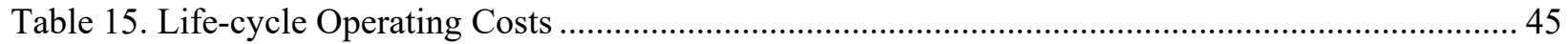




\section{Introduction and Background}

This study examines current operations, transit assets, and infrastructure of the Surat Bus Rapid Transit System (BRTS) in the Indian state of Gujarat and assesses the operational and economic feasibility of transitioning from diesel buses to battery electric buses (BEBs). It includes assessments of BEB range under various scenarios and potential battery life for different chemistries, as well as life-cycle cost comparisons. The analysis leverages advanced vehicle modeling and analysis tools developed by the National Renewable Energy Laboratory (NREL) to identify candidates for fleet electrification at reasonable costs. This report outlines a range of potential outcomes that could be validated through future pilot studies of BEBs on Surat roads.

\subsection{Partner Organizations}

Researchers from the U.S. Department of Energy's (DOE) NREL partnered with Sardar Vallabhbhai National Institute of Technology (SVNIT) Surat to conduct an operational feasibility and economic analysis of Surat BRTS vehicles.

\subsubsection{NREL}

NREL helps U.S. and international fleet operators assess the operational and economic feasibility of alternative fuel vehicles (AFVs) including BEBs. NREL has developed a suite of tools and resources to assist fleets in quantifying efficiency benefits of AFVs. ${ }^{2}$

NREL was asked to provide unbiased, objective analysis to the Surat Municipal Corporation (SMC) on the feasibility of BEBs. NREL's experience in evaluating, measuring, and verifying fleets' deployment of advanced medium- and heavy-duty vehicle technologies has illustrated the relationship between vocational duty cycle and efficiency for different fuel types, as well as the potential impacts on life-cycle costs, barriers to implementation, and commercial viability. ${ }^{3}$ NREL used fleet analysis tools and validation experience to estimate the fuel economy, auxiliary load, required battery capacity, and economic feasibility for the SMC on BRTS routes.

\subsubsection{SVNIT}

SVNIT was founded in 1961with a focus on higher education for civil, mechanical, and electrical engineering. It has since expanded to electronics, computer, production, and chemical engineering, and the electrical engineering department has developed expertise in the utility and automotive sectors. NREL partnered with SVNIT in the development of this assessment to leverage the institute's knowledge of the Surat utility structure and relationships with the SMC. SVNIT played an instrumental role in the collection of data and coordination of responsibility. ${ }^{4}$ Varsha Shah, an SVNIT professor of electrical engineering, also assisted NREL by developing an estimate of transformer costs to support electric vehicle supply equipment (EVSE) in Surat BRTS parking areas (Section 6.1.2).

\footnotetext{
${ }^{2}$ NREL. 2018 “Transportation Research: Data and Tools.” https://www.nrel.gov/transportation/data-tools.html. [Accessed: September 21, 2018].

${ }^{3}$ Kotz, et al. 2018. National Park Service Bus Electrification Study Interim Report. Unreleased

${ }^{4}$ http://www.svnit.ac.in/index.php. [Accessed: January 17, 2019].
} 


\subsubsection{SMC}

$\mathrm{SMC}$ is the local governing body of the Surat district. It was established in 1966. SMC carries out all the tasks and functions with the mission "to make Surat a dynamic, vibrant, beautiful, self-reliant and sustainable city with all basic amenities, to provide a better quality of life." 5 There are nine main departments in the SMC: engineering, health, support revenue, social welfare, secretary, fire and emergency services, culture, and watch and ward. SMC is the key stakeholder in this project, along with the residents of Surat. The BRTS division of the engineering department oversees the BRTS transportation within Surat district. SMC coordinated with SVNIT and NREL, provided BRTS route and bus information, and provided access to the conventional BRTS buses for installation and monitoring of loggers.

\subsection{Surat, India}

Surat is located on the western side of India (Figure 1). It is one of the major cities in the Gujarat state. In 2011, Surat district had a population of 4.5 million, ${ }^{6}$ making it the second-largest city in Gujarat and ninth-largest in India. ${ }^{7}$ Due to Surat's geographical location, many large industries including textile, trade, diamond cutting and polishing, Zari ${ }^{8}$ works, chemical, petrochemical, and natural gas-based businesses have developed there.

The tropical climate in Surat — with a high average daily temperature of $31.3^{\circ} \mathrm{C}$ in May and a low of $22.8^{\circ} \mathrm{C}$ in January - impacts the viability of BEBs in two ways. First, air conditioning is a significant auxiliary load requiring larger battery capacity. Second, high temperatures negatively impact the longevity of lithium-ion batteries. ${ }^{9}$

\footnotetext{
5 Surat Municipal Corporation. 2019. "Corporation Introduction." https://www.suratmunicipal.gov.in/Corporation/Introduction. [Accessed: January 17, 2019].

${ }^{6}$ Surat Municipal Corporation. 2019. “City Introduction.” https://www.suratmunicipal.gov.in/TheCity/Introduction. [Accessed: January 17, 2019].

${ }^{7}$ WikiTravel. 2019. "Surat.” https://wikitravel.org/en/Surat. [Accessed: January 17, 2019].

${ }^{8}$ Utsavpedia. 2019. "Zari." https://www.utsavpedia.com/motifs-embroideries/zari-the-ultimate-precious-metalweaving-art/. [Accessed: January 17, 2019].

${ }^{9}$ Pesaran, et al. 2013. "Addressing the Impact of Temperature Extremes on

Large Format Li-Ion Batteries for Vehicle Applications.” https://www.nrel.gov/docs/fy13osti/58145.pdf
} 


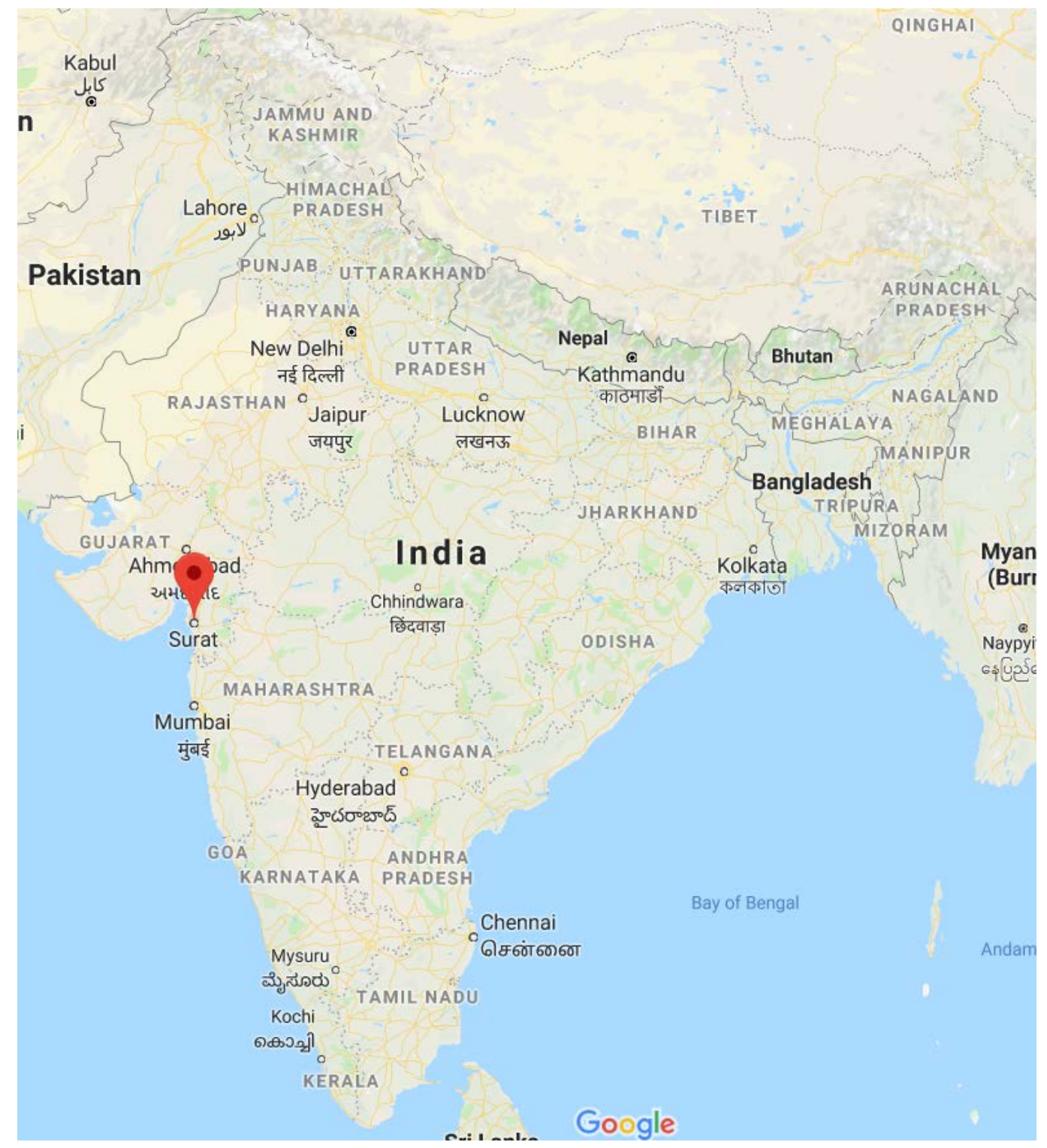

Figure 1. Location of Surat, India ${ }^{10}$

${ }^{10}$ Google Maps. 2019. "Surat, Gujarat, India." https://www.google.com/maps/place/Surat,+Gujarat,+India/@22.6669265,70.5465757,4.99z/data=!4m5!3m4!1s0x3 be04e59411d1563:0xfe4558290938b042!8m2!3d21.1702401!4d72.8310607. [Accessed: January 17, 2019].

This report is available at no cost from the National Renewable Energy Laboratory (NREL) at www.nrel.gov/publications. 
Table 1. Average Meteorological Conditions for Surat ${ }^{11}$

\begin{tabular}{|c|c|c|c|c|c|c|c|c|c|c|c|c|c|}
\hline \multicolumn{14}{|c|}{ Average Temperature } \\
\hline & Annual & Jan & Feb & Mar & Apr & May & Jun & Jul & Aug & Sep & Oct & Nov & Dec \\
\hline${ }^{\circ} \mathrm{C}$ & 27.6 & 22.8 & 24.3 & 28 & 30.4 & 31.3 & 30.3 & 28.2 & 27.8 & 28.2 & 29.2 & 26.8 & 24 \\
\hline \multicolumn{14}{|c|}{ Average High Temperature } \\
\hline & Annual & Jan & Feb & Mar & Apr & May & Jun & Jul & Aug & Sep & Oct & Nov & Dec \\
\hline${ }^{\circ} \mathrm{C}$ & 33.4 & 30.9 & 32.4 & 35.8 & 37.2 & 36.2 & 33.8 & 30.8 & 30.4 & 31.8 & 35.3 & 34.3 & 32 \\
\hline \multicolumn{14}{|c|}{ Average Low Temperature } \\
\hline & Annual & Jan & Feb & Mar & Apr & May & Jun & Jul & Aug & Sep & Oct & Nov & Dec \\
\hline${ }^{\circ} \mathrm{C}$ & 21.7 & 14.7 & 16.2 & 20.1 & 23.6 & 26.3 & 26.7 & 25.5 & 25.1 & 24.6 & 23 & 19.2 & 15.9 \\
\hline \multicolumn{14}{|c|}{ Average Number of Days Above $32^{\circ} \mathrm{C}$} \\
\hline & Annual & Jan & Feb & Mar & Apr & May & Jun & Jul & Aug & Sep & Oct & Nov & Dec \\
\hline Days & 173 & 3 & 9 & 22 & 27 & 28 & 21 & 6 & 3 & 11 & 23 & 16 & 5 \\
\hline \multicolumn{14}{|c|}{ Average Precipitation } \\
\hline & Annual & Jan & Feb & Mar & Apr & May & Jun & Jul & Aug & Sep & Oct & Nov & Dec \\
\hline $\mathrm{mm}$ & 1117 & 2.1 & 1 & 0.8 & 2.2 & 6.4 & 212.8 & 440.8 & 233.4 & 169.7 & 33.5 & 12.4 & 2.1 \\
\hline
\end{tabular}

\subsection{Surat Transit System}

Surat has a well-connected transport system, with 275 city buses and an additional 127 BRTS buses operating on multiple routes within the city. The BRTS buses have access to dedicated lanes (Figure 2), where they travel fixed routes at set times without traffic concerns impeding their predictability. The reliability of these routes makes them good candidates for BEBs, which are primarily constrained by driving range and recharge time. A countervailing consideration is that BRTS buses currently offer air conditioning, which can add a significant auxiliary load on the BEB energy storage system (ESS), reducing the effective driving range. The set routes could also provide convenient locations for extreme fast charging, especially where the BRTS routes overlap.

\subsubsection{Transit Business Model}

City and BRTS buses operate on a cross cost model. In this partnership, private firms operate the buses under the control of SMC. All operating expenses such as maintenance, fuel, and driver salaries are incurred by the operator. SMC pays an agreed price per kilometer to the operator to cover these expenses, and in return, SMC collects all the bus fare proceeds. An agreement between SMC and the operator identifies a set daily distance that each bus must run, irrespective of the number of passengers on board. In addition, the contract specifies the number of years that each operator shall operate the buses.

\footnotetext{
${ }^{11}$ WeatherBase. 2019. "Surat, India." https://www.weatherbase.com/weather/weather.php3?s=4824\&cityname=Surat-Gujarat-India\&units=metric. [Accessed: January 17, 2019].
} 


\subsubsection{BRTS Background}

Development and operation of BRTS for the city of Surat is managed by Surat Sitilink Limited, a wholly owned subsidiary of SMC. SMC defines BRTS as, "A multifaceted project which integrates land use and transport, various forms of public transport services as well as other motorized and nonmotorized modes through various physical, operational and policy interventions to achieve the objective of making Surat an accessible and competitive city." 12

The Surat BRTS includes roadways that are dedicated to buses as shown in Figure 2. The buses have priority at the intersections where they interact with other traffic.

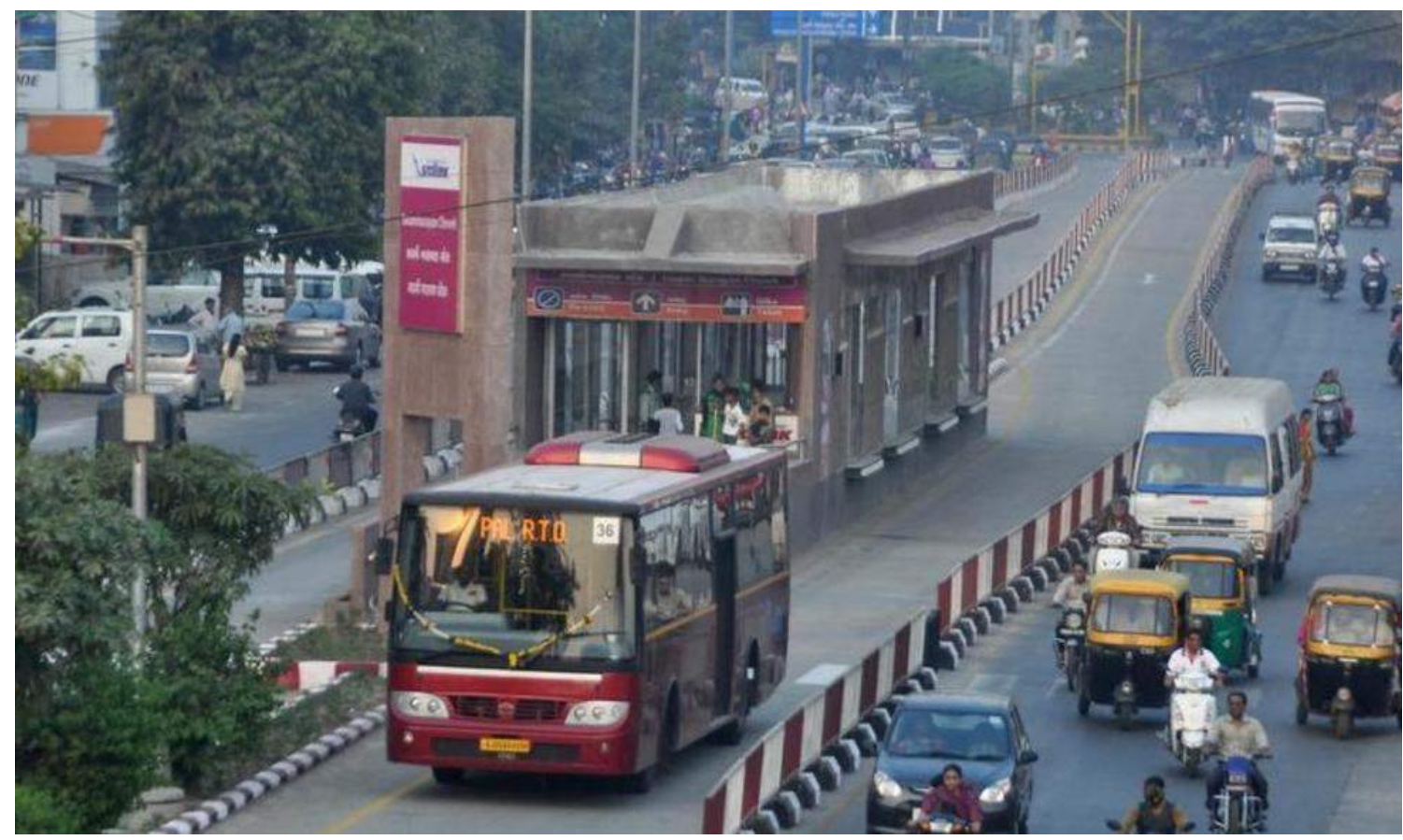

Figure 2. BRTS bus in Surat ${ }^{13}$

\subsubsection{Surat Transit System Operations}

SMC provided information about Surat's transit bus system to NREL to begin this evaluation with a characterization of the current transit operations. Figure 3 displays the span of transit routes across the geographic area of Surat, and Table 2 provides a brief overview of the BRTS and city portions of the transit service.

\footnotetext{
${ }^{12}$ Surat Municipal Corporation. 2019. "BRTS Cell Introduction." https://www.suratmunicipal.gov.in/Departments/BRTSCellIntroduction. [Accessed: January 17, 2019].

${ }^{13}$ Times of India. 2017. "City buses, 3 BRTS routes await inauguration." https://timesofindia.indiatimes.com/city/surat/city-buses-3-brts-routes-awaitinauguration/articleshow/57456944.cms. [Accessed: January 17, 2019].
} 


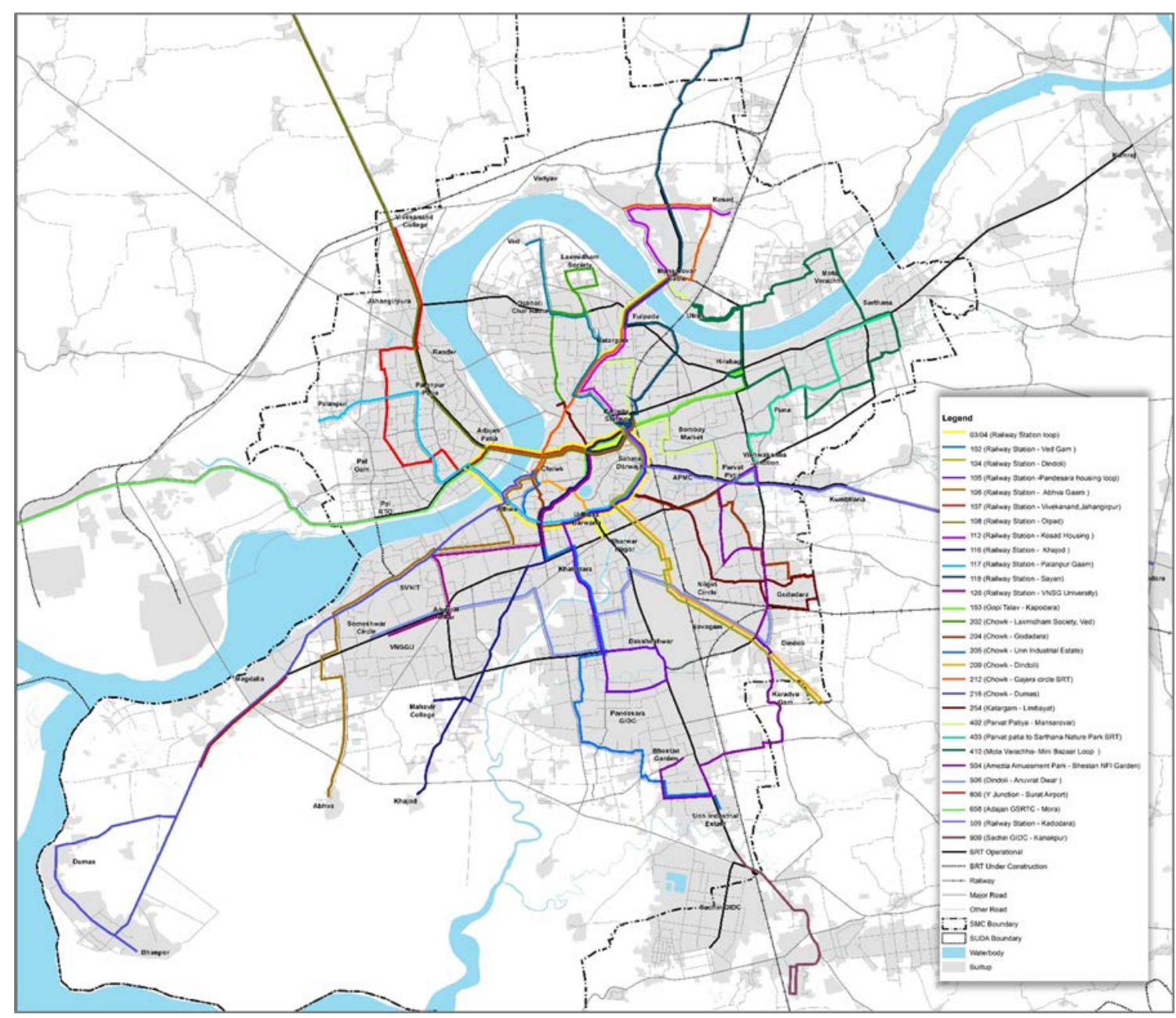

Figure 3. Map of Surat transit system ${ }^{14}$

Table 2. Overview of Surat Transit System

\begin{tabular}{|c|c|c|c|} 
& BRTS & City & Total \\
\hline Buses & 127 & 275 & 402 \\
\hline Routes & 8 & 33 & 41 \\
\hline Depots & 3 & 3 & 6 \\
\hline Operators & 3 & 2 & 5 \\
\hline
\end{tabular}

The number of buses for BRTS and city routes are listed by depot and operator in Table 3. Of the 402 transit buses operating in Surat, 127 are on dedicated BRTS routes, operating out of three of the six depots.

\footnotetext{
${ }^{14}$ Surat Sitilink Ltd. 2018. Provided by Mustafa Sonasath, Assistant Manager of Operations at Surat Sitilink Ltd. in personal correspondence with authors.
} 
Table 3. Surat Transit Depots and Operators

\begin{tabular}{|c|c|c|c|}
\hline Depot & Operator & BRTS Buses & City Buses \\
\hline Bhestan & Prasanna Purple & 66 & - \\
\hline Pal RTO & Adinath & 50 & - \\
\hline Kosad Hansa & Hansa Travels & 11 & - \\
\hline Kosad CSPL & Chartered SPL & - & 1 \\
\hline LP Savani & Chartered SPL & - & 199 \\
\hline Bhestan Garden & Maruti & - & 75 \\
\hline
\end{tabular}

Table 4 lists the number of buses scheduled for each of the eight BRTS routes, along with the number of daily trips and daily distance traveled, according to SMC data. Route 18 requires only four buses and has the smallest daily distance at $186 \mathrm{~km} / \mathrm{bus}$. All other BRTS routes have 12 or more buses each scheduled to travel at least $209 \mathrm{~km} /$ day.

Table 4. Overview of Surat BRTS Routes

\begin{tabular}{|c|c|c|c|c|c|c|}
\hline $\begin{array}{l}\text { BRTS } \\
\text { Route }\end{array}$ & $\begin{array}{c}\text { Number } \\
\text { of } \\
\text { Buses }\end{array}$ & $\begin{array}{l}\text { Daily Trips, } \\
\text { Peak }\end{array}$ & $\begin{array}{l}\text { Daily Trips, } \\
\text { Off Peak }\end{array}$ & $\begin{array}{c}\text { Daily Trips, } \\
\text { Total }\end{array}$ & $\begin{array}{c}\text { Daily } \\
\text { Distance, } \\
\text { Total [km] }\end{array}$ & $\begin{array}{c}\text { Daily } \\
\text { Distance, } \\
\text { Per Bus [km] }\end{array}$ \\
\hline 11 & 13 & 119 & 152 & 271 & 3,147 & 242 \\
\hline 12 & 26 & 145 & 183 & 328 & 6,469 & 249 \\
\hline 14 & 20 & 80 & 164 & 244 & 4,856 & 243 \\
\hline 15 & 16 & 78 & 140 & 218 & 4,212 & 263 \\
\hline 16 & 18 & 100 & 146 & 246 & 3,788 & 210 \\
\hline 17 & 20 & 64 & 136 & 200 & 4,180 & 209 \\
\hline $17 e$ & 12 & 103 & 86 & 189 & 3,024 & 252 \\
\hline 18 & 4 & 64 & 46 & 110 & 743 & 186 \\
\hline
\end{tabular}

Figure 4 shows the average fuel economy of the baseline buses - all of which are diesel-fueledby daily distance traveled for each BRTS bus route. The routes are identified as BRTS or city routes, and the size of the data marker indicates the number of buses operating on each route. BRTS routes have four to 26 buses operating on a route, while the city routes range from two to 14 buses per route. Except for one city route, all buses travel between $150 \mathrm{~km}$ and $275 \mathrm{~km}$ daily. It is clear from the figure that BRTS routes generally have the most buses per route, traveling the greatest daily distance with the poorest fuel economy. This indicates opportunities to improve efficiency and reduce of emissions with the introduction of electrified transit buses. 


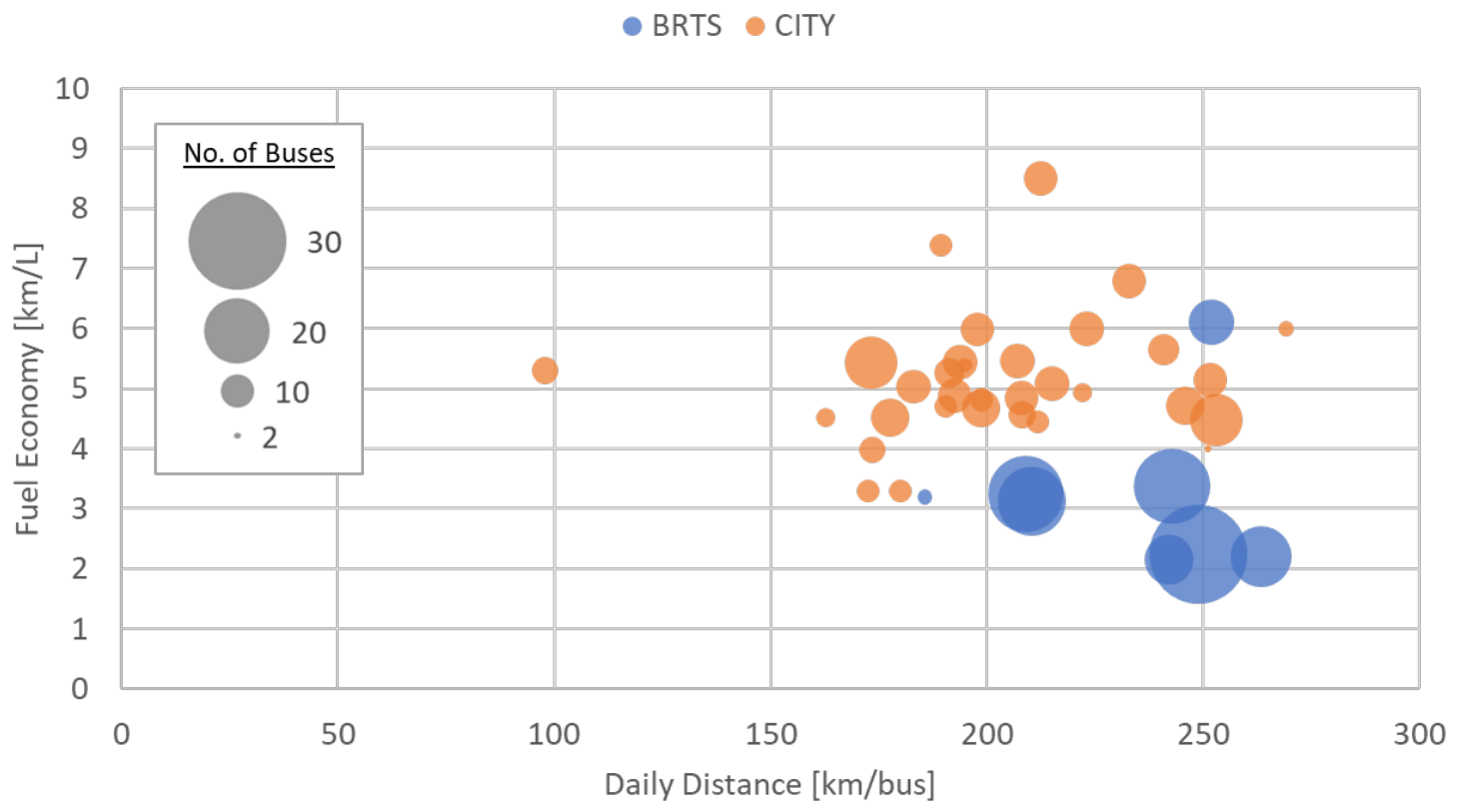

Figure 4. Average diesel fuel economy by daily driving distance for all routes

SMC plans to electrify a large percentage of its fleet over the next several years, starting with a pilot program using 10 to 15 BEBs on BRTS routes. NREL has been engaged to identify existing bus routes where BEBs could operate and to estimate the life-cycle costs of the replacement BEBs in comparison to acquiring new diesel buses, including an estimate of charging infrastructure costs.

\subsection{Smart Cities}

Surat was selected in the first round of applications in 2016 by the Indian Ministry of Housing and Urban Affairs as one of 20 Indian cities to be developed as a "Smart City" under the Government of India's Smart Cities Mission. Launched in 2015, the Smart Cities Mission promotes sustainable development, transit electrification, and improved urban transport options..$^{15,16}$

SMC, Special Purpose Vehicles, Surat Sitilink Limited, and Surat Smart City Development Limited worked with Google to add real-time bus information in Google Maps, making it

\footnotetext{
15 Times of India. 2015. "Full list of 98 smart cities." https://timesofindia.indiatimes.com/india/Full-list-of-98-smartcities/articleshow/48694723.cms?from=mdr. [Accessed: January 17, 2019].

${ }^{16}$ Government of India. 2019. "Smart Cities Mission." http://smartcities.gov.in/content/innerpage/smart-cityfeatures.php. [Accessed: January 17, 2019].
} 
possible for commuters to more easily plan their trips. Surat is the first city in Gujarat and second in India to launch real-time transit information with Google Maps. ${ }^{17,} 18$

SMC has used smart technology to increase bus ridership from 3,000 riders per day in August 2016 to 65,000 per day by November $2017 .{ }^{19}$ The focus of this technology has included realtime monitoring at the SMC Smart City Center (Figure 5) to ensure bus reliability and improve the rider experience.

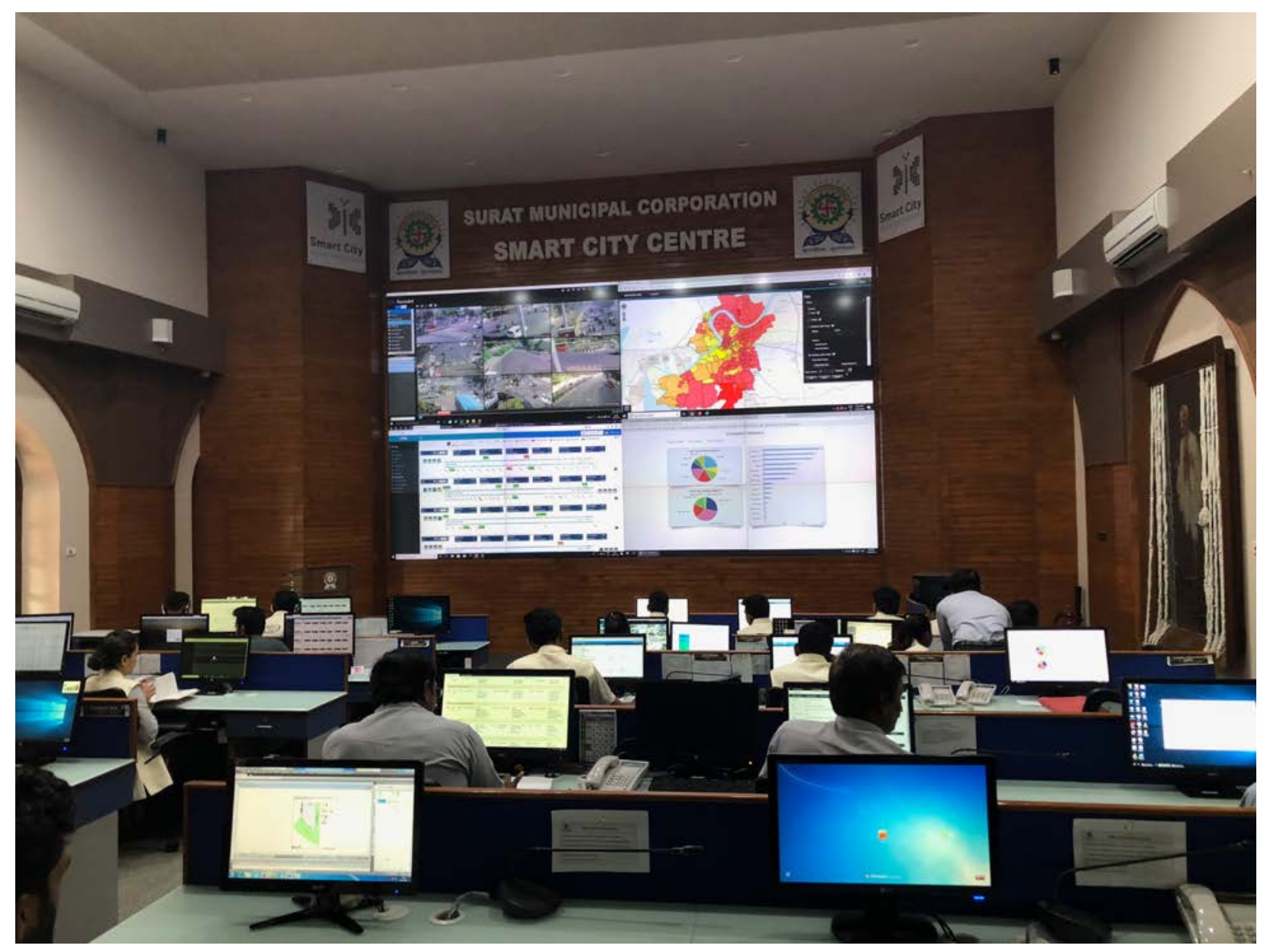

Figure 5. SMC Smart City Centre 20

\footnotetext{
${ }^{17}$ Surat Smart City. 2017. "Real Time Transit Launch." http://www.suratsmartcity.com/PressNote/RealTimeTransitLaunch. [Accessed: January 17, 2019].

${ }^{18}$ Commuters can download the web application "Surat Sitilink" to track buses and pay for tickets at https://www.suratmunicipal.gov.in/EServices/SuratSitilinkApp. [Accessed April 12, 2019].

${ }^{19}$ Dash. 2017. "How Surat got people to ditch autorickshaw rides, opt for buses," https://timesofindia.indiatimes.com/city/delhi/how-surat-got-people-to-ditch-autorickshaw-rides-opt-forbuses/articleshow/61611309.cms. [Accessed: January 17, 2019].

${ }^{20}$ Desai. 2019.
} 


\section{Battery Electric Bus Market}

There appear to be at least seven automotive manufacturers currently offering or planning to offer BEBs to the India market, but NREL researchers were only able to obtain data on offerings from three manufacturers at the time of writing this report: BYD (partnered with Goldstone Infratech Ltd.), Tata Motors Ltd., and Ashok Leyland. ${ }^{21,22,23}$ Considering the size of the bus market in India, the aggressive incentive programs available from the Indian government for adoption of BEBs, and the growing international market of BEB manufacturers, it is likely that more electric options will be offered in the near future.

Based on the available information, two different models of BEBs are offered by each of the three automotive manufacturers. Table 5 summarizes and compares the key specifications across the three established manufacturers. Currently, none of the manufacturers are offering BEBs with on-route charging capability, although Ashok Leyland offers a swappable battery pack.

\footnotetext{
${ }^{21}$ Government of India, DHI. 2018. "Recommendations of the Committee Constituted to Decide Benchmark Price for Electric Buses to be Procured by Different STUs, for Release of Demand Incentives."

https://dhi.nic.in/writereaddata/UploadFile/Benchmark\%20price\%20for\%20Electric\%20Buses63666299596397561 6.pdf. [Accessed: January 17, 2019].

${ }^{22}$ Singh, Saluja. 2018. "Goldstone-BYD, Tata Motors grab E-Bus contracts." https://economictimes.indiatimes.com/goldstone-byd-tata-motors-grab-e-buscontracts/articleshow $/ 63406325$.cms?utm source $=$ contentofinterest\&utm medium=text\&utm campaign $=$ cppst. [Accessed: January 17, 2019].

${ }^{23}$ UITP. n.d. "Electric Buses Procurement In India - Indian Cities Got The Viable Rates." https://india.uitp.org/sites/default/files/documents/Procurement $\% 20$ of $\% 20$ Electric $\% 20$ buses $\% 20$ in $\% 20$ India $\% 20$ \%2020032018.pdf. [Accessed: January 17, 2019].
} 
Table 5. Key Specifications for Battery Electric Buses Available in India

\begin{tabular}{|c|c|c|c|c|c|}
\hline $\begin{array}{c}\text { OEM } \\
\text { BEB model }\end{array}$ & $\begin{array}{c}\text { Goldstone } \\
\text {-BYD } \\
\text { K7 }\end{array}$ & $\begin{array}{l}\text { Goldstone } \\
\text {-BYD } \\
\text { K9 }\end{array}$ & $\begin{array}{c}\text { Tata Motors } \\
\text { Ultra Electric } \\
6 / 9 \mathrm{EV}\end{array}$ & $\begin{array}{c}\text { Tata Motors } \\
\text { Starbus Electric } \\
9 / 12 \mathrm{EV}\end{array}$ & $\begin{array}{l}\text { Ashok Leyland } \\
\text { Circuit-F and Circuit-S }\end{array}$ \\
\hline GVWR (kg) & 13500 & 18000 & 10200 & 16200 & - \\
\hline $\begin{array}{l}\text { Size (mm - } \\
\text { length } x \\
\text { width } x \\
\text { height) }\end{array}$ & $\begin{array}{c}8900 x \\
2465 x \\
2930\end{array}$ & $\begin{array}{c}12000 x \\
2520 x \\
3340\end{array}$ & $\begin{array}{c}9000 x \\
2340 x \\
3380\end{array}$ & $\begin{array}{c}12000 x \\
2570 x \\
3700\end{array}$ & $\begin{array}{c}9400 x \\
2600 x \\
900\end{array}$ \\
\hline $\begin{array}{l}\text { Passenger } \\
\text { Capacity }\end{array}$ & $31+$ driver & $39+$ driver & $\begin{array}{c}26+\text { driver } \\
+13 \text { standees }\end{array}$ & $\begin{array}{c}40+\text { driver } \\
+22 \text { standees }\end{array}$ & $\begin{aligned} & 23-39 \text { seated } \\
+ & 23-30 \text { standing }\end{aligned}$ \\
\hline $\begin{array}{l}\text { Motor } \\
\text { Maximum } \\
\text { Power }\end{array}$ & $180 \mathrm{~kW}$ & $180 \mathrm{~kW}$ & $\begin{array}{c}145 \mathrm{~kW} \\
\text { Operating range: } \\
0-2,500 \mathrm{rpm}\end{array}$ & $\begin{array}{c}145 \mathrm{~kW} \\
\text { Operating range: } \\
0-2,500 \mathrm{rpm}\end{array}$ & $\begin{array}{c}250 \text { kW (peak) } \\
150 \text { kW (continuous) } \\
\text { Torque: } 900 \text { Nm (peak) } \\
360 \text { Nm (continuous) }\end{array}$ \\
\hline $\begin{array}{l}\text { Battery Size } \\
\text { (kWh) }\end{array}$ & $162 \mathrm{kWh}$ & $324 \mathrm{kWh}$ & - & - & $\begin{array}{c}256 \text { kWh or } \\
64 \text { kWh (swappable) }\end{array}$ \\
\hline $\begin{array}{c}\text { Electrical } \\
\text { Regeneration }\end{array}$ & Available & Available & Available & Available & Available \\
\hline Range (km) & $\begin{array}{l}\text { Up to } 200 \\
\text { km }\end{array}$ & $\begin{array}{l}\text { Up to } 250 \\
\text { km }\end{array}$ & $\begin{array}{c}215 \mathrm{~km} \\
\text { (as per CMVR) }\end{array}$ & $\begin{array}{c}151 \mathrm{~km} \\
\text { (as per CMVR) }\end{array}$ & - \\
\hline $\begin{array}{l}\text { Charging } \\
\text { Time (hours) }\end{array}$ & $2-3$ hours & $4-5$ hours & $\begin{array}{l}\text { 6-7 hours } \\
\text { (slow option) } \\
\text { 2.5-3 hours } \\
\text { (fast option) }\end{array}$ & $\begin{array}{l}\text { 6-7 hours } \\
\text { (slow option) } \\
\text { 2.5-3 hours } \\
\text { (fast option) }\end{array}$ & Less than 3 hours \\
\hline
\end{tabular}

\subsection{Policies and Incentives}

SMC is interested in deploying BEBs to reduce pollution in the Surat urban area as part of a broader strategy coordinated by the Indian national government. India has prioritized BEBs through an incentive program known as Faster Adoption and Manufacturing of Hybrid and Electric Vehicles (FAME).

The original FAME I program provided incentives for up to $60 \%$ of the purchase cost of BEBs and capped those incentives at ₹10M or ₹8.5M depending on the percentage of localization (or the percentage of bus manufacturing within India). ${ }^{24},{ }^{25}$ FAME I offered an incentive for

\footnotetext{
24 The majority of the monetary values in this report are written in Indian rupees (denoted as ₹ or INR) or derivations as noted (e.g. million INR). NREL used 71.029 INR to 1 U.S. dollar (USD) as the conversion rate in this report based on Indian Rupee, the Economy Forecast Agency (http://dollarrupee.in/), January 17, 2019.

${ }^{25}$ One lakh $=100,000$ INR. One crore $=10,000,000$ INR.
} 
BEB charging infrastructure as well, providing an additional $10 \%$ on top of the total bus incentive. ${ }^{26,27}$

The Government of India superseded FAME I with a proposal for the FAME II program in April 2019. The FAME II proposal provides BEB incentives based on the size of the energy storage system (ESS). Every kWh of ESS in a BEB qualifies for ₹20,000 in grant funding up to $40 \%$ of the cost of the vehicle. ${ }^{28}$ In addition, FAME II will cover up to $100 \%$ of the project costs of one slow charger per BEB or one fast charger for every ten buses. ${ }^{29}$

Indian policies such as the National Auto Fuel Policy 2003 and the Auto Fuel Vision \& Policy 2025 require diesel buses to produce fewer emissions. The National Green Tribunal, which resolves environmental disputes involving multidisciplinary issues, has passed a ruling that heavy diesel vehicles in the Delhi National Capital Region that are more than 10 years old must be retired. In addition, the Bureau of Energy Efficiency Star Ratings is setting higher fuel economy standards for buses. The additional emission controls increase the cost of diesel bus acquisition and maintenance. As a result, many bus operators are beginning to favor the adoption of BEBs.

\footnotetext{
${ }^{26}$ Government of India, Ministry of Heavy Industries and Public Enterprises, DHI. 2017. Minutes of the 9th Meeting of the Project Implementation and Sanctioning Committee Held Under the Chairmanship of Secretary Heavy Industry on 20th December 2017. https://dhi.nic.in/writereaddata/UploadFile/dhi-didm-MOM9-meetingPISC.pdf. [Accessed: January 17, 2019].

${ }^{27}$ This report uses 71.029 USD to INR as the conversion rates per "Indian Rupee: The Economy Forecast Agency," http://dollarrupee.in/. [Accessed: January 17, 2019]. 1 lakh = 100,000 INR; 1 crore = 1,000,000 INR.

${ }^{28}$ Government of India, DHI. 2019. Operational Guidelines for Delivery of Demand Incentive under FAME India Scheme: Phase - II - regarding. https://dhi.nic.in/writereaddata/UploadFile/DHI\%20FAME\%20PHASEII22March2019.pdf. [Accessed April 8, 2019].

${ }^{29}$ Government of India, DHI. 2019. Notification: Scheme for Faster Adoption and Manufacturing of Vehicles in India Phase II (FAME Phase II). https://www.fame-india.gov.in/WriteReadData/userfiles/file/FAME-

II\%20Notification.pdf. [Accessed April 12, 2019].
} 


\section{Approach}

In June 2018, NREL researchers traveled to Surat to collect data on BRTS and city bus operations, and to meet with the SMC commissioner, staff, and partners at SVNIT Surat. The primary purpose of this trip was to gather second-by-second data on bus operation, including velocity and location, which NREL then distilled into operation statistics to estimate BEB feasibility.

\subsection{Data Collection}

NREL worked with SMC and SVNIT Surat to compile information on the Surat BRTS and city buses. In its Surat Smart City Center, SMC collects data on key operational characteristics of its buses (Figure 5) such as number of trips, distance traveled, fuel consumed and arrival/departure time for all routes. SMC also collects GPS data on its buses at a rate of one sample every three to five seconds.

In addition to utilizing the sample data provided by SMC, NREL installed data loggers on existing baseline buses to develop a detailed characterization of each BRTS route, beyond scheduled stop times and average speed data available from SMC. NREL used Trip Recorder 747 ProS GPS recorders (Figure 6) to instrument 16 buses operating on BRTS routes and 24 buses operating on City routes. The trip recorders logged latitude, longitude, elevation, and vehicle speed at a frequency of one hertz $(\mathrm{Hz})$ when the instrumented buses were in motion. The data were collected over four days in June 2018.

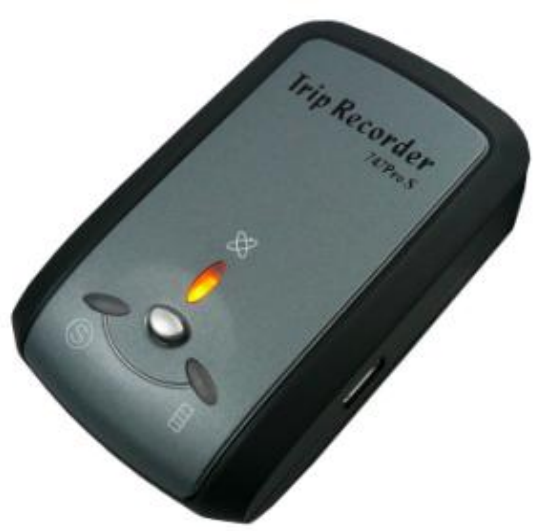

Figure 6. Trip Recorder 747 ProS

Although data were collected on city bus routes as well, NREL focused on the BRTS routes where SMC intends to begin its deployment of BEBs. The collected data were analyzed for quality and for adherence of each bus to the planned route. Minimal data processing was necessary to eliminate a few outliers from the dataset, and a vehicle speed of less than 0.5 kilometers per hour ( $\mathrm{kph}$ ) was considered to be zero for the purpose of this analysis, due to known GPS scatter at low speeds. Extraneous trips not adhering to the planned BRTS route for each bus were removed from the dataset. In addition, because this analysis focused on the requirements for full days of transit service on each route, partial days of operation were not included in the analysis. Except for Route 18, which has a scheduled daily distance of $186 \mathrm{~km}$ per bus, a daily distance traveled of $200 \mathrm{~km}$ or more per bus was considered a full day of service 
for the BRTS routes. Due to the short logging duration and the variability of operation for some of the instrumented buses, the installed data loggers captured between one and four full workdays for each of the eight BRTS routes, for a total of 19 days of operation.

\subsection{BRTS Route Characterization}

NREL has developed a suite of tools that characterize vehicle drive cycles and analyze driving behavior for a wide variety of vehicle types, weight classes, and vocations. One of these tools - a component of the Drive-cycle Rapid Investigation, Visualization, and Evaluation (DRIVE) analysis toolset ${ }^{30}$ — uses vehicle speed data with a sampling frequency of one $\mathrm{Hz}$ or higher to calculate an extensive set of route statistics. The route-specific metrics calculated from these driving speed profiles are independent of vehicle size, type, or powertrain, allowing the routes to be characterized and compared objectively and quantitatively. Examples of the metrics include maximum and average driving speeds, acceleration and deceleration rates, stop durations, and number of stops per kilometer.

Two notable route metrics are the characteristic acceleration, $\tilde{a}$, and aerodynamic speed, vaero, described by O'Keefe, et al., and derived from the energy-based road load equation. ${ }^{31}$ Dividing characteristic acceleration by the square of aerodynamic speed (Equation 1) defines kinetic intensity $(\mathrm{ki})$, another important metric that represents the ratio of specific inertial energy required to propel a vehicle to the specific energy lost to aerodynamic drag. Kinetic intensity is a measure of the aggressiveness or driving intensity of a route and is a reliable indication of the suitability for electric/hybrid powertrains.

$$
k i=\frac{\text { characteristic acceleration }}{(\text { aerodynamic speed })^{2}}=\frac{\tilde{\mathrm{a}}}{\left(v_{\text {aero }}\right)^{2}}
$$

The collected speed data for each of the 19 full BRTS work days were fed into the NREL analysis to create a detailed characterization of each BRTS route for further comparison. Statistics for routes that had more than one valid day of collected data were averaged across all valid days to establish one set of representative statistics for each BRTS route-eight in total.

NREL has also developed the Fleet DNA database with detailed commercial vehicle drive-cycle data. ${ }^{32}$ This extensive collection of real-world driving profiles and aggregated summary statistics enables researchers and analysts to evaluate operational characteristics and vehicle performance considerations for dozens of different vehicle types, vocations, weight classes, locations, and powertrains, leading to optimized vehicle-route combinations. Transit bus data available in the FleetDNA database were used in NREL's analysis of the Surat BRTS routes.

\footnotetext{
${ }^{30}$ NREL. 2018. "DRIVE: Drive-Cycle Rapid Investigation, Visualization, and Evaluation Analysis Tool." https://www.nrel.gov/transportation/drive.html. [Accessed: January 21, 2019].

${ }^{31}$ O'Keefe, et al. 2007. "Duty Cycle Characterization and Evaluation Toward Heavy Hybrid Vehicle Applications." SAE World Congress and Exhibition. https://www.nrel.gov/docs/gen/fy07/40929.pdf. [Accessed:

${ }^{32}$ NREL. 2018. "Fleet DNA: Commercial Fleet Vehicle Operating Data."

https://www.nrel.gov/transportation/fleettest-fleet-dna.html. [Accessed: January 18, 2019].
} 


\subsection{ESS Model Description}

\subsubsection{Model Description}

With GPS speed as the only available in-use data, NREL developed a variation of the FASTSim modeling tool to analyze the power requirements and battery size for the Surat electric buses. ${ }^{33}$ FASTSim and the derivation used for this report are backward-looking models, meaning that with knowledge of the vehicle state (i.e., speed, acceleration, vehicle characteristics, etc.), it solves to find the power requirement necessary to achieve that state. Inputs to the model are vehicle speed, road grade, and the data sampling increment (timestep). Each component takes a backwards step in series, with the model using logged data to calculate the power to or from the battery. Diagram 1 shows the chronology of the simulation.

\section{Battery $\leftarrow$ Motor $\leftarrow$ Transmission $\leftarrow$ Differential $\leftarrow$ Wheel $\leftarrow$ Chassis $\leftarrow$ Logged Data}

In Equation 2, recorded data are used to calculate the total force necessary from the vehicle in order to meet the driving profile. The road load equation is simpler for a vehicle tested on a dynamometer, as the road grade is held constant at zero.

$$
F_{\text {road }}=\frac{d v}{\mathrm{dt}}+C_{d l} v^{2}+m g C_{r r}
$$

The wheel model converts linear force, $F$, and speed, $v$, to torque, $\tau$, and rotational speed, $\omega$, respectively, using the radius of the tire, $r_{\text {tire }}$, in Equations 3 and 4.

$$
\begin{aligned}
& \tau_{\text {wheel }}=F_{\text {road }} r_{\text {tire }} \\
& \omega_{\text {wheel }}=\frac{v_{\text {vehicle }}}{r_{\text {tire }}}
\end{aligned}
$$

Components with gears will modify the speed and torque using Equations 5 and 6, respectively, using knowledge of the gear ratio, $r_{\text {gear }}$. The component efficiency, $\eta$, is used to divide the torque in traction $\left(\eta_{\text {trans }}^{-1}\right)$ and multiply the torque in regeneration $\left(\eta_{\text {trans }}^{+1}\right)$.

$$
\begin{gathered}
\omega_{\text {motor }}=\omega_{\text {trans }} r_{\text {gear }} \\
\tau_{\text {motor }}=\frac{\tau_{\text {trans }}}{r_{\text {gear }}} \eta_{\text {trans }}^{ \pm 1}
\end{gathered}
$$

Rotational speed and torque are multiplied and divided by gear ratios and efficiencies in the driveline until the motor, where the electrical power requirement is calculated in Equation 7.

$$
P_{\text {battery }}=\tau_{\text {motor }} \omega_{\text {motor }} \eta_{\text {motor }}\left(\tau_{\text {motor }}, \omega_{\text {motor }}\right) \pm 1
$$

\footnotetext{
${ }^{33}$ NREL. 2018. "FASTSim: Future Automotive Systems Technology Simulator." https:/www.nrel.gov/transportation/fastsim.html. [Accessed: January 18, 2019].
} 
Motor efficiency is a function of speed and torque. The motor map used in the model is shown in Figure 7. This efficiency map was derived from electric transit bus data stored in NREL's FleetDNA database.

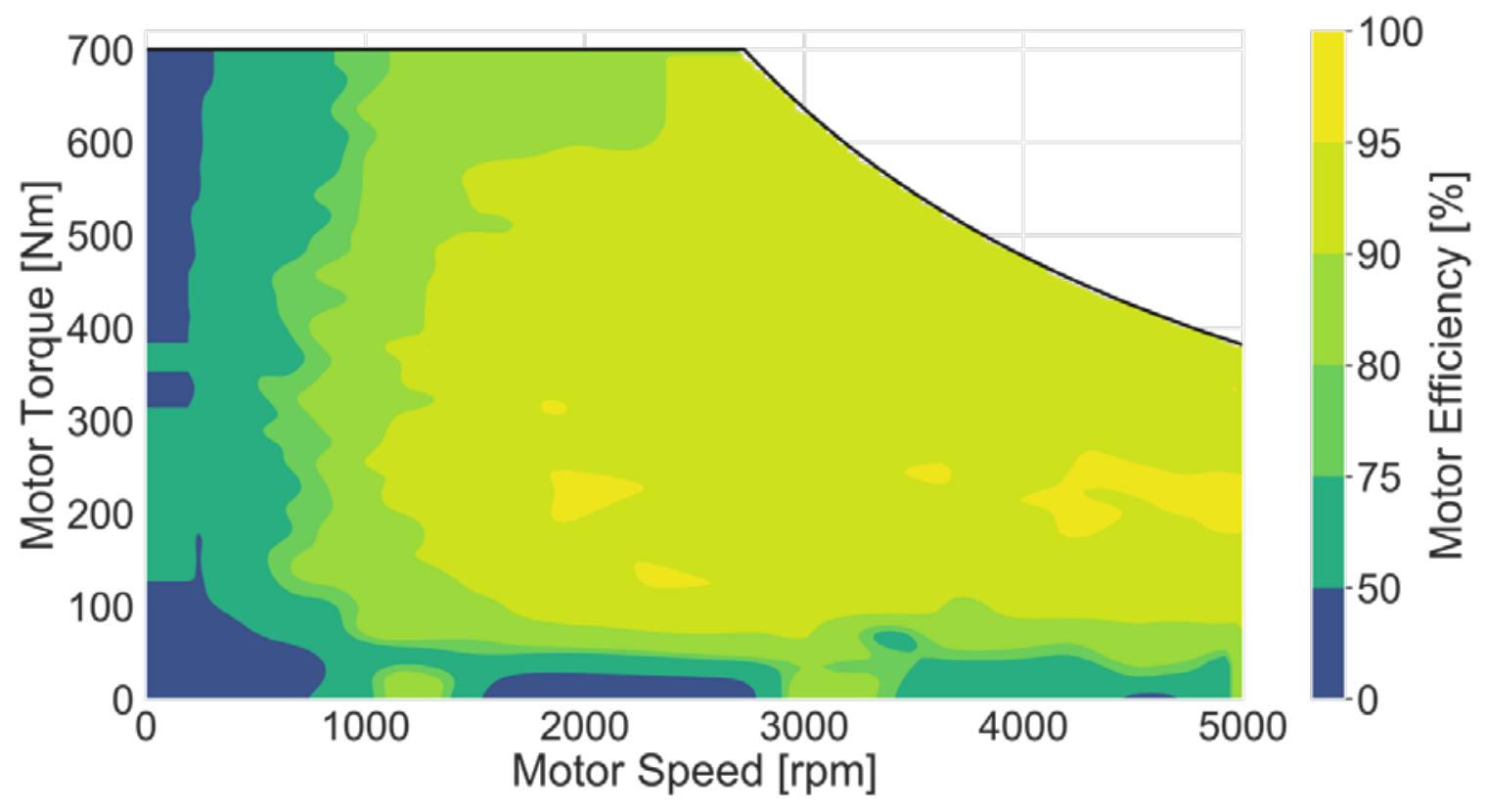

Figure 7. Motor efficiency map

The model was validated using data from BEBs operating in California. In most cases, measured and modeled daily consumption matched within 10\% (as seen in Figure 8), indicating that the model is a good approximation of real-world transit bus operations. However, the authors did not have access to the buses specifically available in India. Additionally, the data collected in California included road grade. Elevation data collected in Surat was deemed not sufficiently accurate for road-grade estimation; thus, energy consumption was simulated without road grade. The model will under-predict energy consumption when road grade is not included, with only limited effect as Surat is a relatively flat city. 


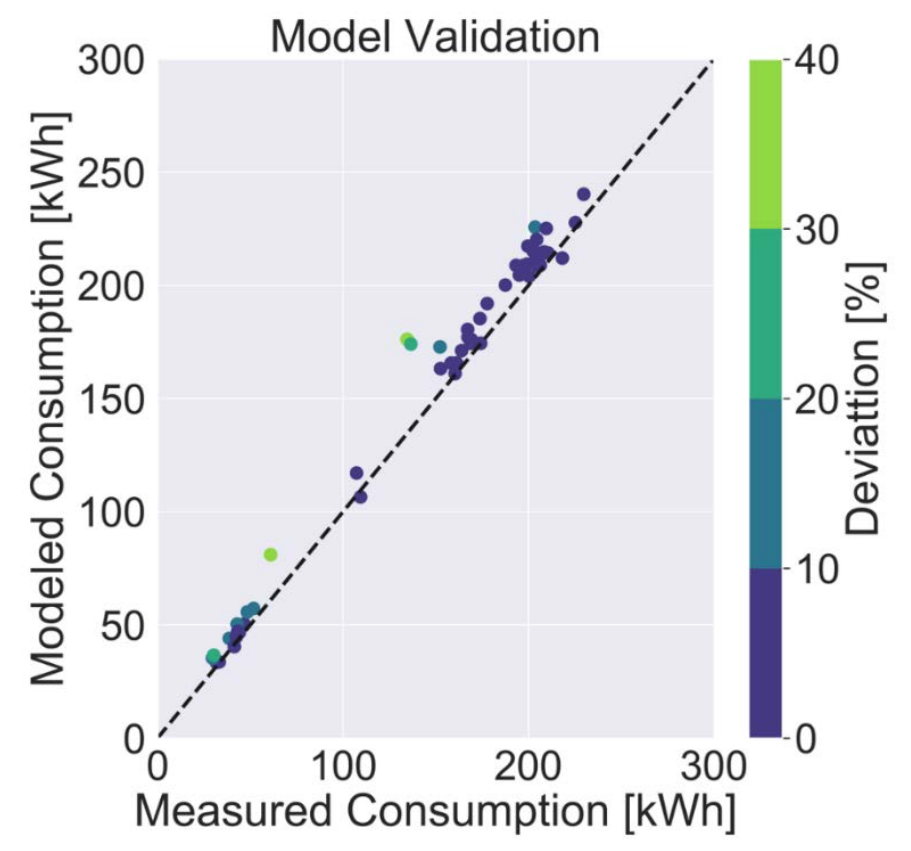

Figure 8: Comparison of modeled results to measured results 


\section{Operational Assessment Results}

Following the approach outlined in Section 3, the logged vehicle data were analyzed to characterize each BRTS route. The speed profiles from all 19 BRTS bus days were applied to NREL's model to determine the daily BEB energy requirements for each route. Researchers also investigated temperature and mass sensitivities. The results show that the high kinetic intensity of Surat BRTS routes translates to significant efficiency improvements by using BEBs. Depending on temperature and mass, the results indicate that a significant portion of the Surat BRTS fleet could be replaced by BEBs currently available in India.

\subsection{BRTS Route Profiles and Statistics}

The map in Figure 9 shows the paths of all eight BRTS routes and the locations of the depots where the BRTS buses are housed. The BRTS system operates along major corridors and spans a wide portion of Surat's geographic area. Significant sections of the routes overlap, utilizing shared depots and bus lanes. These areas of overlap could be effective locations for on-route fast chargers, which could supplement depot chargers or serve as primary power sources. Individual BRTS route maps are available in Appendix A.

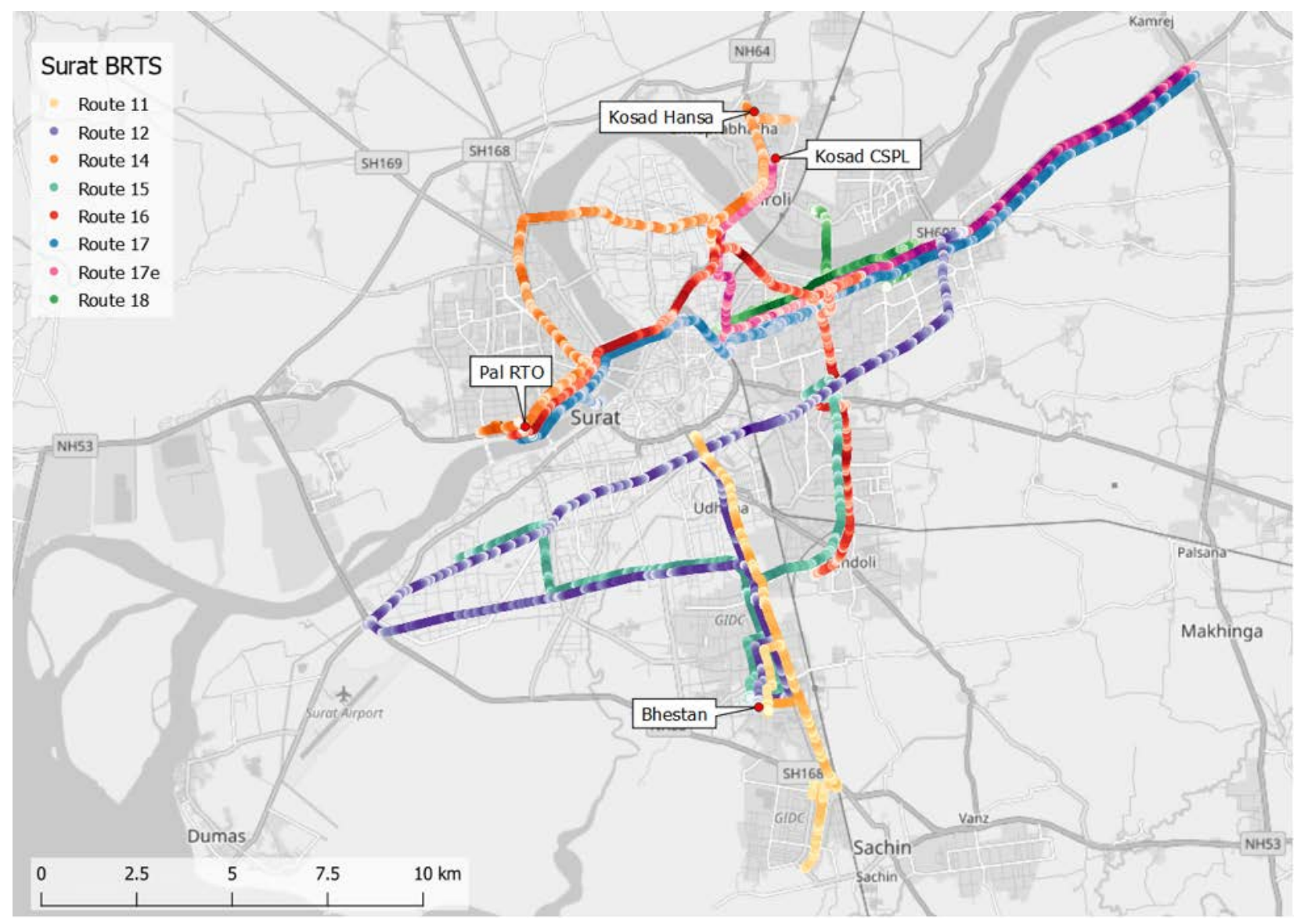

Figure 9. Map of logged BRTS routes and depot locations 
Figure 10 provides an example of a typical speed profile for BRTS routes, showing more than 14 hours of total daily operation with a vehicle speed fluctuating frequently between $0 \mathrm{kph}$ and 50 $\mathrm{kph}$. The Route 11 bus accumulated approximately $240 \mathrm{~km}$ during this day.

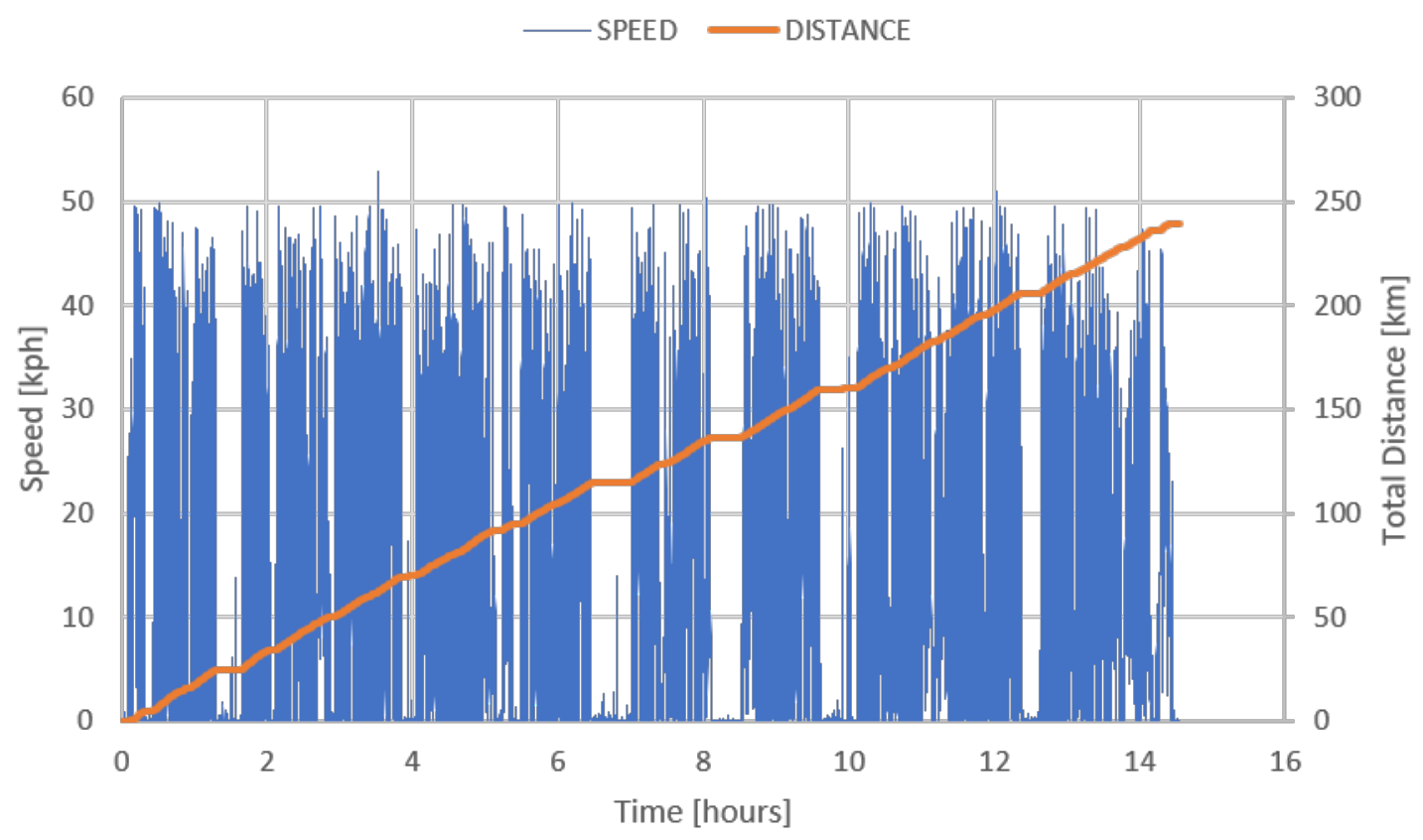

Figure 10. Example daily drive cycle - Route 11

NREL generated detailed driving statistics from all 19 speed profiles for analysis of the BRTS routes. Statistics for routes which had more than one full day of collected data were averaged. A selection of the average summary statistics is listed in Table 7.

A typical full day of service for a bus operating on a BRTS route covers 200-280 km during 1015 hours of operation. Route 18 is an exception, having a smaller total distance due to the slower average speed and shorter route length, yet it still covers nearly $180 \mathrm{~km}$ in 12.8 hours. Most routes have a daily driving time (when the vehicle is moving) of 9-11 hours and a driving average speed of 22-28 kph. Route 11 and 18 have slower speeds, at 16.0 and $17.5 \mathrm{kph}$, respectively. Average stops per kilometer for the BRTS routes range from a low of 1.72 for Route 17 to a high of 4.00 for Route 18. 
Table 6. BRTS Route Summary Statistics from Logged Data

\begin{tabular}{|c|c|c|c|c|c|c|c|c|}
\hline BRTS Route & 11 & 12 & 14 & 15 & 16 & 17 & $17 e$ & 18 \\
\hline Daily Total Distance [km] & 239.2 & 255.8 & 226.4 & 276.0 & 206.5 & 242.5 & 223.2 & 178.3 \\
\hline Daily Total Time [hrs] & 14.5 & 14.9 & 11.0 & 14.5 & 11.5 & 10.8 & 11.9 & 12.8 \\
\hline Daily Driving Time [hrs] & 10.0 & 10.3 & 9.2 & 11.0 & 9.1 & 8.9 & 9.3 & 10.2 \\
\hline Maximum Speed [kph] & 52.9 & 58.5 & 62.2 & 64.7 & 62.4 & 55.6 & 59.7 & 58.7 \\
\hline Total Average Speed [kph] & 16.4 & 17.2 & 20.6 & 19.0 & 18.0 & 22.4 & 18.8 & 13.9 \\
\hline Driving Average Speed [kph] & 24.0 & 24.8 & 24.7 & 25.1 & 22.7 & 27.2 & 24.0 & 17.5 \\
\hline Average Acceleration $\left[\mathrm{m} / \mathrm{s}^{2}\right]$ & 0.30 & 0.32 & 0.41 & 0.33 & 0.39 & 0.35 & 0.43 & 0.36 \\
\hline Average Deceleration $\left[\mathrm{m} / \mathrm{s}^{2}\right]$ & -0.60 & -0.72 & -0.53 & -0.54 & -0.51 & -0.43 & -0.47 & -0.41 \\
\hline Average Stop Duration [sec] & 25.7 & 22.9 & 11.4 & 18.8 & 14.1 & 16.2 & 15.5 & 12.9 \\
\hline Median Stop Duration [sec] & 8.0 & 8.0 & 5.0 & 6.0 & 5.5 & 4.0 & 6.0 & 4.0 \\
\hline Stops per Kilometer [1/km] & 2.66 & 2.74 & 2.52 & 2.42 & 2.92 & 1.72 & 2.64 & 4.00 \\
\hline Kinetic Intensity [1/km] & 2.08 & 2.09 & 2.17 & 1.85 & 2.21 & 1.54 & 1.83 & 2.79 \\
\hline
\end{tabular}


Figure 11 plots the kinetic intensity and driving average speed of each route. The kinetic intensity is a measure of the aggressiveness or intensity of driving on a route, as detailed in Section 3.2. Routes with frequent stops and higher kinetic intensity are generally good candidates for vehicle electrification, because they can capitalize on the use of efficient electric motors and ample opportunities to recuperate inertial energy through regenerative braking.

Route 18 has a low driving average speed and the highest kinetic intensity at $2.79 \mathrm{~km}^{-1}$, and Route 17 has the highest driving average speed and the lowest kinetic intensity at $1.54 \mathrm{~km}^{-1}$. If considering only the ability to recapture energy from braking, Route 18 would be the best candidate for electrification. However, both routes have relatively high kinetic intensity compared to the high-speed long-haul applications common among tractor trailers.

Overlaid on the chart for reference are corresponding transit bus data from NREL's FleetDNA ${ }^{34}$ database of real-world drive cycles. These data points show the relationship between $k i$ and driving average speed for transit buses operating at various locations throughout the United States. As this figure represents primarily city transit routes, it is not expected that these data necessarily will match the characteristics of the BRTS routes, but it is worth noting that the BRTS routes fall on the lower-speed side of the data cluster and tend to have above average kinetic intensity for this type of vehicle operation, relative to the selection of U.S. transit buses.

Figure 12 shows the relationship between the characteristic acceleration and the aerodynamic speed, with lines of constant kinetic intensity included for reference. The BRTS routes are clustered around a kinetic intensity of $2 \mathrm{~km}^{-1}$, which is slightly higher than most of the FleetDNA data points.

\footnotetext{
${ }^{34}$ NREL. 2018. "Fleet DNA: Commercial Fleet Vehicle Operating Data." https://www.nrel.gov/transportation/fleettest-fleet-dna.html. [Accessed: January 18, 2019].
} 


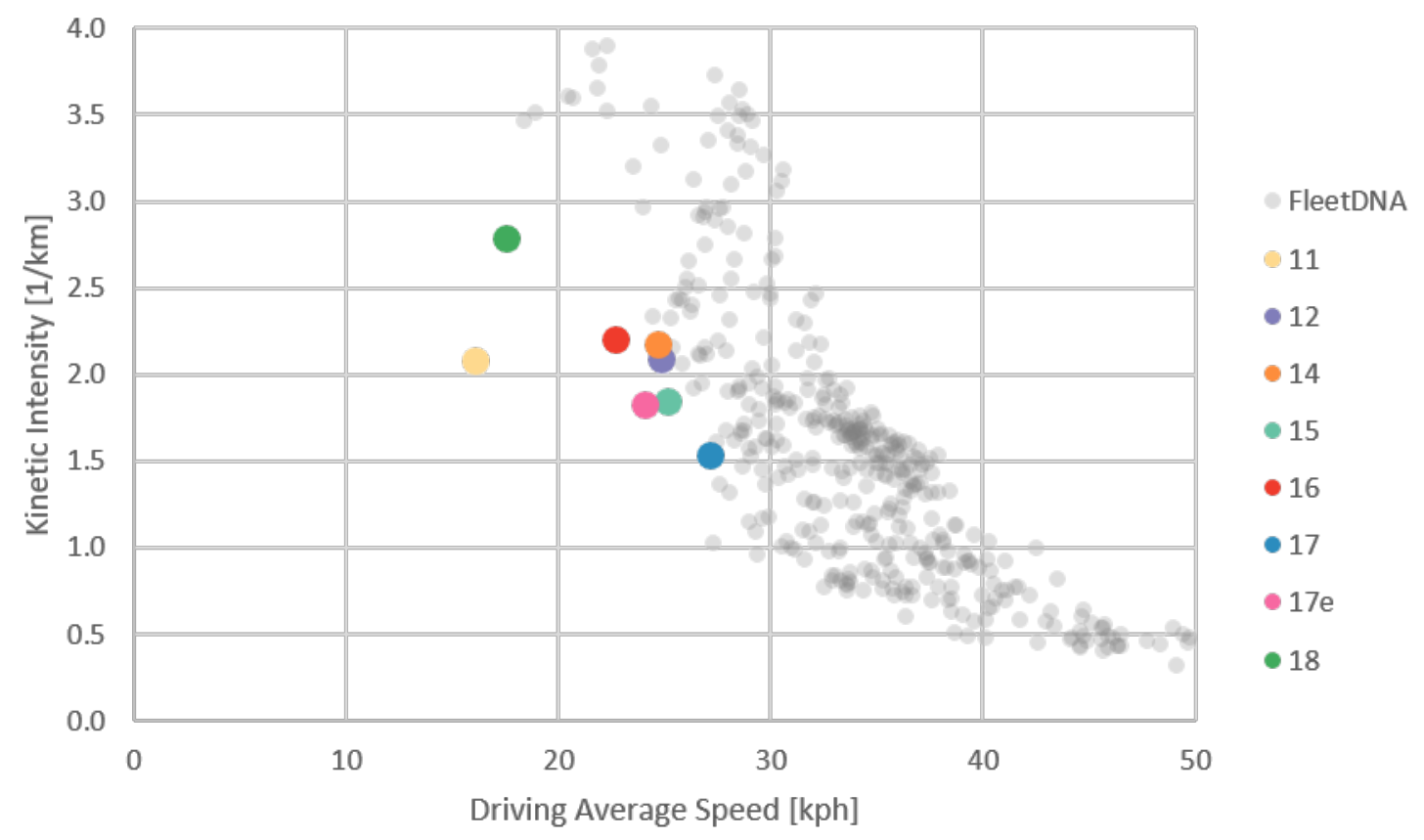

Figure 11. Kinetic intensity vs driving average speed for BRTS routes

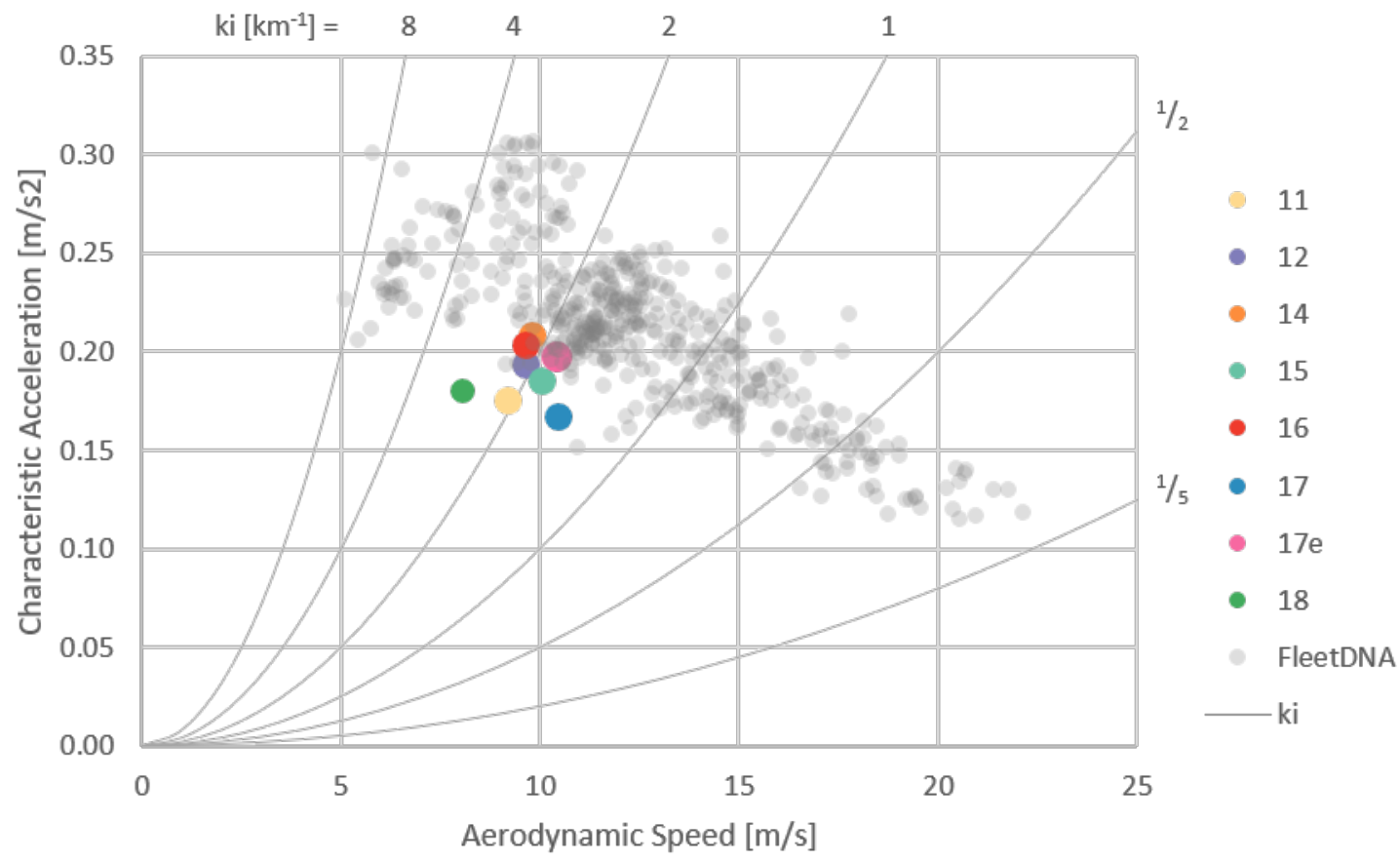

Figure 12. Characteristic acceleration vs aerodynamic speed for BRTS routes 


\subsection{BEB Modeling Results}

The electric transit bus model described in Section 3.3 was used to simulate BEB operation on all eight BRTS routes. Input to the model was an entire day of logged vehicle speed data for each route - the same speed profiles used to develop the route statistics. Where multiple days of operation were recorded for a route, all days were simulated independently -19 in all. The model calculates the energy required for a BEB to drive the route in exactly the same way it was driven by the conventional vehicle, as demonstrated in Figure 13, where the "measured" trend line is recorded data from a conventional bus and the "modeled" line is the speed achieved by the electric bus model.

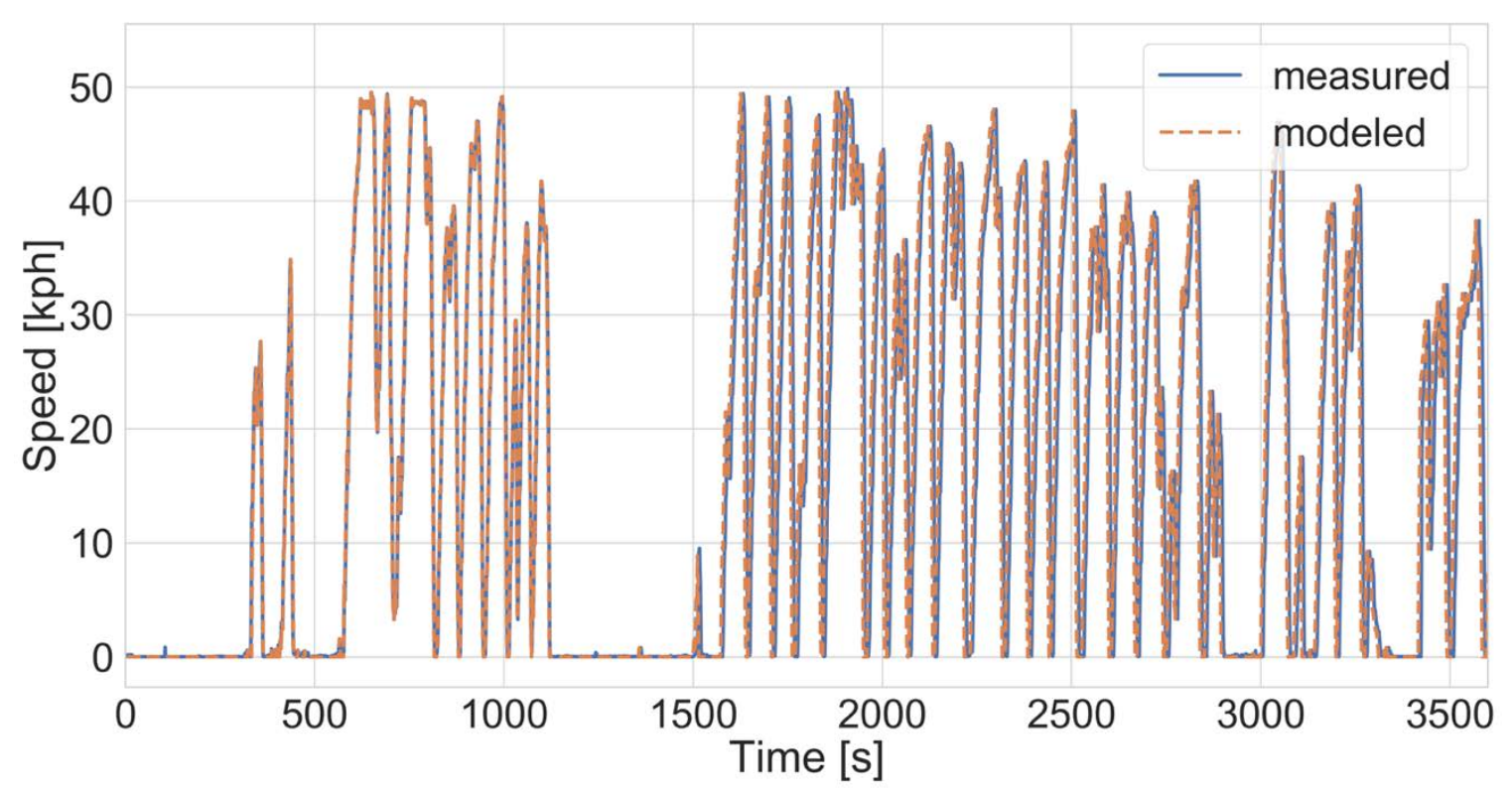

Figure 13. Example speed profile for a measured conventional bus and the modeled electric bus

The driving speed profile is used to estimate instantaneous power required from the vehicle battery as shown in Figure 14. If the model is able to complete the route without deviating significantly from the speed profile of the conventional vehicle - that is, the simulated electric bus meets the required driving performance for the route - then the battery power estimate can be integrated over an entire day to calculate the total energy used by the vehicle. 


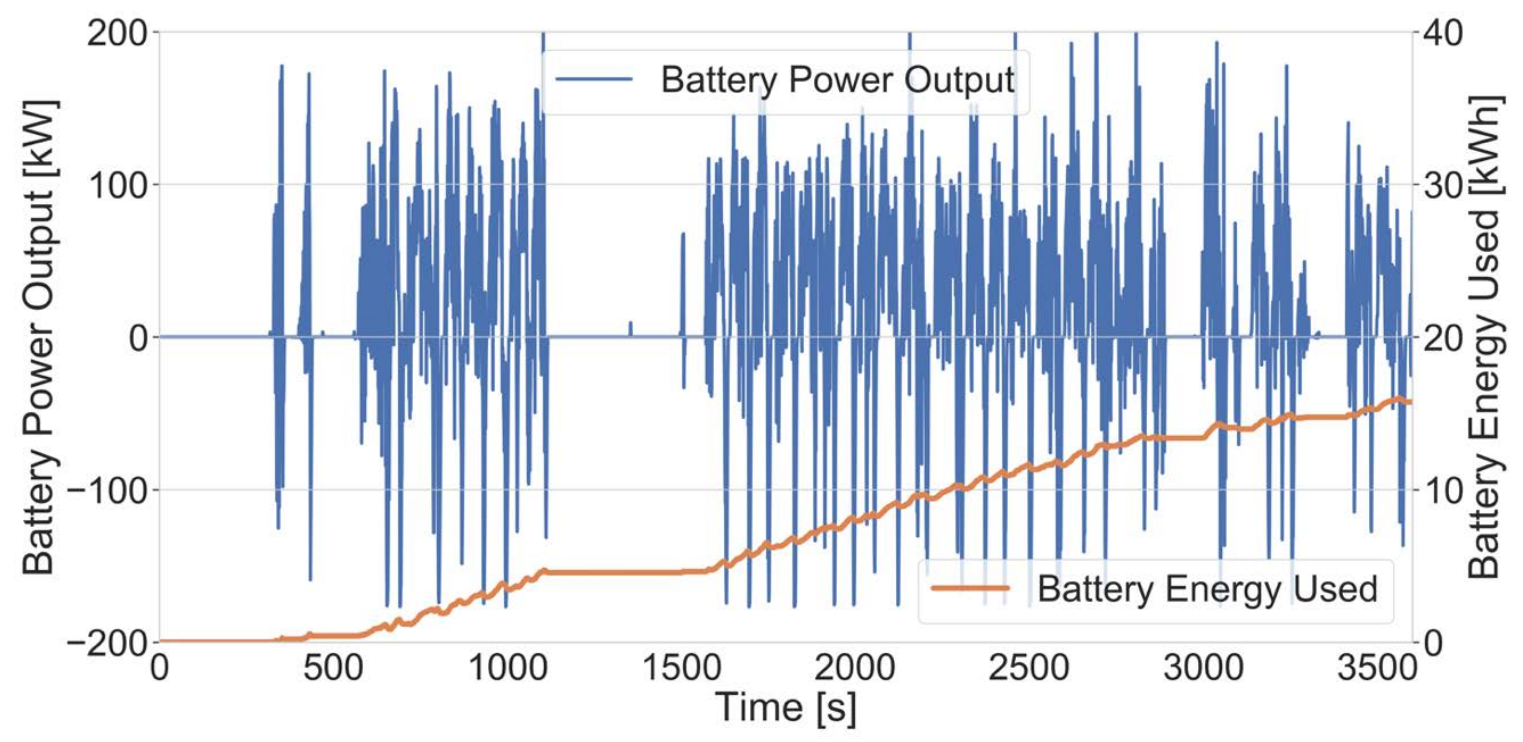

Figure 14. Instantaneous power requirement and cumulative energy use

The Sankey diagram in Figure 15 shows an example of the flow path of energy through the BEB as simulated on Route 11. In the BEB model, electricity is converted to rotational power used to overcome drag and friction forces and to accelerate the vehicle. When the brakes are applied, a portion of that energy is recaptured and returned to the battery through the electric motor during regenerative braking. By recapturing energy through regenerative braking, electrified drivetrains (hybrids included) partially recharge their batteries using energy that would otherwise be dissipated as heat from conventional brake pads. Absent from the diagram is energy used by the bus to climb hills. Elevation data logged from Surat was not accurate enough to approximate the grade of the road for modeling purposes. However, Surat is a relatively flat city.

In contrast, the flow of energy for a nonhybrid conventional bus is unidirectional, and none of the kinetic energy of the bus can be recaptured (Figure 16). For both bus types, the model incorporates energy losses due to aerodynamic drag, rolling resistance, mechanical friction, and thermal losses in vehicle components, as well as energy used for auxiliary vehicle loads such as air conditioning and on-board electronics. Notably, most inefficiencies are the same for electric and diesel buses, such as rolling resistance and aerodynamic drag, but an electric motor can operate at a much higher average rate of efficiency than is possible for a diesel engine. This is largely a factor of diesel buses losing significant amounts of energy due to heat rejection from combustion and engine losses. 


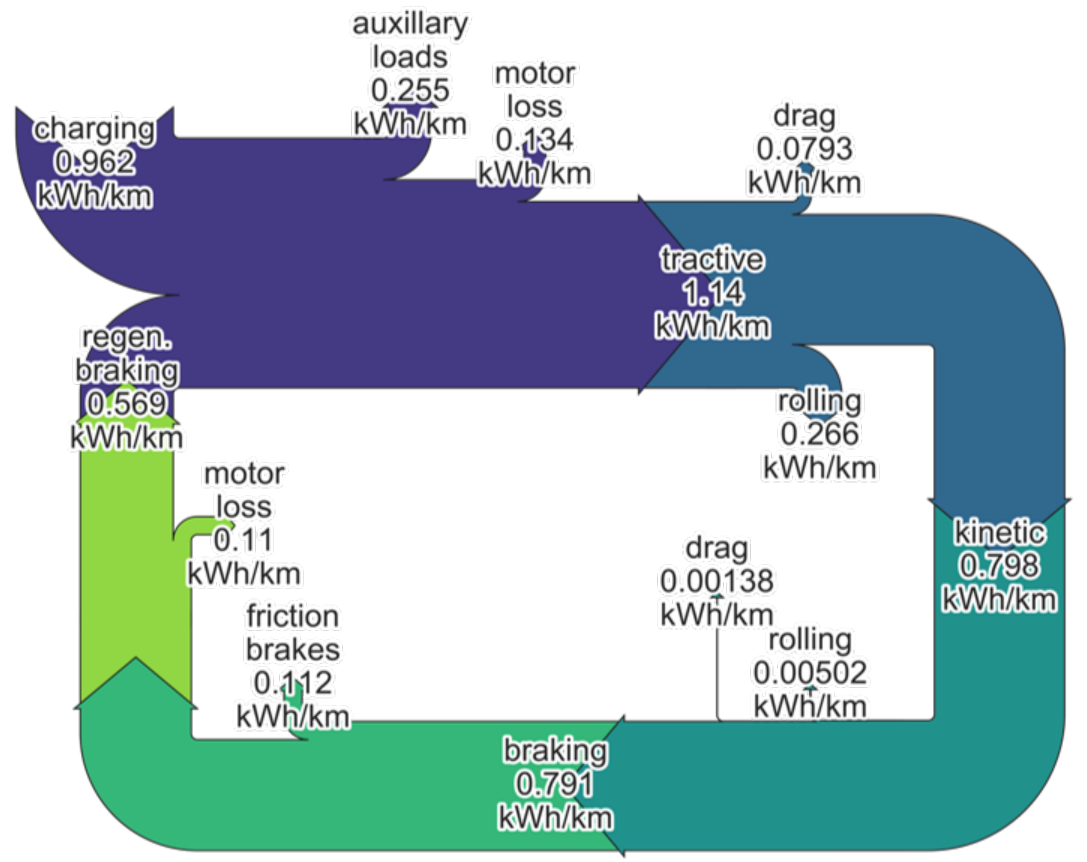

Figure 15. Sankey diagram displaying the dissipation of battery energy for a BEB on Route 11, normalized by route distance

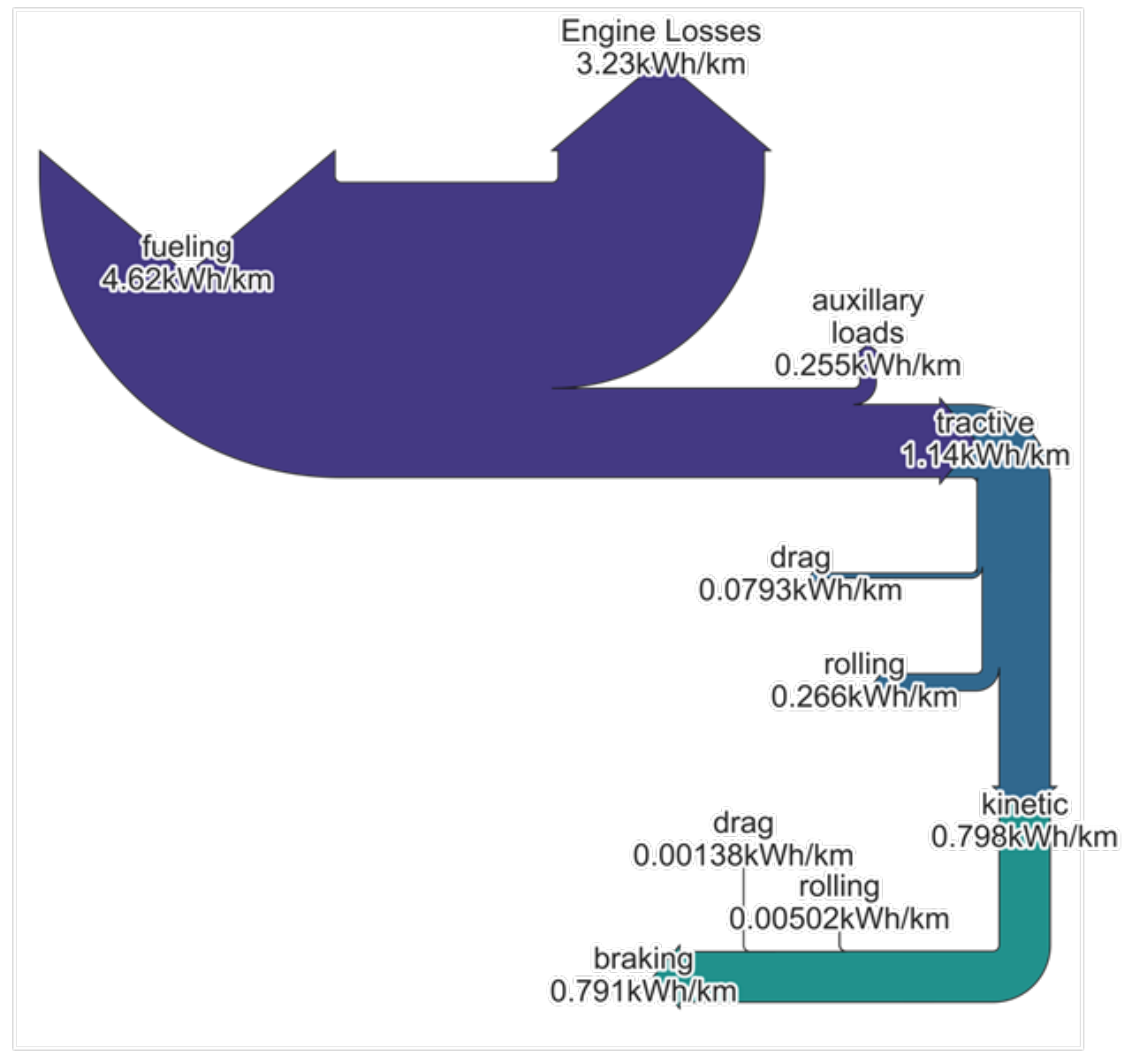

Figure 16. Sankey diagram displaying the dissipation of fuel energy for a conventional bus on Route 11, normalized by route distance 
Using the results of the vehicle model, Figure 17 compares the fuel economy of the diesel buses and BEBs for each BRTS route. The diesel bus results are averages of data from the existing diesel buses in service as provided by SMC. The BEB fuel economy values are modeling results assuming a vehicle mass of $14,000 \mathrm{~kg}$, a constant ambient temperature of $28^{\circ} \mathrm{C}$, and dry road conditions. The electrical energy consumption (kWh) for the BEBs was converted to diesel liter equivalent (dLe) fuel consumption using a conversion factor of $9.94 \mathrm{kWh} / \mathrm{dLe}$. The modeled results for BEBs were generally three to five times more fuel efficient than the conventional diesel bus fuel records for the relevant routes. This benefit is especially pronounced on routes with low average speed and more stops per mile.

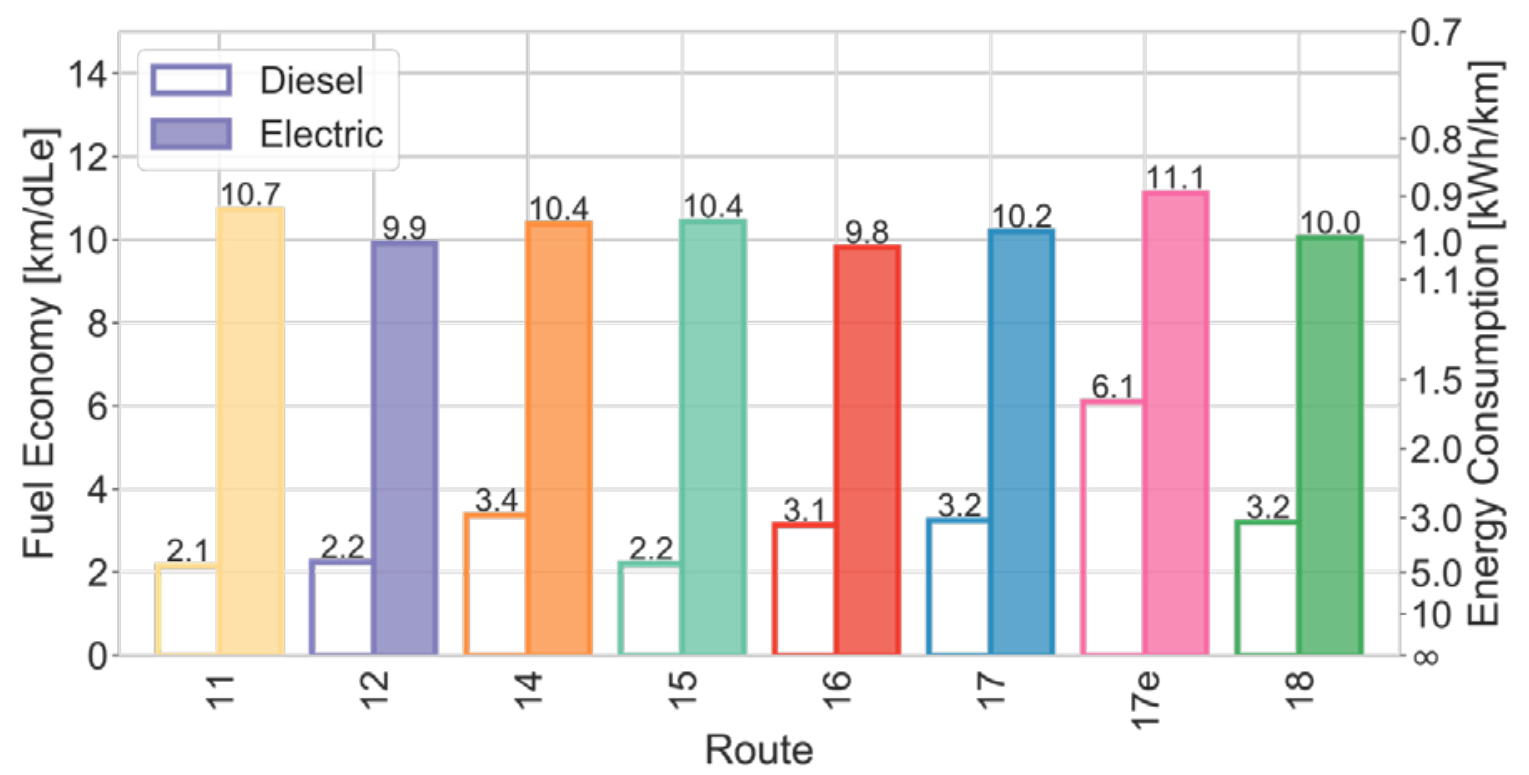

Figure 17. Fuel economy by BRTS route for baseline diesel buses (measured in-use data) and BEBs (modeled results)

A chief concern when adopting electric vehicles is driving range. Assuming that BEBs will be required to drive the same routes for the same distance between recharging events as the conventional buses, a minimum battery size can be estimated. The required battery size will be determined by the daily distance and the average energy consumption rate $(\mathrm{kWh} / \mathrm{km})$ of the bus.

In addition to route characteristics (average speed, driving intensity, etc.), the two factors that most significantly impact the energy consumption rate include vehicle mass (vehicle + passengers) and weather conditions. Heavier buses consume more energy, vehicle airconditioning systems require a significant amount of energy in Surat's extremely hot climate, and the city's monsoon season could impact bus energy consumption as well.

Figure 18 shows the impact of daily average ambient temperature on the energy consumption rate of the electric bus. The BEB was modeled on each BRTS route with the daily average temperature ranging from $15^{\circ} \mathrm{C}$ to $40^{\circ} \mathrm{C}$. As the temperature increases, more energy is required to run auxiliary air conditioning loads, which increases the BEB's overall energy consumption rate by approximately $0.08 \mathrm{kWh} / \mathrm{km}$ for every $5^{\circ} \mathrm{C}$ of temperature increase. The average ambient 
temperature in Surat is $28^{\circ} \mathrm{C}$. Ambient temperature was used primarily to estimate power consumption by the vehicle's air conditioning system.

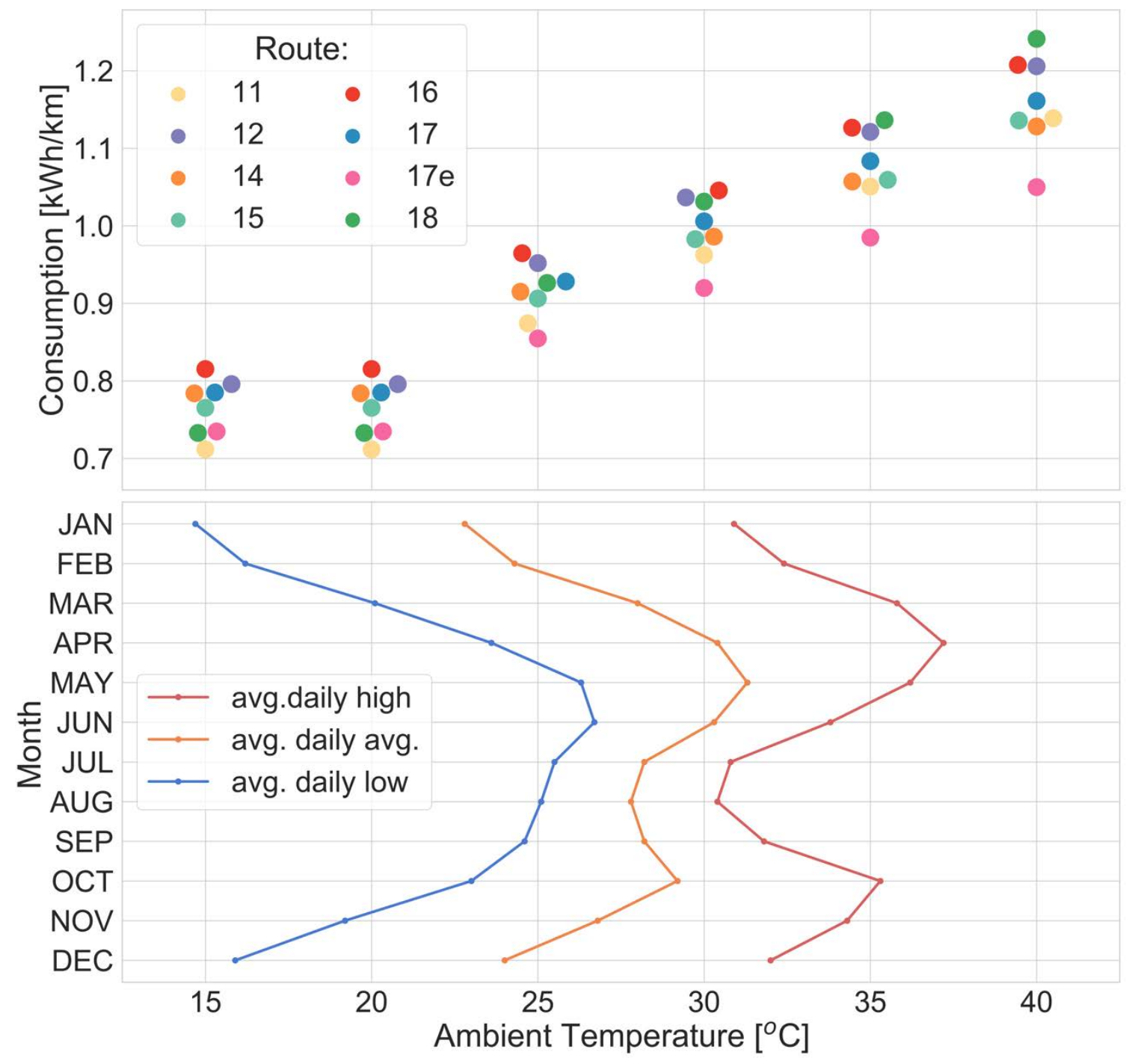

Figure 18. Impact of ambient temperature on BEB energy consumption rate

Road wetness influences vehicle efficiency as well. Ejsmont, J., et al. found that a $0.8 \mathrm{~mm}$ water film could increase the rolling resistance of tires traveling at $30 \mathrm{~km} / \mathrm{hr}$ by $30 \%$ compared to dry conditions. ${ }^{35}$ These tests took place in Denmark in October and may not be perfectly applicable to Surat's climate. The report authors noted that tires cooled off more on wet roads, partially deflating them, which accounted for an undetermined percentage of the impacts to rolling resistance. In addition to this confounding factor, driving speeds are likely to decrease on wet roads, potentially mitigating the impact of impaired rolling resistance. Furthermore, the monsoon season in Surat typically takes place from July to September, when average daily high

\footnotetext{
${ }^{35}$ Ejsmont, J., et. al. 2015. "Influence of Road Wetness on Tire-Pavement Rolling Resistance." Journal of Civil Engineering and Architecture 9. http://www.davidpublisher.org/Public/uploads/Contribute/566e64a472e9f.pdf.
} 
temperatures and air conditioning needs tend to be lower than average, but not as low as average October temperatures in Denmark. Road testing on Surat roads or a similar climate during dry and wet conditions would be the best way to determine these effects. Driving through deep flooding may also present safety and functionality concerns for BEB traction batteries.

The energy consumption rate (or efficiency) of the BEB is sensitive to the total vehicle weightthe sum of the vehicle curb weight and weight of passengers - which should not exceed the gross vehicle weight rating (GVWR). The starting curb weight of a bus can vary significantly between models based on overall size and construction, ESS capacity and other factors, yet is essentially constant for the life of the bus. The total weight of the bus in operation varies continuously based on passenger loading.

Figure 19 highlights the impact of the vehicle weight on the BEB's energy consumption rate. Assuming an ambient temperature of $28^{\circ} \mathrm{C}$, the BEB was modeled on each BRTS route with vehicle mass settings swept from $7,000 \mathrm{~kg}$ to $18,000 \mathrm{~kg}$. This represents the estimated range of vehicle mass from the commercially-available BEBs described in Table 5, according to specifications of GVWR and passenger loading. The range of estimated vehicle mass corresponding to each BEB in the table is shown at the bottom of Figure 19. 


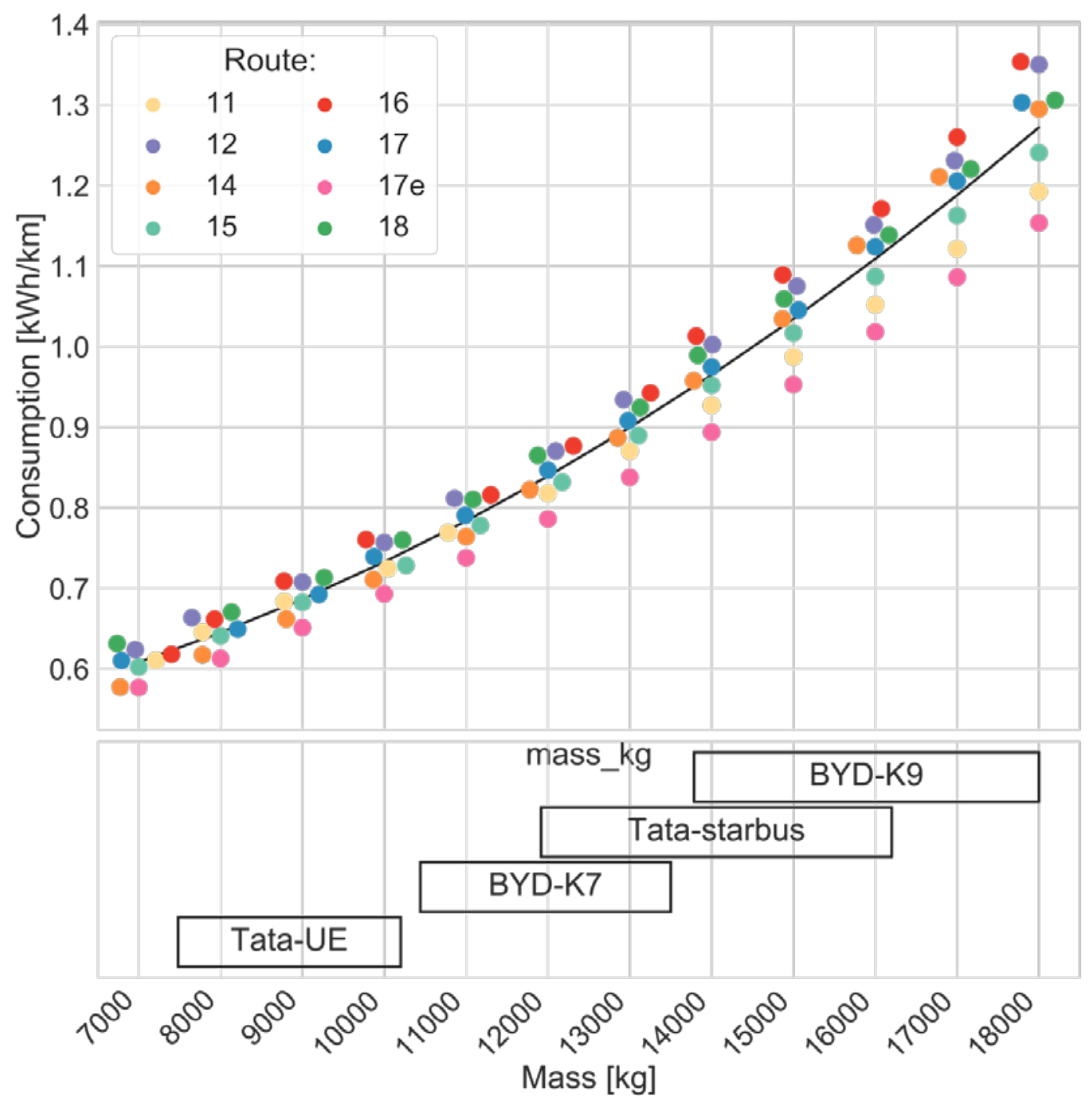

Figure 19. Impact of vehicle mass on BEB energy consumption rate

As a point of comparison, Table 8 outlines a range of efficiencies that can be expected at any given point in time, depending on temperature and bus mass including the passenger load. For context, the GVWR of the Tata 9-meter BEB is $10,200 \mathrm{~kg}$, and the GVWR for the BYD 12meter BEB is $18,000 \mathrm{~kg}$ (Table 5). 
Table 7. BEB Efficiency by Temperature and Mass (kWh/km)

\begin{tabular}{c|c|c|c|c|c|}
\multirow{2}{*}{ Mass (kg) } & \multicolumn{5}{|c}{ Temperature $\left.\mathbf{~}^{\circ} \mathbf{C}\right)$} \\
\hline & $\mathbf{2 5}$ & $\mathbf{2 8}$ & $\mathbf{3 0}$ & $\mathbf{3 5}$ & $\mathbf{4 0}$ \\
\hline 7,000 & 0.56 & 0.61 & 0.64 & 0.72 & 0.80 \\
\hline 8,000 & 0.60 & 0.65 & 0.68 & 0.76 & 0.84 \\
\hline 9,000 & 0.64 & 0.69 & 0.72 & 0.80 & 0.89 \\
\hline 10,000 & 0.69 & 0.74 & 0.77 & 0.85 & 0.93 \\
\hline 11,000 & 0.74 & 0.79 & 0.82 & 0.90 & 0.98 \\
\hline 12,000 & 0.79 & 0.84 & 0.88 & 0.96 & 1.04 \\
\hline 13,000 & 0.85 & 0.90 & 0.94 & 1.02 & 1.10 \\
\hline 14,000 & 0.92 & 0.97 & 1.00 & 1.08 & 1.17 \\
\hline 15,000 & 0.99 & 1.04 & 1.07 & 1.15 & 1.24 \\
\hline 16,000 & 1.07 & 1.12 & 1.15 & 1.23 & 1.32 \\
\hline 17,000 & 1.15 & 1.20 & 1.23 & 1.31 & 1.40 \\
\hline 18,000 & 1.23 & 1.28 & 1.32 & 1.40 & 1.48 \\
\hline
\end{tabular}

Identifying the appropriate ESS capacity for BEBs can be challenging. It is important that the buses have sufficient range to meet the daily service requirements of the BRTS routes without significantly oversizing the ESS, which would increase bus mass and incur unnecessary capital costs.

The minimum size of battery required for the BEB to meet the daily service needs of BRTS routes is determined by the energy consumption rate of the BEB and the daily distance traveled. Energy consumption rates could range from a low of approximately $0.74 \mathrm{kWh} / \mathrm{km}$ for a lighter $(10,000 \mathrm{~kg})$ bus operating on a mild-temperature $\left(28^{\circ} \mathrm{C}\right)$ day, $)$ to a high of approximately 1.32 $\mathrm{kWh} / \mathrm{km}$ for a heavy $(16,000 \mathrm{~kg})$ bus operating on a hot $\left(40^{\circ} \mathrm{C}\right)$ day in Surat. Factoring in the daily distance variation for BRTS routes results in a wide range of potential minimum ESS sizes.

It is helpful to consider how much of the existing BRTS bus fleet could be electrified (replaced by BEBs) for each increase in ESS capacity. Each BRTS route has a different daily range requirement, which means service on different routes could be achieved by BEBs with different ESS capacities. Each of the eight routes also has a different number of buses operating every day, adding up to the total BRTS fleet of 127 buses.

Figure 20 shows how the minimum ESS capacity corresponds to the cumulative percentage of BRTS fleet that could be electrified, for a range of average efficiencies. The left trend line in the figure represents conditions of higher efficiency (an average energy consumption rate of 0.74 $\mathrm{kWh} / \mathrm{km}$ for a $10,000 \mathrm{~kg}$ bus at $28^{\circ} \mathrm{C}$ ), and the right trend line represents lower fuel efficiency conditions (an energy consumption rate of $1.32 \mathrm{kWh} / \mathrm{km}$ for a $16,000 \mathrm{~kg}$ bus at $40^{\circ} \mathrm{C}$ ). The thick blue trend line in the middle corresponds to an average efficiency of $1.08 \mathrm{kWh} / \mathrm{km}$ for a 14,000 $\mathrm{kg}$ bus at $35^{\circ} \mathrm{C}$. As the ESS capacity increases, each step change in the trend lines represents the number of buses operating on one of the eight routes, in order of increasing daily route distance, thereby showing the cumulative percentage of the BRTS service met by BEBs. 
For example, assuming an average efficiency of $1.08 \mathrm{kWh} / \mathrm{km}$ (thick blue line), BEBs with 250 $\mathrm{kWh}$ of energy storage could replace over $40 \%$ of the BRTS buses - those operating on Routes $18,16,17 \mathrm{e}$, and 14 . BEBs with ESS capacity of at least $280 \mathrm{kWh}$ could replace almost $90 \%$ of the fleet. Electrifying $100 \%$ of the BRTS fleet with buses of a single type or size would require BEBs with ESS capacity of $300 \mathrm{kWh}$ or greater, for this middle efficiency case.

Because the BRTS bus fleet will not be electrified all at once, SMC can use this relationship to plan the acquisition of each additional group of BEBs based on the routes to be electrified, the expected efficiency, the size of ESS available, and the number of buses being purchased. To begin, SMC could acquire the first four BEBs with an ESS capacity of approximately $200 \mathrm{kWh}$ and operate them exclusively on Route 18 as an initial pilot program. SMC may also benefit from piloting a small number of BEBs along various routes to test the actual range under various real-world conditions.

When calculating the necessary ESS capacity for BEBs, SMC should consider that rated battery capacity may be larger than usable capacity and that traction batteries will degrade over time. Manufacturer warranties often specify $80 \%$ or $85 \%$ of original capacity as the level at which batteries should be replaced, correlating to a required increase in initial ESS capacity of $17 \%$ to $25 \%$. As a point of reference, $312.5 \mathrm{kWh}$ of usable ESS degraded to $80 \%$ will provide the equivalent range of a $250 \mathrm{kWh}$ ESS.

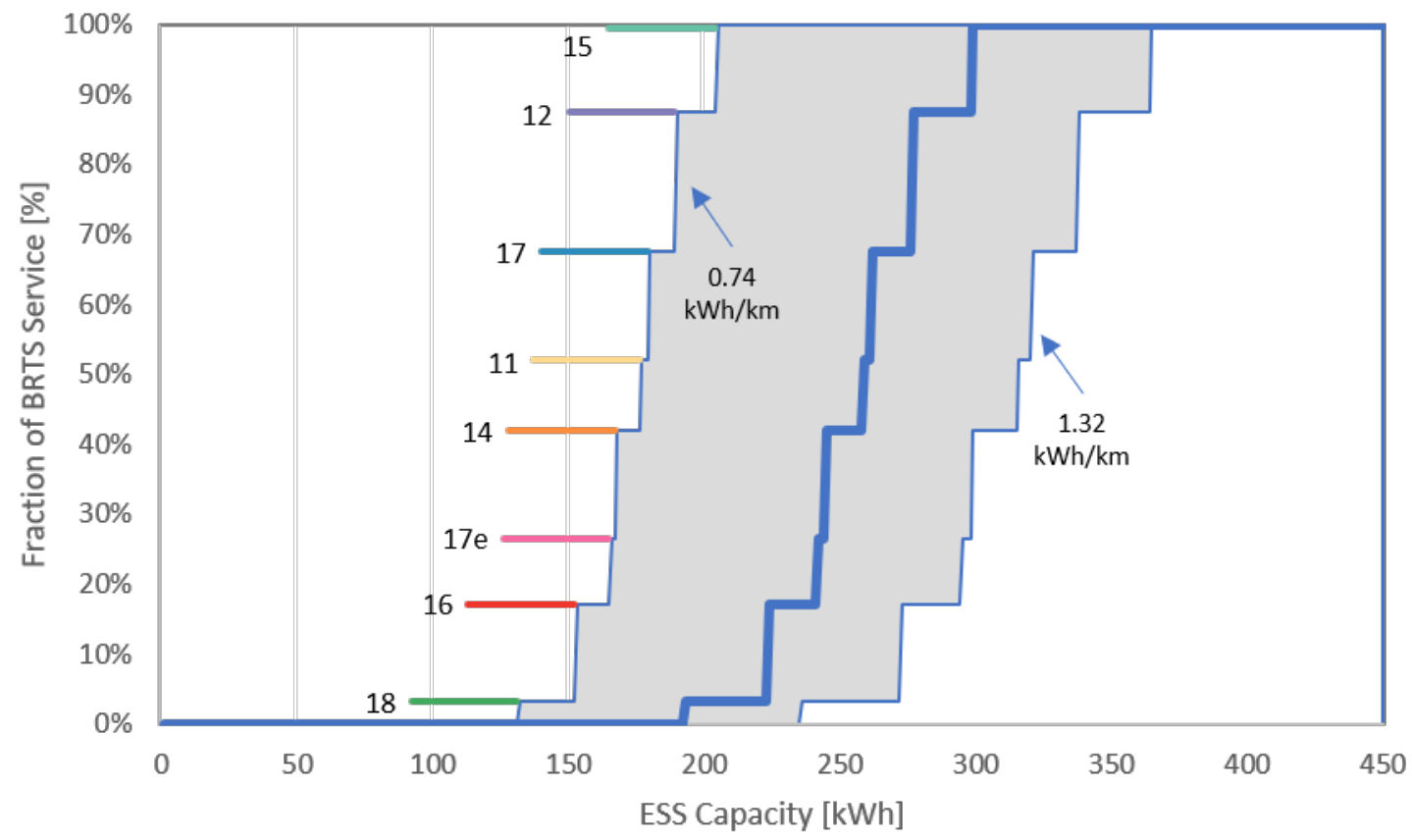

Figure 20. Cumulative fraction of BRTS bus fleet vs ESS capacity 


\section{Battery Life Longevity}

Battery lifetime and rate of degradation depend on several factors, including battery chemistry, age, temperature, the rate of charge and discharge, and the constantly varying state of charge (SOC). While a full analysis of battery longevity would exceed the scope of this report, NREL researchers investigated the potential degradation of generic versions of the battery chemistries under consideration: lithium nickel manganese cobalt oxide (NMC) specified by Ashok Leyland, lithium iron phosphate (LFP) specified by BYD, and lithium nickel cadmium aluminum (NCA), which is another common battery technology. Real-world results will vary based on the percentage and configuration of elements used by each manufacturer, pack-cooling technology, and other factors, such as the amount of time the battery packs are fully charged each day, which puts additional stress on the battery.

NREL conducted an analysis using the Battery Lifetime Analysis and Simulation Tool (BLAST) to examine battery degradation. ${ }^{36,37}$ The analysis highlighted the sensitivity of battery lifetime to differences in chemistry and temperature impacts, rather than predicting the actual battery lifetime for BEBs that may be acquired by SMC. Therefore, several assumptions were made to simplify the analysis. The team modeled batteries with $500 \mathrm{kWh}$ capacity for the analysis to ensure there was excess charging capacity to meet the service requirements of all BRTS routes. The batteries were modeled to be discharged according to the power requirements of each route, determined by the vehicle power requirements model. They were charged nightly, beginning when the bus returned to the depot from each route, and scheduled to charge at a fixed rate necessary to reach $100 \%$ capacity one hour before the beginning of operation the following day. Figure 22 shows the modeled state of charge during a 24-hour period for each BRTS route.

The analysis also considered three temperature scenarios-labeled "Min.", "Max.", and "Avg."-where it was assumed that the battery pack temperature matched one of the ambient temperature profiles shown in Figure 23. The three profiles are averages of the weekly minimum, maximum, and average ambient temperatures, respectively. Without any active battery packcooling, battery temperatures could be significantly higher, which would reduce the lifetime of the batteries. Active cooling would maintain lower temperatures, which would extend the battery lifetime.

\footnotetext{
${ }^{36}$ NREL._"BLAST: Battery Lifetime Analysis and Simulation Tool Suite". https://www.nrel.gov/transportation/blast.html. [Accessed: October 22, 2018].

${ }^{37}$ Neubauer, J., Wood, E. 2014. Thru-life impacts of driver aggression, climate, cabin thermal management, and battery thermal management on battery electric vehicle utility. https://www.sciencedirect.com/science/article/pii/S0378775314002766
} 


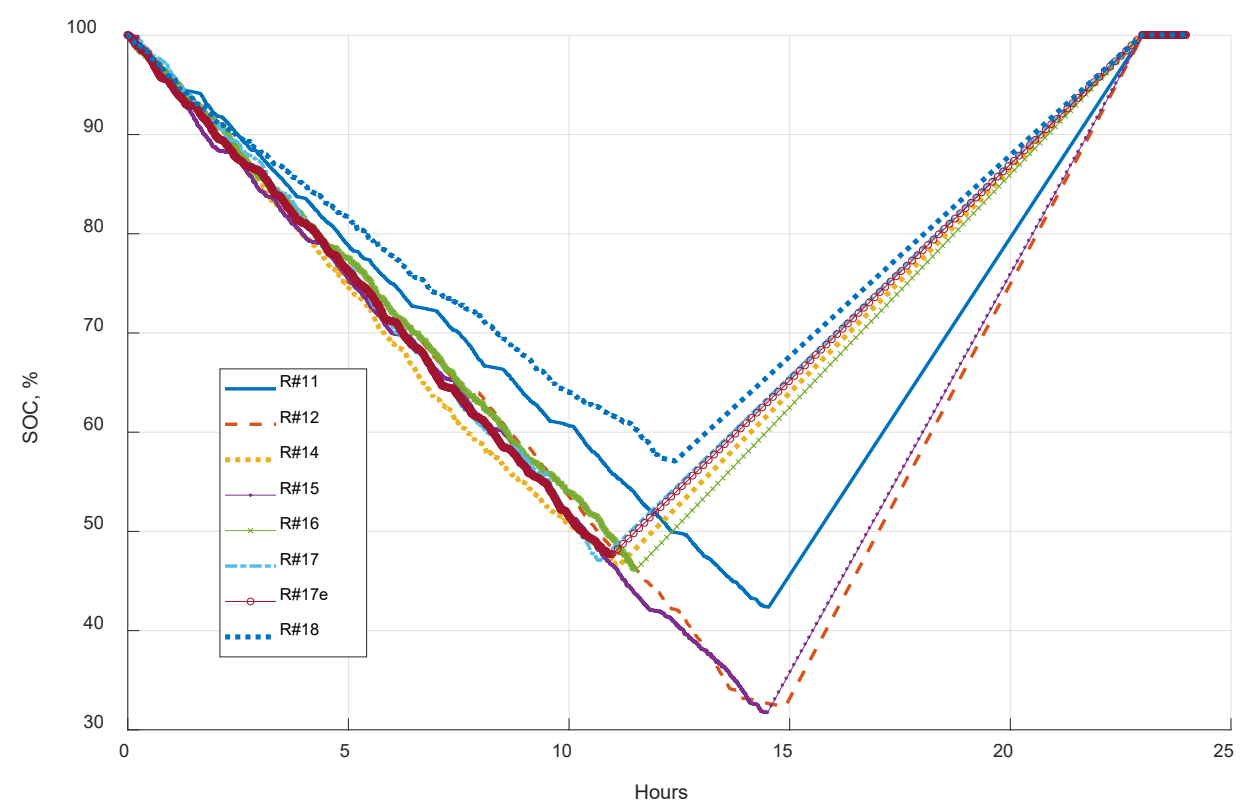

Figure 21. ESS charge and discharge profile for model

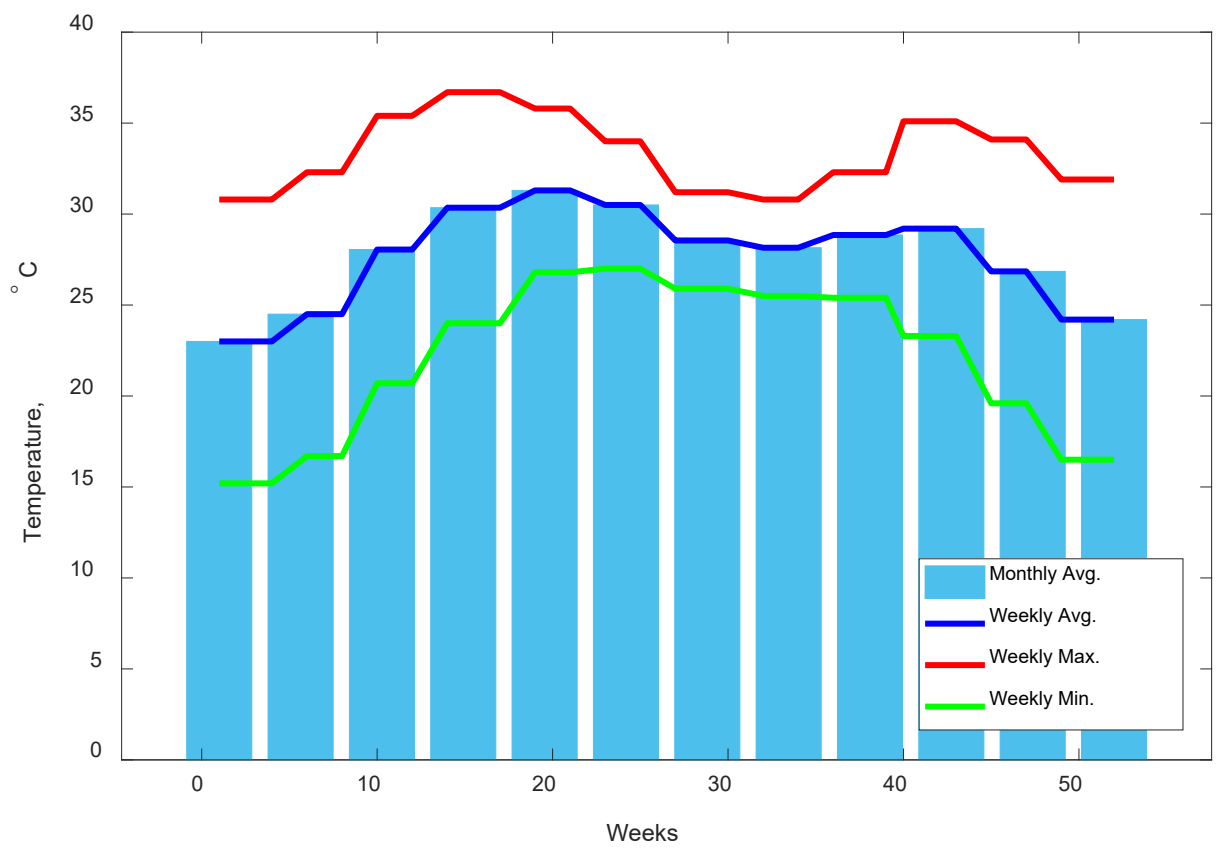

Figure 22. Ambient temperature profiles for model ${ }^{38}$

${ }^{38}$ Weatherbase. "Surat." 2019. https://www.weatherbase.com/weather/weather.php3?s=4824\&cityname=SuratGujarat-India\&units=metric. [Accessed: January 17, 2019]. 
The analysis considers $20 \%$ an acceptable degradation factor. Battery degradation accelerates as the overall percentage of nominal capacity is lost, and approximately $80 \%$ of nominal capacity is a common cutoff level for original equipment manufacturer (OEM) battery warranties.

Based on the assumptions described above, Table 8 displays the estimated number of years of operation it will take the various battery technologies to deplete to $80 \%$ of their original capacity. The results vary based on the technology used, battery temperature, and the daily battery depletion along each route. Routes 12 and 15 require the most daily energy, and therefore the batteries are more fully depleted, while Route 18 reflects the lowest daily depletion.

Table 8. Years to Reach $80 \%$ Charge Capacity

\begin{tabular}{|c|c|c|c|c|c|c|c|c|c|c|}
\hline \multirow[b]{2}{*}{ Route } & \multicolumn{3}{|c|}{ NMC } & \multicolumn{3}{|c|}{ LFP } & \multicolumn{3}{|c|}{ NCA } & \multirow{2}{*}{$\begin{array}{c}\text { Max } \triangle S O C \\
10 \text { Years }\end{array}$} \\
\hline & Avg. T & Max. T & Min. T & Avg. $T$ & Max. T & Min. T & Avg. $T$ & Max. T & Min. T & \\
\hline 11 & 5.3 & 1.4 & $>10$ & 3.5 & 2.3 & 5.6 & 5.6 & 3.4 & 9 & $57.6 \%$ \\
\hline 12 & 3 & 1 & 9.4 & 3.5 & 2.3 & 5.6 & 5.2 & 3 & 7.6 & $67.6 \%$ \\
\hline 14 & 5.8 & 1.6 & $>10$ & 3.5 & 2.3 & 5.6 & 5.8 & 3.5 & 9.5 & $53.5 \%$ \\
\hline 15 & 2.9 & 1 & 9 & 3.5 & 2.3 & 5.6 & 5.2 & 3 & 7.6 & $68.3 \%$ \\
\hline 16 & 5.8 & 1.6 & $>10$ & 3.5 & 2.3 & 5.5 & 5.7 & 3.5 & 9.4 & $53.9 \%$ \\
\hline 17 & 5.9 & 1.6 & $>10$ & 3.5 & 2.3 & 5.5 & 5.8 & 3.5 & 9.4 & $53.0 \%$ \\
\hline $17 e$ & 6 & 1.6 & $>10$ & 3.5 & 2.3 & 5.5 & 5.8 & 3.5 & 9.5 & $52.4 \%$ \\
\hline 18 & 9.5 & 3 & $>10$ & 3.5 & 2.3 & 5.6 & 6.2 & 3.9 & $>10$ & $43.0 \%$ \\
\hline
\end{tabular}

The biggest takeaway from the battery lifetime analysis is that SMC should require a battery warranty acceptable to Surat BRTS as part of the solicitation process. This could include battery replacement coverage for the seven-year operational period and 500,000 km that SMC buses are likely to run, but SMC will need to work with OEMs to negotiate terms. SMC should also work to implement effective smart charging solutions in tandem with the deployment of electric buses to maximize battery life.

Actual performance will vary based on several factors, including the actual depth of discharge allowed by the vehicle manufacturer. For example, Transpower limits the battery SOC range of its electric truck batteries to improve the longevity. If the total energy used from batteries is limited to $80 \%$ of their capacity, they can cycle 2,000 to 3,000 times, but if they are limited to $70 \%$ of their total energy, they can cycle 5,000 times. ${ }^{39}$ Operators can also improve battery life by maintaining a battery SOC closer to the middle of its range, rather than fully charging or fully discharging. SMC could consider minimizing battery depletion by operating BEBs along shorter routes on days when air conditioning loads are expected to peak or on particularly wet days when

\footnotetext{
${ }^{39}$ Transpower USA. Electric Class 8 Truck Product Description. 2014. http://www.transpowerusa.com/downloads/Electric-Class-8-Truck-Description-TransPower-08-08-14.pdf. [Accessed: January 22, 2019].
} 
road conditions may reduce efficiency. Using multiple BEBs along a longer route in adverse conditions could achieve the same purpose.

Because of these considerations, battery lifetime represents a significant risk factor to the economic feasibility of converting the SMC transit fleet to BEBs. The cost of battery replacement is another major economic challenge. While electric vehicle battery pack costs in 2017 were approximately $\$ 219 / \mathrm{kWh}(₹ 15,555 / \mathrm{kWh})$ in the United States, the DOE goal for pack costs is $\$ 100 / \mathrm{kWh}(₹ 7,103 / \mathrm{kWh})$ by 2022 , and $\$ 75 / \mathrm{kWh}(₹ 5,327 / \mathrm{kWh})$ in the long term. ${ }^{40}$ Assuming these goals are achieved in India, and batteries need to be replaced in 2022, they will cost less than half of what they currently cost. In addition, the government of India reduced the goods and services tax on lithium-ion batteries from $28 \%$ to $18 \%$ in July 2018 , although the import duty was raised from $10 \%$ to $20 \%$. This will reduce the pack costs for batteries produced in India, but the costs will remain the same for imported batteries. ${ }^{41}$

${ }^{40}$ DOE Vehicle Technologies Office. 2018. Batteries: 2017 Annual Progress Report. https://www.energy.gov/sites/prod/files/2018/06/f52/Batteries FY2017 APR Final FullReport-webopt.pdf. [Accessed: January 17, 2019].

${ }^{41}$ Rajeshwari. 2018. Mercom India. "GST on Li-Ion Batteries Reduced from 28 to 18 Percent". https://mercomindia.com/gst-li-ion-batteries-reduced-from-28-to-18-percent/. [Accessed: January 17, 2019]. 


\section{Life-cycle Cost Comparison}

The economic feasibility of BEBs depends on several factors, which can be summarized as a combination of capital expense (capex) and operating expense (opex). The capex includes purchase of the bus itself as well as charging equipment, while the variable opex consists mostly of fuel and maintenance costs. Insurance and accident costs are assumed to be equal for diesel and electric buses, and therefore are not factored into the life-cycle cost comparison. Furthermore, the analysis does not include the cost of diesel fueling stations; the authors assumed that the diesel infrastructure is already in place or the buses fuel at publicly available stations, whereas the electric charging equipment must be installed to support new BEBs. This section also assumes that BEBs would replace diesel buses at a ratio of one to one. However, to electrify routes with a longer range without on-route charging or battery swapping, Surat may need to acquire additional BEBs.

\subsection{Capital Expense}

Capex for BEBs can be divided into bus purchase costs and installed EVSE costs. Both the vehicle and charging equipment costs for BEBs are subsidized by the FAME program. The proposed FAME II program was introduced in April 2019. Under the plan, BEBs qualify for incentives equaling ₹20,000/kWh up to $40 \%$ of the cost of the vehicle, and one slow charger per BEB or one fast charger for every ten BEBs will be funded through the grant program. ${ }^{42}$ The following calculations are based on the FAME II proposal, assuming that it is formalized in its current form.

\subsubsection{Bus Costs}

The Department of Heavy Industry (DHI) committee that oversees the FAME program set FAME I incentive amounts for BEBs based on benchmark prices using the lowest bid among nine cities for each bus category. ${ }^{43}$ Bus categories were based on bus length, seating capacity, battery capacity, and floor height. This report uses those categories and prices as an approximation of prices that Surat could secure in its bid for BEBs. However, actual costs may differ.

To highlight the wide range of potential BEB purchase costs, Figure 24 and Figure 25 show the submitted bid prices for BEBs from seven OEMs to solicitations from municipal corporations in 10 Indian cities. ${ }^{44}$ Some cities requested gross cost contract (GCC) bids, which include opex, and others requested outright purchase contracts. Therefore, the charts are divided into GCCs (INR/km) and outright purchase bids (INR Million), and cover 9-meter and 12-meter BEBs

\footnotetext{
${ }^{42}$ Government of India, DHI. 2019. Operational Guidelines for Delivery of Demand Incentive under FAME India Scheme: Phase - II - regarding. https://dhi.nic.in/writereaddata/UploadFile/DHI\%20FAME\%20PHASEII22March2019.pdf. [Accessed April 8, 2019].

${ }^{43}$ Government of India, DHI. 2018. Recommendations of the Committee Constituted to Decide Benchmark Price for Electric Buses to be Procured by Different STUs, for Release of Demand Incentives. https://hi.nic.in/writereaddata/UploadFile/Benchmark\%20price\%20for\%20Electric\%20Buses63666299596397561 6.pdf. [Accessed: January 17, 2019].

${ }^{44}$ UITP. 2018. Electric Buses Procurement in India - Indian Cities Got the Viable Rates. https://india.uitp.org/sites/default/files/documents/Procurement $\% 20$ of $\% 20$ Electric $\% 20$ buses $\% 20 \mathrm{in} \% 20 \mathrm{India} \% 20$ \%2020032018.pdf. [Accessed: January 17, 2019].
} 
either with or without air conditioning (AC or non-AC). The life-cycle cost comparison in this report uses the benchmark outright purchase figures with adjustments for electricity prices available in Surat and additional assumptions regarding charging equipment. The life-cycle costs over seven years for BEBs calculated in this report amount to between ₹ $26 / \mathrm{km}$ and ₹ $40 / \mathrm{km}$, placing the report estimates on the low end of the range shown in Figure 24. There is significantly more variation within the submitted bids for GCCs, which might include accident and insurance costs.

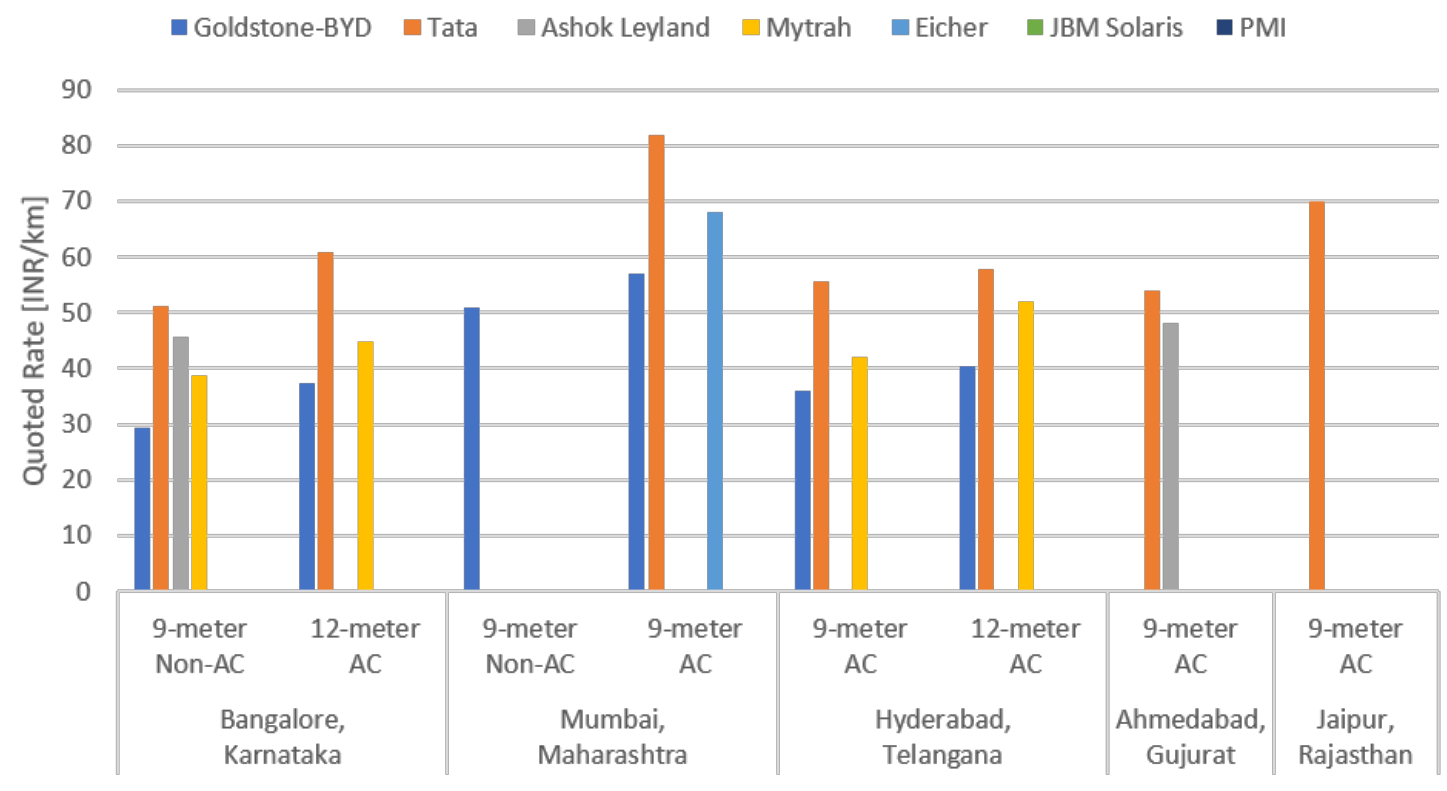

Figure 23. Quoted rates for electric buses - gross cost contract (GCC) 


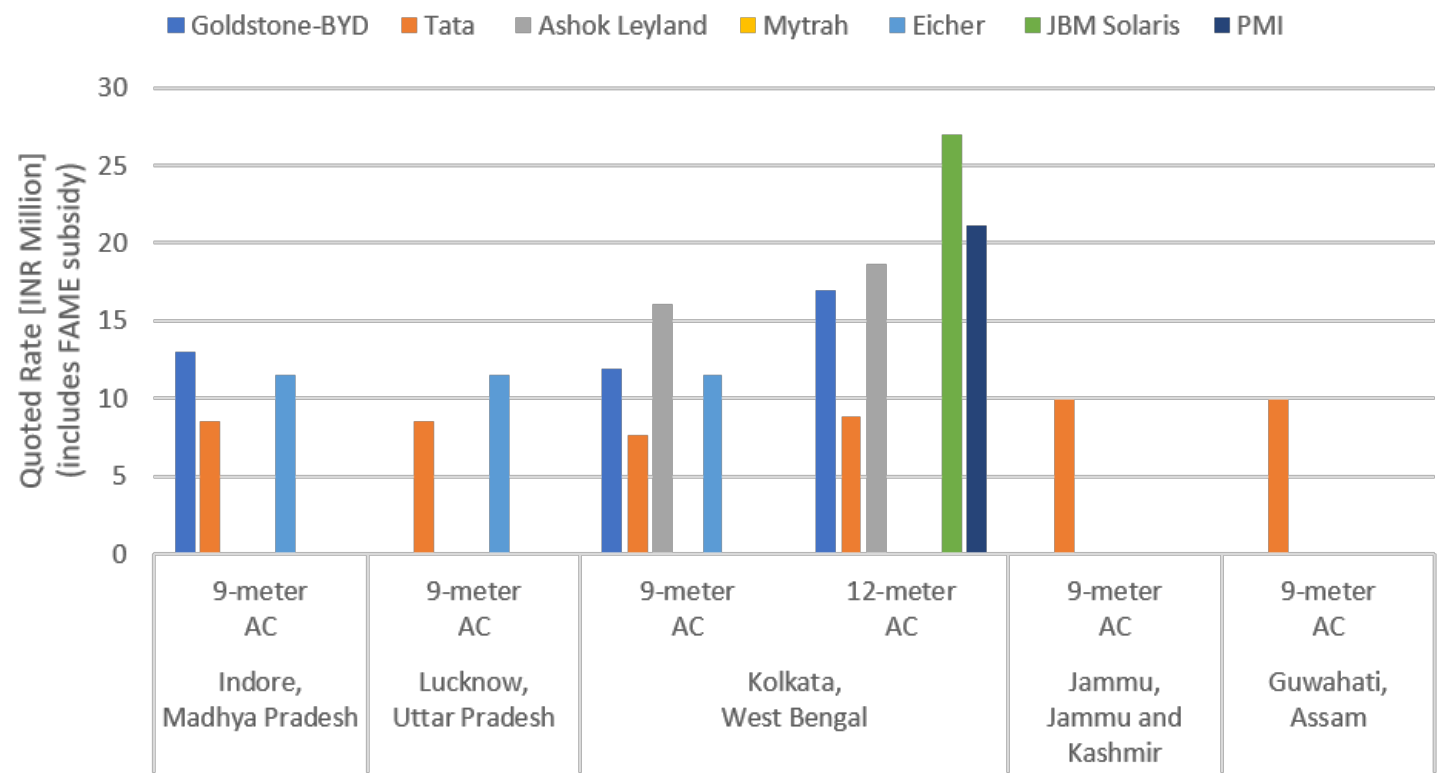

Figure 24. Quoted rates for electric buses - outright purchase

Table 10 compares the original purchase cost and the cost after FAME II incentives for benchmark BEBs and two diesel buses sold in India. ${ }^{45}$ As additional points of reference, a report from the Lawrence Berkley National Laboratory includes production cost estimates of approximately ₹2M for 9-meter diesel buses, ₹6M for 12-meter diesel buses, ₹5M for 9-meter BEBs, and ₹ $10 \mathrm{M}$ for 12 -meter BEBs. ${ }^{46}$

Table 9. Bus Purchase Costs Before and After FAME Incentives

\begin{tabular}{|c|c|c|c|c|c|c|c|}
\hline Manufacturer & $\begin{array}{l}\text { Fuel } \\
\text { Type }\end{array}$ & $\begin{array}{l}\text { Length } \\
\text { (m) }\end{array}$ & $\begin{array}{c}\text { Passenger } \\
\text { Capacity }\end{array}$ & $\begin{array}{c}\text { Battery } \\
\text { Capacity } \\
\text { (kWh) }\end{array}$ & $\begin{array}{l}\text { Purchase } \\
\text { Cost }\end{array}$ & $\begin{array}{l}\text { FAME II } \\
\text { Incentive }\end{array}$ & $\begin{array}{l}\text { Cost After } \\
\text { FAME II } \\
\text { Incentive }\end{array}$ \\
\hline Tata & Electric & 9 & 31 & 125 & $₹ 7,490,000$ & $₹ 2,500,000$ & $₹ 4,990,000$ \\
\hline Tata & Electric & 12 & 40 & 125 & $₹ 8,800,000$ & $₹ 2,500,000$ & $₹ 6,300,000$ \\
\hline BYD & Electric & 9 & 31 & 162 & ₹12,297,600 & $₹ 3,240,000$ & $₹ 9,057.600$ \\
\hline BYD & Electric & 12 & 40 & 324 & ₹17,519,400 & $₹ 6,480,000$ & $₹ 11,039,400$ \\
\hline Tata & Diesel & 12 & 44 & - & ₹3,300,000 & $₹ \quad \quad-$ & $₹ 3,300,000$ \\
\hline Volvo & Diesel & 12 & 32 & - & $₹ 8,800,000$ & $₹$ & $₹ 8,800,000$ \\
\hline
\end{tabular}

\footnotetext{
${ }^{45}$ Global Green Growth Institute and Center for Study of Science, Technology, and Policy. 2015. Electric Buses in India: Technology, Policy and Benefits.

http://www.cstep.in/uploads/default/files/publications/stuff/CSTEP_Electric_Buses_in_India_Report 2016.pdf. [Accessed: January 17, 2019].

${ }^{46}$ Khandekar, et. al. 2018. The Case for All New City Buses in India to be Electric. http://etapublications.lbl.gov/sites/default/files/india_electric_city_buses.pdf. [Accessed: January 17, 2019].
} 
While the purchase costs of BEBs are higher than those of the diesel buses, after accounting for FAME incentives they are more competitive.

\subsubsection{EVSE Costs and Considerations}

The FAME II program proposes to provide grants for up to $100 \%$ of the cost of one slow charger per BEB and one fast charger for every ten BEBs. ${ }^{47}$ Slow and fast EVSE were not defined in the DHI notification; the authors assumed that a unit capable of charging a BEB overnight would be considered slow in the context of FAME II, and an on-route charger would be considered fast. Assuming the Surat BRTS qualifies for the 100\% EVSE project cost incentive, there will be no cost associated with EVSE. This differs significantly from the FAME I program, which offered $10 \%$ of the bus costs as an incentive for EVSE.

There are multiple depot-charge or on-route charge strategies that Surat could employ. If SMC elects to purchase a depot-charge bus, it could rotate high-power direct current fast charger (DCFC) ports overnight among multiple BEBs or install a slower, dedicated EVSE port to each vehicle. Alternatively, SMC could acquire a BEB with on-route ultra-fast charging (typically employing an automatic conductive coupler such as a pantograph or wireless charging pads) or swappable batteries. The types of charging are illustrated in Figure 25.

(a)

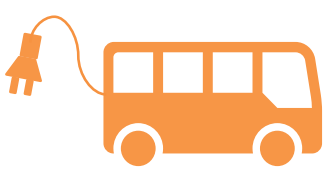

(b)

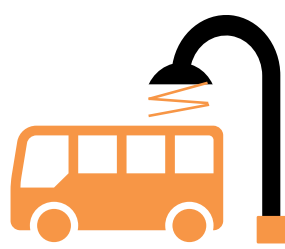

(c)

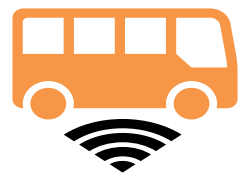

Figure 25. EVSE connection types

(a) handheld conductive (b) automatic conductive (c) automatic wireless

None of the BEBs identified in this report as available in India currently offer on-route charging options. However, Ashok Leyland offers a BEB with swappable batteries that could function in a fashion similar to that of on-route ultra-fast-charging, with designated locations along a bus route to swap the depleted batteries with fully charged batteries. This minimizes the wait time for bus operators, but it requires designated locations for BEB battery exchange. The company operating the swapping would then use one of the strategies outlined in Figure 25 to charge the depleted batteries. Costs for battery swapping in India were not available publicly, but the GCC bids in Bangalore and Ahmedabad might include those costs (Figure 24).

As an example of a depot-charge option, BYD buses can charge using the GB/T standard DCFCs or IEC 62196 Type 2 alternating current (AC) connectors. ${ }^{48} \mathrm{~GB} / \mathrm{T}$ DCFC currently can provide

\footnotetext{
${ }^{47}$ Government of India, DHI. Notification: Scheme for Fast Adoption and Manufacturing of Electric Vehicles in India Phase II(FAME India Phase II). https://www.fame-india.gov.in/WriteReadData/userfiles/file/FAMEII\%20Notification.pdf

${ }^{48}$ Song, N. BYD Auto Asia-Pacific Auto Sales Division. 2018. "Personal Communication with Author.".
} 
up to $237.5 \mathrm{~kW}$ of charging power, ${ }^{49}$ although $150-\mathrm{kW}$ chargers appear more common on clearinghouse sites such as Alibaba. Type 2 AC EVSE can charge at up to $43 \mathrm{~kW}$ on $63 \mathrm{~A}$ threephase power $(415 \mathrm{~V})$. In order to provide up to $324 \mathrm{kWh}$ between 11:00 p.m. and 6:00 a.m. (which would fully charge the battery of a BYD 12-meter BEB overnight), the EVSE must provide $52 \mathrm{~kW}$ of continuous power (assuming 10\% efficiency loss from the EVSE to battery). Although the batteries are unlikely to be fully depleted every day, EVSE units do not always provide the maximum rated power listed by the manufacturer, especially as ESS capacity approaches $100 \%$. Therefore, Surat may want to consider a $60 \mathrm{~kW} \mathrm{DCFC.}$

In case SMC does not qualify for the full EVSE project costs, an approximation of unit and installation costs may prove useful. The authors could not ascertain cost data on EVSE units sold in India, and installation expenses depend heavily on power availability, electrical upgrades, and surface disruptions such as trenching through concrete. In a 2015 report on nonresidential U.S. EVSE costs, the DOE estimated 24-90 kW DCFC unit costs between ₹710,000 - ₹2,800,000 and average installation costs of about ₹ $149,000 .{ }^{50}$ Assuming an average unit purchase price of $₹ 178,000$ for a $60 \mathrm{~kW}$ charger in addition to the installation cost, unsubsidized EVSE would cost $₹ 3,270,000$. SMC may be able to achieve lower costs by installing Type 2 AC EVSE if $43 \mathrm{~kW}$ is sufficient and the BEBs can accept $43 \mathrm{~kW}$ AC, or by installing $150 \mathrm{~kW}$ DCFC and rotating charging among three buses overnight. However, rotating the charging cords or moving the buses throughout the night would increase labor costs. Detailed electrical and labor assessments at the depots would be necessary to determine the optimal charging strategy.

It is unclear whether the FAME II definition of EVSE project costs will include upgrades to the distribution transformer. Therefore, SVNIT Surat analyzed the costs of installing a distribution transformer to provide apparent power at up to $800 \mathrm{kVA}$ (standard transformer size with more than enough capacity for $10 \mathrm{BEBs}$ charging at $60 \mathrm{~kW}$ ) or $1,250 \mathrm{kVA}$ (more than enough capacity for charging 15 buses at $60 \mathrm{~kW}$ or 10 BEBs at $100 \mathrm{~kW}$ ). While the transformers are specified at standard sizes, the analysis used $600 \mathrm{kVA}$ and 1,000 kVA respectively for setup charges because they more accurately reflect likely power requirements for 10 or $15 \mathrm{BEBs}$ at $60 \mathrm{~kW}$. As shown in Table 11, the expected charges from the utility include a refundable security deposit, which accounts for over $75 \%$ of the total charges.

\footnotetext{
${ }^{49}$ Kane. 2018. "China is Developing New GB/T Fast Charging Standard at $900 \mathrm{~kW}$.” Inside EVs. https://insideevs.com/china-new-gb-t-fast-charging-standard-900-kw/. [Accessed: January 17, 2019].

${ }^{50}$ DOE. 2015. Costs Associated with Non-Residential Electric Vehicle Supply Equipment: Factors to consider in the implementation of electric vehicle charging stations.

http://www.afdc.energy.gov/uploads/publication/evse_cost_report_2015.pdf. [Accessed: January 17, 2019 ].
} 
Table 10. Utility Setup Charges for 600 and 1,000 kVA Transformers

\begin{tabular}{l|c|c|}
\hline Setup Charges & $\mathbf{6 0 0}$ kVA & $\mathbf{1 0 0 0 ~ k V A ~}$ \\
\hline Registration Charges & $₹ 6,000$ & $₹ 10,000$ \\
\hline Service Connection Charges & $₹ 10,400$ & $₹ 16,000$ \\
\hline Pro Rata Charges & $₹ 690,000$ & $₹ 1,150,000$ \\
\hline Security Deposit (refundable) & $₹ 3,294,000$ & $₹ 5,553,000$ \\
\hline Line Charges (approximate) & $₹ 350,000$ & $₹ 350,000$ \\
\hline Total & $\mathbf{8 4 , 3 5 0 , 4 0 0}$ & $₹ 7, \mathbf{0 7 9 , 0 0 0}$ \\
\hline
\end{tabular}

In addition, there would be costs associated with installing the distribution transformer. SVNIT estimates that the total costs associated with an $800-\mathrm{kVA}$ transformer would be $₹ 2,730,000$, while a 1,250-kVA transformer would cost ₹3,320,000.

Table 11. Distribution Transformer Costs

\begin{tabular}{l|c|c|}
\hline Equipment Type & $\mathbf{8 0 0}$ kVA & $\mathbf{1 2 5 0 ~ k V A ~}$ \\
\hline $\begin{array}{l}\text { BIS 1180 Level, 2 (11/433), } \\
\text { OLTE Tap, ONAN, Copper } \\
\text { Wound }\end{array}$ & $₹ 1,280,000$ & $₹ 1,570,000$ \\
\hline $\begin{array}{l}\text { 11 kVA Switchyard } \\
\text { 1250 A VCB and High-Tension } \\
\text { Cable }\end{array}$ & $₹ 325,000$ & $₹ 325,000$ \\
\hline $\begin{array}{l}\text { LT Main PCC Panel with APFC } \\
\text { Panel (approximate) }\end{array}$ & $₹ 550,000$ & $₹ 325,000$ \\
\hline Cabling and Other Accessories & $₹ 250,000$ & $₹ 750,000$ \\
\hline Total & $₹ 2,730,000$ & $₹ 350,000$ \\
\hline
\end{tabular}

SVNIT diagrammed the installation of the high-tension (HT) vacuum circuit breaker (VCB), transformer, low-tension (LT) bus, and LT panel with automatic power factor control (APFC) as shown in Figure 26.

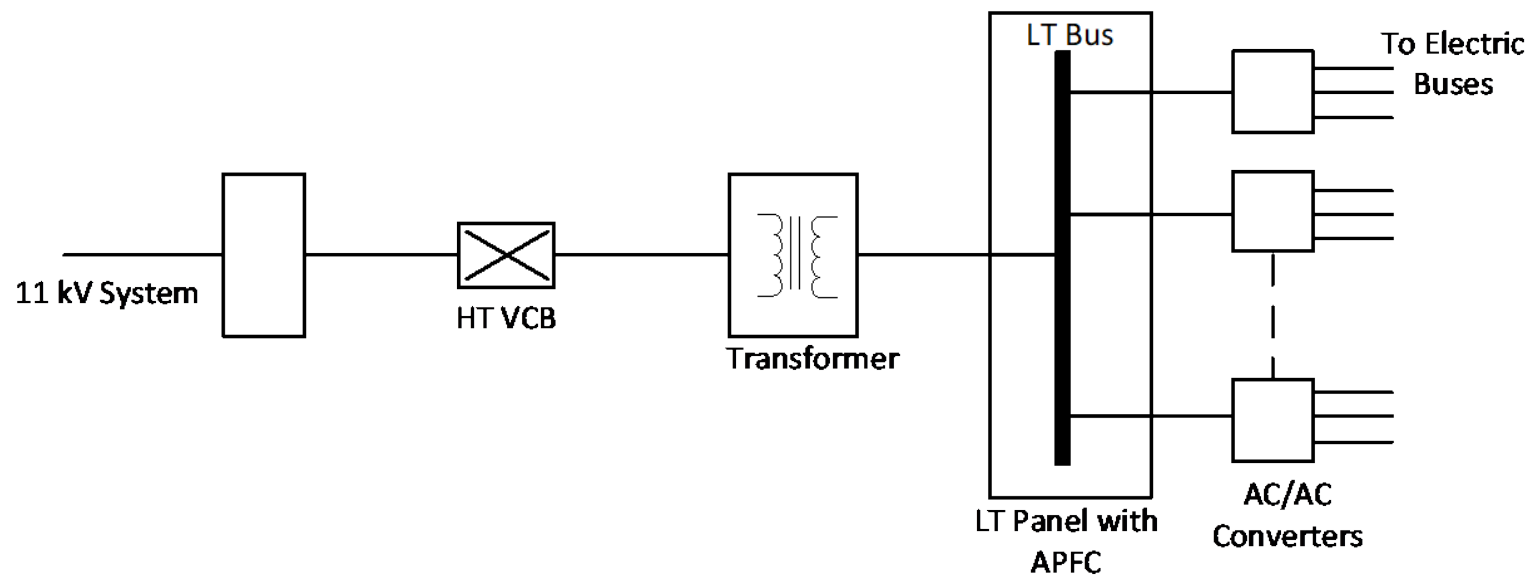

Figure 26. Single line diagram of electrical upgrades to support BEBs 
Sufficient detail was not available to isolate electrical upgrades within the overall installation cost estimates provided in the DOE 2015 cost report. ${ }^{51}$ However, the total costs associated with electrical upgrades, including the charges for new service and the security deposit, total $₹ 7,080,400$ for ten 60 -kW EVSE, or ₹708,040 per unit. Excluding the security deposit—which can be refunded as a bill credit - the total would be ₹3,786,400. This is approximately one quarter of the ₹1,491,609 estimated for overall EVSE installation costs. It is likely that the balance of installation costs - such as trenching, pouring a concrete pad, and configuring the EVSE-would not equal three times the cost of the electrical upgrades, suggesting that the DOE installation cost estimates for the United States are higher than SMC's costs would be.

As noted above, the FAME II program proposal includes a provision to pay for $100 \%$ of the cost of EVSE. Therefore, it is likely that all of the EVSE costs for the Surat BEBs will be reimbursed. However, they could be as high as 15 lakh per EVSE without incentives.

\subsection{Operational Costs}

The two primary opex factors assessed in this report are fuel and maintenance. BEBs are significantly more efficient than diesel buses on the basis of energy content. Combined with low electricity costs in Surat, fuel costs for BEBs are far less than those for diesel buses. However, the maintenance cost comparisons are not as clear.

\subsubsection{Fuel Costs}

BEBs achieve significantly higher fuel efficiency than conventional diesel buses-modeled at approximately two to five times higher in this report (see Figure 17 for estimates along Surat BRTS routes). NREL performed an analysis to estimate the costs for depot-charging BEBs based on available tariff schedules from Dakshin Gujarat Vij Company (DGVCL).$^{52}$ The HTP-1 tariff was applied for high-tension electricity supply above $100 \mathrm{kVA}$. This tariff includes energy (consumption) charges, demand changes, a power factor adjustment, and time-of-use rebates. For power availability between 500 and $1,000 \mathrm{kVA}$, the energy charge is $₹ 4.2 / \mathrm{kWh}$. The demand charge for $612 \mathrm{kVA}(10 \times 60 \mathrm{~kW}$ EVSE units with a $98 \%$ power factor) is ₹ 104,184 per month.

SMC should be able to take advantage of adjustments for maintaining power factor above $95 \%$ (₹0.0006/kWh for $98 \%$ power factor), as well as time-of-use rate rebates ( $₹ 0.40 / \mathrm{kWh}$ for charging between 10:00 p.m. and 6:00 a.m.). In total, monthly energy costs for charging 10 BEBs at $293 \mathrm{kWh} / \mathrm{night}$ (which includes a $10 \%$ efficiency loss) would be $₹ 438,650$. For a BEB fuel efficiency of $1.12 \mathrm{kWh} / \mathrm{km}\left(16,000 \mathrm{~kg}\right.$ at $28^{\circ} \mathrm{C}$, Table 8), this equates to ₹6.20/km. At lower tension ( $<100 \mathrm{kVA}$, for 1-2 EVSE only), the rate for EV charging is simply ₹4.1/kWh, which equates to ₹4.59/km using the same efficiency.

\footnotetext{
${ }^{51}$ DOE 2015. Costs Associated with Non-Residential Electric Vehicle Supply Equipment: Factors to consider in the implementation of electric vehicle charging stations. http://www.afdc.energy.gov/uploads/publication/evse_cost_report_2015.pdf. [Accessed: January 17, 2019].
}

\footnotetext{
${ }^{52}$ Paschim Gujarat Vij Company Limited. 2018. Truing up for FY 2016-17 and Determination of Tariff for FY 2018-19. http://www.gercin.org/uploaded/document/3667c615-84ea-44ff-9eb7-ee58fe742fd5.pdf. [Accessed: October 20, 2018].
} 
The diesel fuel prices reported by SMC were ₹74.30/liter. As shown in Table 13, for a fuel efficiency of $3.50 \mathrm{~km} / \mathrm{liter}$, this results in fuel costs of ₹21.23/km; for $2.20 \mathrm{~km} / \mathrm{liter}$, fuel costs would be ₹ $33.77 / \mathrm{km}$.

\begin{tabular}{|c|c|c|c|c|}
\hline Bus & $\begin{array}{c}\text { Fuel Price } \\
\text { (INR/energy } \\
\text { unit) }\end{array}$ & $\begin{array}{c}\text { Fuel Efficiency } \\
\text { (km/energy } \\
\text { unit) }\end{array}$ & $\begin{array}{l}\text { Charging } \\
\text { Efficiency }\end{array}$ & $\begin{array}{l}\text { Fuel Cost } \\
\text { (INR/km) }\end{array}$ \\
\hline Tata 9m 125 kWh Electric & $₹ 5.73$ & 1.45 & 0.90 & $₹ 4.38$ \\
\hline Tata $12 \mathrm{~m} 125$ kWh Electric & $₹ 5.17$ & 1.04 & 0.90 & ₹5.55 \\
\hline BYD 9m 165 kWh Electric & ₹5.38 & 1.19 & 0.90 & ₹5.02 \\
\hline BYD $12 \mathrm{~m} 324$ kWh Electric & $₹ 4.98$ & 0.89 & 0.90 & $₹ 6.20$ \\
\hline Tata $12 \mathrm{~m}$ Diesel & $₹ 74.30$ & 3.50 & $\mathrm{~N} / \mathrm{A}$ & $₹ 21.23$ \\
\hline Volvo 12m Diesel & $₹ 74.30$ & 2.20 & $\mathrm{~N} / \mathrm{A}$ & ₹33.77 \\
\hline
\end{tabular}

\subsubsection{Maintenance Costs}

Available data on BEB maintenance costs in India are limited because few BEBs had been deployed in the country as of 2018. However, NREL completed three U.S. BEB evaluations from 2017 to 2018, including maintenance cost comparisons between electric and conventional (diesel and CNG) buses. ${ }^{53,54,55}$ In the reference reports, NREL standardizes labor rates at $\$ 50 /$ hour (or ₹3,551/hour) to estimate maintenance costs. For this economic analysis, the authors converted the labor rates based on relative average wages between India and the United States to ₹299/hour. ${ }^{56}$ Parts costs were assumed to remain the same in either country. Although the actual bus manufacturing and labor rates may be different, these results provide a levelized approach for comparison and constitute the best data available. The sample size is limited to $21 \mathrm{BEBs}$ and 10 diesel buses.

Many of the buses studied by NREL were under warranty for the duration of the evaluations. In these cases, NREL has no insight into the cost of work performed by the warrantors. One exception is the 2014 Proterra 35-foot Catalyst bus, which concluded the warranty period during the bus evaluation and carried significantly higher overall maintenance costs and propulsionspecific costs (three to six times higher) than any other set of buses analyzed. This evaluation may be indicative of BEB maintenance costs in the period immediately following warranty, when bus operator technicians are learning to troubleshoot electric propulsion system problems.

\footnotetext{
${ }^{53}$ Eudy, Jeffers. 2018. Foothill Transit Agency Battery Electric Bus Progress Report. https://www.nrel.gov/docs/fy19osti/72207.pdf. [Accessed: January 17, 2019].

${ }^{54}$ Eudy, Jeffers. 2018. Zero-Emission Bus Evaluation Results: King County Metro Battery Electric Buses. https:/www.transit.dot.gov/sites/fta.dot.gov/files/docs/research-innovation/115086/zero-emission-bus-evaluationresults-king-county-metro-battery-electric-buses-fta-report-no-0118.pdf. [Accessed: January 17, 2019 ].

${ }^{55}$ Eudy, Jeffers. 2018. Zero-Emission Bus Evaluation Results: County Connection Battery Electric Buses. https://www.nrel.gov/docs/fy19osti/72864.pdf. [Accessed: January 17, 2019].

${ }_{56}$ Nation Master. "Country vs. Country: India and United States Compared: Labor Stats."

https:/www.nationmaster.com/country-info/compare/India/United-States/Labor. [Accessed January 30, 2019 ].
} 
However, these buses also suffered from low-voltage battery failures due to accessories such as fareboxes and cameras drawing power continuously from batteries instead of switching off.

Excluding the set of 35-ft Proterra BEBs would yield BEB total maintenance costs of ₹3.02/km, considerably less than the total maintenance costs of ₹ $11.76 / \mathrm{km}$ with those particular BEBs included. This difference when excluding the outlier is enough to impact the overall life-cycle cost comparison between BEBs and diesel buses. Table 14 provides a summary of maintenance costs (converted to INR $/ \mathrm{km}$ ) from the U.S. BEB evaluations.

Table 13. Maintenance Costs for Electric and Diesel Buses from NREL Evaluations

\begin{tabular}{|c|c|c|c|c|}
\hline Bus & $\begin{array}{l}\text { Fuel } \\
\text { Type }\end{array}$ & $\begin{array}{l}\text { Total Maintenance } \\
\text { (INR/km) }\end{array}$ & $\begin{array}{l}\text { Propulsion System } \\
\text { Maintenance (INR/km) }\end{array}$ & $\begin{array}{c}\text { Number } \\
\text { of } \\
\text { Buses }\end{array}$ \\
\hline Gillig 29 ft BAE Systems 2016 & Electric & ₹3.86 & ₹1.56 & 4 \\
\hline Proterra 35 ft Catalyst 2014 & Electric & ₹18.32 & ₹8.65 & 12 \\
\hline Proterra $40 \mathrm{ft}$ Catalyst 2016 & Electric & ₹2.98 & $₹ 1.56$ & 2 \\
\hline Proterra $40 \mathrm{ft}$ Catalyst 2015 & Electric & ₹1.92 & ₹0.23 & 3 \\
\hline Gillig 40 ft Cummins ISL 2015 & Diesel & ₹5.18 & ₹2.26 & 3 \\
\hline Gillig 29 ft Cummins ISL-9 2014 & Diesel & $₹ 7.77$ & ₹3.09 & 7 \\
\hline Weighted Average & Electric & $₹ 11.76$ & $₹ 5.42$ & 21 \\
\hline Weighted Average & Diesel & $₹ 7.00$ & $₹ 2.84$ & 10 \\
\hline
\end{tabular}

The weighted average of maintenance costs across the evaluations are similar between electric and diesel buses, but there is significant deviation within each category. In addition to the limitations described above, these costs do not account for battery replacements that may be necessary as the electric buses age, or diesel engine rebuilds that are typical at the midlife point of these buses in the United States.

\subsubsection{Life-cycle Operating Costs}

Total operational costs are based on the fuel costs shown in Table 12 and the weighted average maintenance costs shown in Table 13. Average daily driving distance was based on a weighted average of BRTS route distance (distance of each route multiplied by the number of buses assigned to each route per SMC). This equated to $236 \mathrm{~km} /$ day. NREL assumed that both diesel and electric buses were available $85 \%$ of the time based on U.S. industry standards and that they would operate for at least seven years based on recent proposed contract periods by other major Indian cities. ${ }^{57}$ Table 15 shows the inputs for and results of these calculations.

\footnotetext{
${ }^{57}$ UTIP. 2018. "Electric Buses Procurement in India -Indian Cities Got the Variable Rates." https://india.uitp.org/sites/default/files/documents/Procurement $\% 20$ of $\% 20$ Electric $\% 20$ buses $\% 20 \mathrm{in} \% 20$ India $\% 20$ \%2020032018.pdf. [Accessed: January 17, 2019].
} 
Table 14. Life-cycle Operating Costs

\begin{tabular}{|c|c|c|c|c|c|c|c|}
\hline Bus & $\begin{array}{c}\text { Fuel } \\
\text { Cost } \\
\text { (INR/km) }\end{array}$ & $\begin{array}{c}\text { Maintenance } \\
\text { Cost } \\
\text { (INR/km) }\end{array}$ & $\begin{array}{l}\text { Daily Travel } \\
\text { Distance } \\
\text { (km/day) }\end{array}$ & $\begin{array}{c}\text { Daily } \\
\text { Operating } \\
\text { Cost }\end{array}$ & Availability & $\begin{array}{l}\text { Years of } \\
\text { Operation }\end{array}$ & $\begin{array}{l}\text { Lifetime } \\
\text { Operating } \\
\text { Cost }\end{array}$ \\
\hline $\begin{array}{c}\text { Tata 9m } \\
125 \mathrm{kWh} \\
\text { Electric }\end{array}$ & $₹ 4.38$ & $₹ 11.76$ & 236 & $₹ 3,806$ & $85 \%$ & 7 & $₹ 8,264,729$ \\
\hline $\begin{array}{l}\text { Tata } 12 \mathrm{~m} \\
125 \mathrm{kWh} \\
\text { Electric }\end{array}$ & $₹ 5.55$ & $₹ 11.76$ & 236 & $₹ 4,081$ & $85 \%$ & 7 & $₹ 8,863,977$ \\
\hline $\begin{array}{l}\text { BYD 9m } \\
162 \text { kWh } \\
\text { Electric }\end{array}$ & $₹ 5.02$ & $₹ 11.76$ & 236 & $₹ 3,958$ & $85 \%$ & 7 & $₹ 8,594,739$ \\
\hline $\begin{array}{l}\text { BYD } 12 \mathrm{~m} \\
324 \mathrm{kWh} \\
\text { Electric }\end{array}$ & $₹ 6.20$ & $₹ 11.76$ & 236 & $₹ 4,235$ & $85 \%$ & 7 & $₹ 9,198,202$ \\
\hline $\begin{array}{l}\text { Tata } 12 \mathrm{~m} \\
\text { Diesel }\end{array}$ & $₹ 21.23$ & $₹ 7.00$ & 236 & $₹ 6,655$ & $85 \%$ & 7 & $₹ 14,453,775$ \\
\hline $\begin{array}{l}\text { Volvo } 12 \mathrm{~m} \\
\text { Diesel }\end{array}$ & $₹ 33.77$ & $₹ 7.00$ & 236 & $₹ 9,613$ & $85 \%$ & 7 & $₹ 20,877,633$ \\
\hline
\end{tabular}

\subsection{Total Cost of Ownership}

Total cost of ownership is calculated by summing all of the inputs described in sections 6.1 and 6.2 As noted earlier, NREL did not attempt to calculate insurance or accident costs under the assumption that they would not differ between diesel and electric buses. The analysis does not account for the benefits from reduced emissions or local economic impacts.

Figure 27 shows the total cost of ownership of each bus examined in Section 6. In most cases, the BEBs are less expensive to own and operate than the diesel buses over seven years, although the larger battery size of the most expensive BEB may be necessary to support Surat BRTS routes. This is largely a function of the lower fuel cost per $\mathrm{km}$ for BEBs, as well as of the incentives provided under the FAME program. The total estimated cost of ownership for the BYD $324 \mathrm{kWh}$ BEB is ₹20,237,602, while the Tata Starbus diesel bus is ₹17,753,775. However, if the maintenance costs are more in line with the BEBs under warranty in NREL's U.S. reports (see Section 6.2.2), the $324 \mathrm{kWh}$ BEB life-cycle cost drops to ₹15,761,821. 


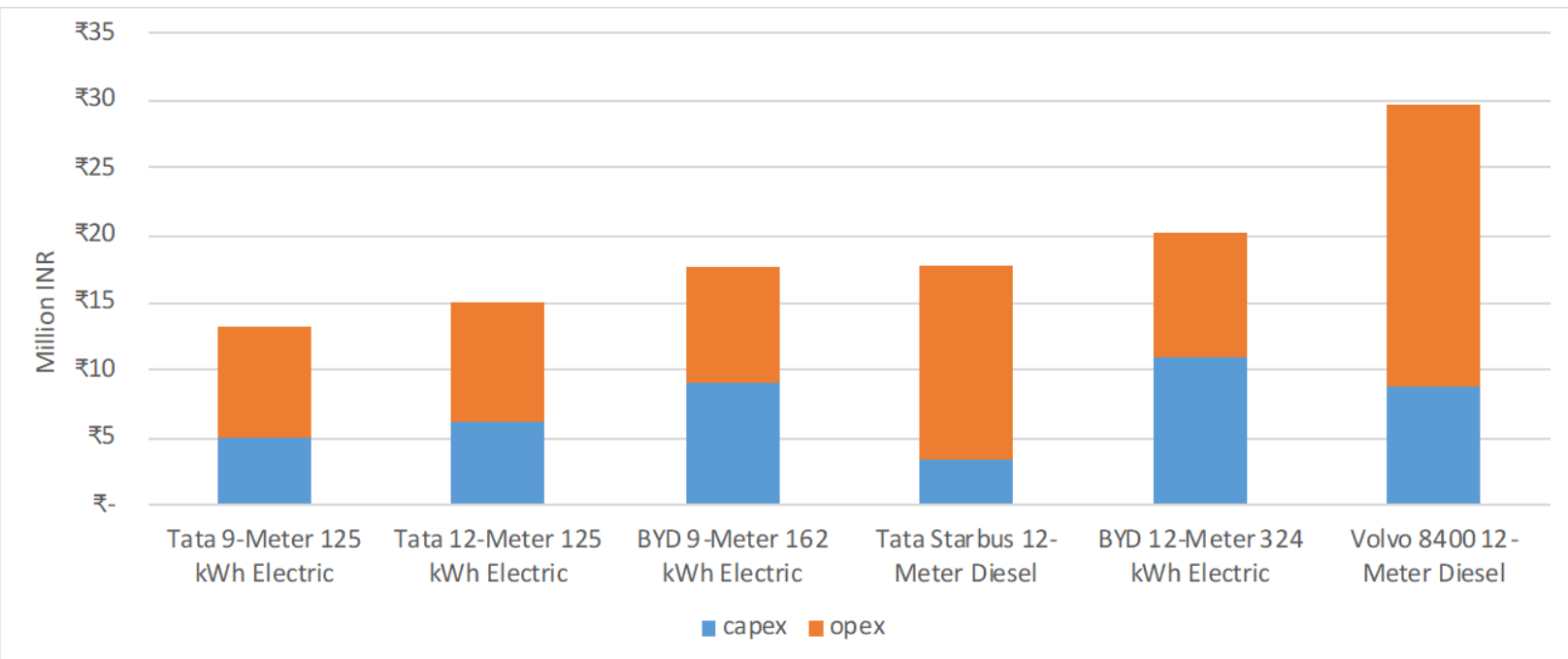

Figure 27. Total estimated cost of ownership

This report is available at no cost from the National Renewable Energy Laboratory (NREL) at www.nrel.gov/publications. 


\section{Conclusion}

Bus electrification promises improved efficiency and reduced operating costs for the Surat BRTS, but there are several considerations to make before deploying BEBs along all BRTS routes. As described in Section 4.2, the NREL model predicts vehicle efficiency to vary significantly depending on vehicle mass and ambient temperature, among other factors. SMC should carefully weigh factors affecting battery degradation when sizing ESS capacity, planning BEB operations, and negotiating warranties.

Available BEB options appear to allow SMC to begin electrification of the BRTS fleet with favorable results. Assuming an efficiency of $1.08 \mathrm{kWh} / \mathrm{km}$ or better, depot-charge BEBs with ESS capacity of $250 \mathrm{kWh}$ or greater could replace conventional buses for half of the BRTS routes. Factoring in $20 \%$ battery degradation before replacement, the initial ESS requirement for those buses would be at least $312.5 \mathrm{kWh}$ of usable capacity. On particularly hot or wet days, BEB efficiency will be reduced.

With an ESS of that size, BEB costs are comparable to diesel buses available in India. Depending on whether the estimates include outlier maintenance costs for a limited sample size of U.S buses past the warranty period, a $324 \mathrm{kWh}$ BEB could cost $14 \%$ more or $11 \%$ less than the more affordable diesel bus considered (see Section 6.2.2 for details).

The FAME II program proposes to cover the entire EVSE cost of one slow charger per BEB or one fast charger per $10 \mathrm{BEBs}$. Although it appears that EVSE installation costs will be covered by these incentives, Section 6.1.2 includes cost considerations for depot-charging EVSE.

On-route charging is not currently available for the BEBs identified in this report, and therefore was not yet analyzed with respect to BRTS bus service, but this charging strategy could be an effective way to reduce BEB battery size. On-route fast-charging BEBs with smaller battery packs may prove to be a more suitable option than that of extended-range depot-charging BEBs for the longest BRTS routes. This should be investigated as manufacturers in India begin offering the technology. Important considerations for on-route strategies include access to land and power supply, electrical demand charges incurred by high-power fast chargers, planning for layover time at charging stations, and battery lifetime impacts of high-powered charging. Battery replacement and vehicle maintenance warranties are important considerations regardless of charging strategy.

SMC would benefit from a small deployment of BEBs to validate the operational model and financial projections against actual conditions in Surat. This would minimize Surat's risk exposure and allow SMC to work through technical challenges. A strategy employed in the United States is to purchase a specified number of BEBs pending a short-term test trial of one to five buses. This could involve shadowing a diesel bus operation along actual routes with a dummy payload and auxiliary loads operating to simulate real service. The test trial could measure performance in hot, cold, dry, and wet conditions. A long-term trial will be necessary to understand maintenance costs, and validating propulsion battery lifetime in-situ will take several years.

Securing a favorable warranty from the manufacturer for the bus and battery can shift some of the maintenance risk to the OEM, reducing barriers for early adopters of the technology and 
further encouraging other municipal corporations to deploy BEBs. An in-service evaluation to compare diesel and electric buses once deployed would provide a more comprehensive understanding of the performance and cost differences between the two technologies. ${ }^{58}$

BEBs hold great promise for improving fleet efficiency and reducing operational costs. This report illustrates that several Surat BRTS routes could begin operating BEBs currently available in India. Subsequent analysis of those buses in operation can refine ESS capacity estimates for longer routes and extreme weather as well as determine how much money Surat could save through bus electrification in the long term. As SMC begins realizing benefits, Surat bus operators will gain valuable experience, and the lessons learned can inform the adoption of BEBs throughout India and the world.

${ }^{58}$ A description of this type of evaluation and several example reports are available at https://www.nrel.gov/hydrogen/fuel-cell-bus-evaluation.html. 


\section{Appendix A. BRTS Maps by Route Number}
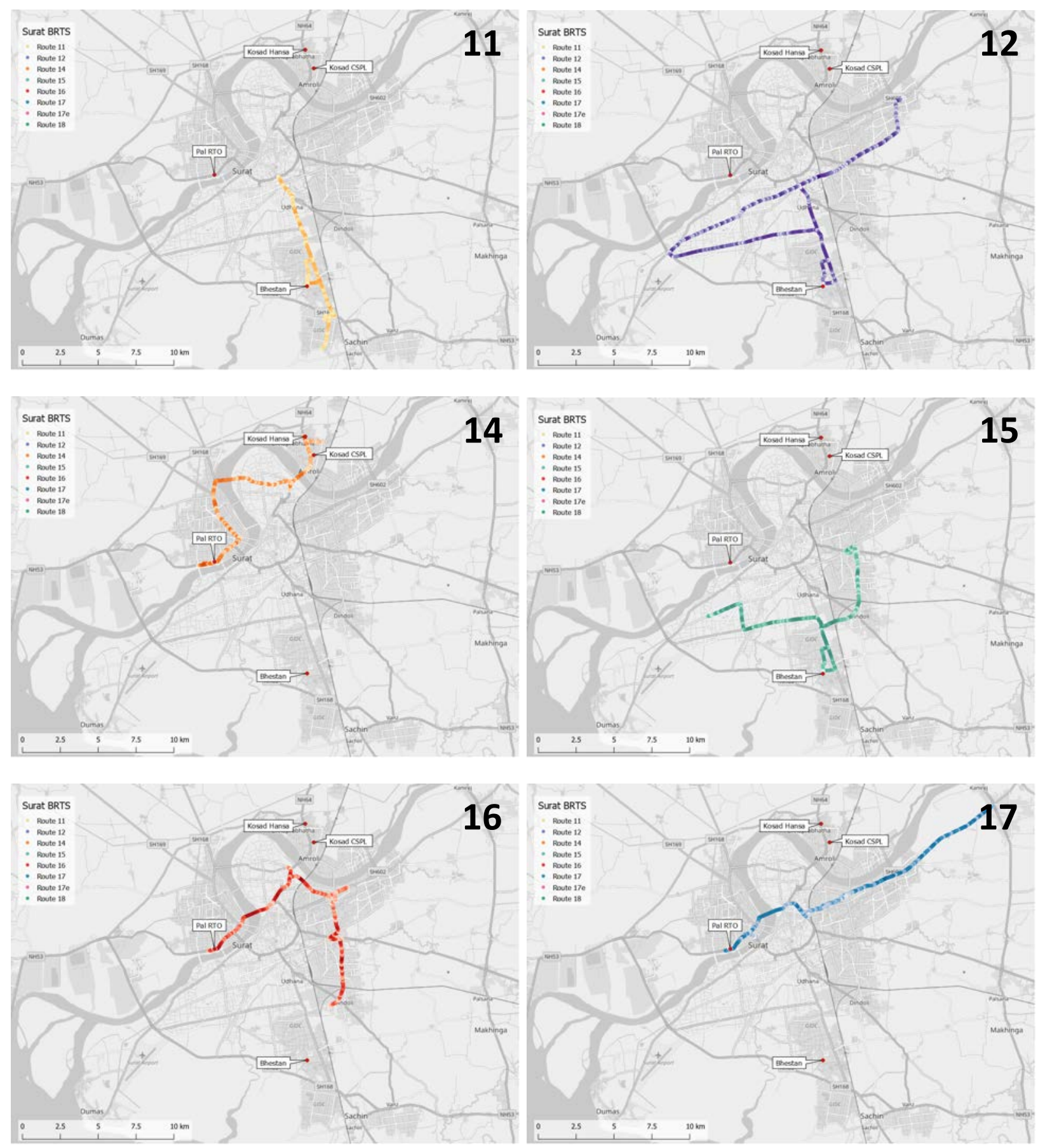

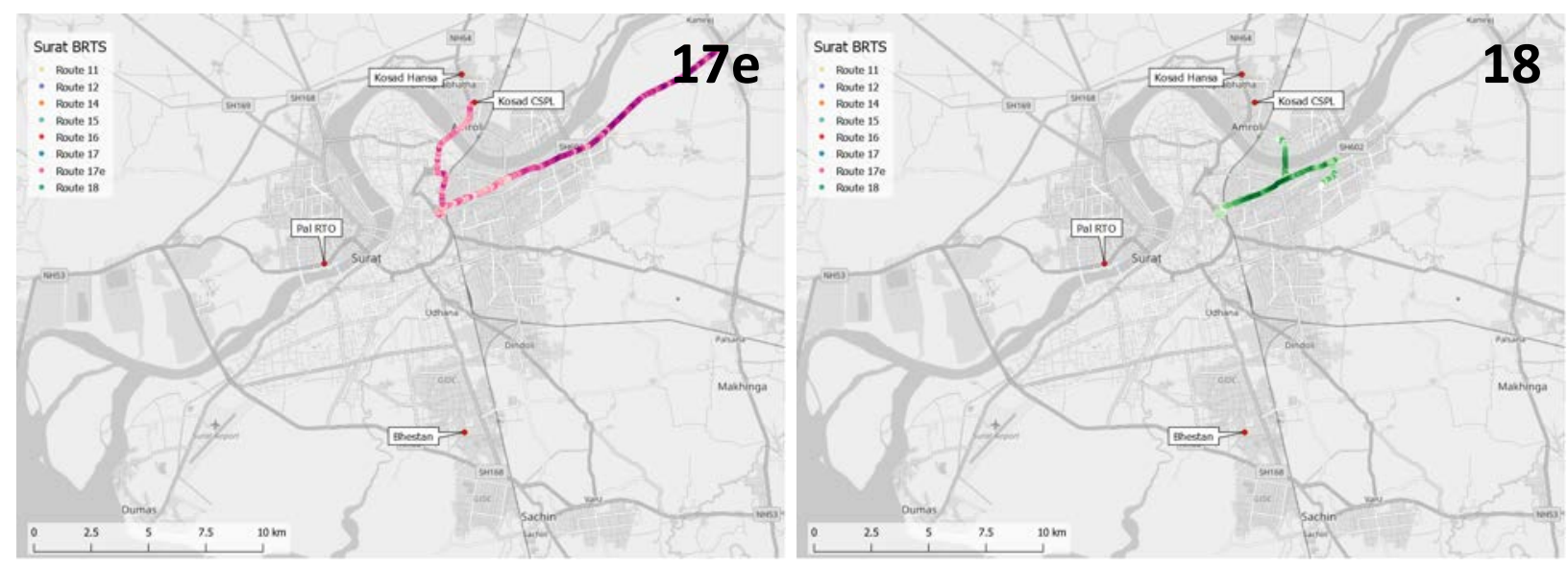

This report is available at no cost from the National Renewable Energy Laboratory (NREL) at www.nrel.gov/publications. 